University of Redlands

\title{
Geospatial Equipment Management System
}

A Major Individual Project submitted in partial satisfaction of the requirements for the degree of Master of Science in Geographic Information Systems

by

Jian Ping Sim

Douglas M. Flewelling, Ph.D., Committee Chair

Ruijin Ma, Ph.D.

August 2015 
Geospatial Equipment Management System

Copyright (C) 2015

by

Jian Ping Sim 
The report of Jian Ping Sim is approved.
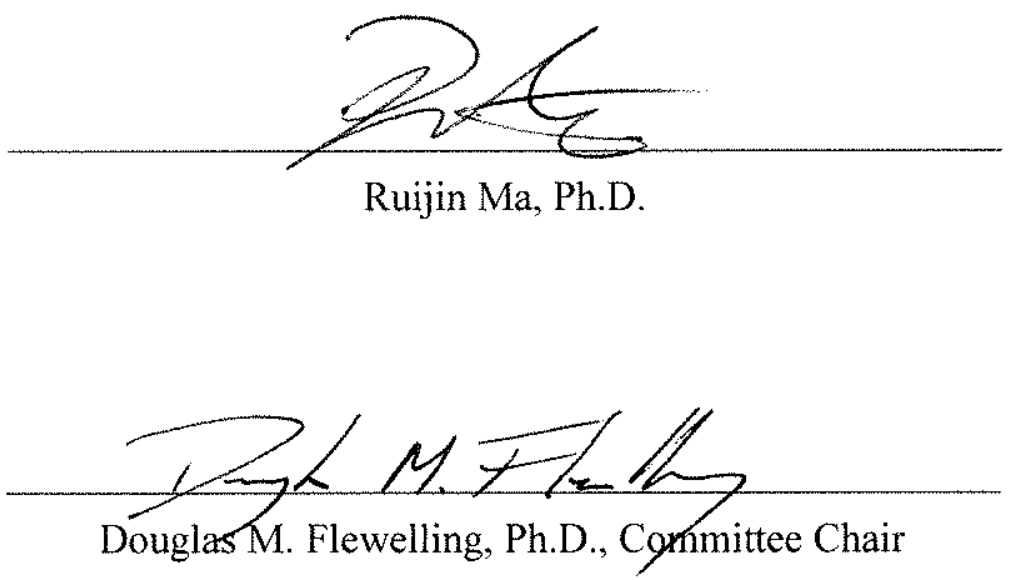

August 2015 



\section{Acknowledgements}

I would like to express my deepest appreciation to my loving wife, Xin-wei, and beautiful daughter, Qian Hui, who have been my motivation and encouragement throughout the program. Thank you for keeping my sanity in check despite the lack of sleep and the caffeine overdose.

I would like to thank my advisor, Professor Douglas "Conceptual" Flewelling, who provided me with invaluable advice for the project, and countless hours of meetings to hone the project to its current sophistication. Thank you for being my GIS-database-iOSgame-analytics advisor. I would also like to extend my appreciation to Mark Kumler, Fang Ren, Ruijin Ma, and Nader Afzalan, for being my geo-mentor. My sincere thanks to Lynn, for putting up with my writing skills (or lack of). Many thanks to Andreas, Nate, and Ruben in Lewis Hall for providing clockwork support to the program.

Thank you Cohort 25, 25.5, 26, 27, and 27.5 for being part of this journey. I will not forget the laughter we have had in Lewis Hall 104. The Central Apartment pool gatherings have also made our time here unforgettable. Aldous, I would not have completed the project without your timely iPhone loan. Karina, thank you for the necessary feedbacks on the project. Matt, Neel, Shilpi, John, and all of the Central Apartment-lites, thank you for your friendship and all the best in your future endeavors.

Last but definitely not the least, my points-of-contact for this project: Jeff Abel and Elena Adams from Abel Fire Equipment; Sam Lanier and Cassie Hansen from FireWhat. Thank you for the working opportunity in the domain of emergency inventory management. It has been my pleasure working on this project. 



\section{Abstract \\ Geospatial Equipment Management System}

by

Jian Ping Sim

This paper presents the development of a customized mobile application for assets management in the field. During emergency incidents such as wildfires, equipment such as trailers and tents are often redeployed in various locations - some without the Internet. In addition, inventory management using word documents, spreadsheets, or schematic diagrams, results in ambiguous or inaccurate location and status recordings. A customized iOS mobile application was developed to allow field staff to update their equipment locations and statuses quickly and easily to a centralized geodatabase, by scanning a QR code on the equipment. This mobile capability could also be used offline. A dashboard application was configured to visualize equipment deployment locations with options to filter what was displayed. The limitations of the application were analyzed, and recommendations were suggested. Finally, the paper concludes by stating the future work possible, and the envisioned technology-enabled inventory management in the emergency disaster domain. 



\section{Table of Contents}

Chapter 1 - Introduction ........................................................................................ 1

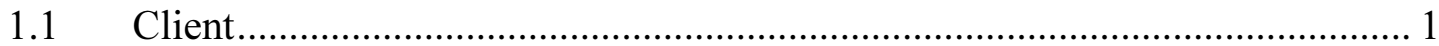

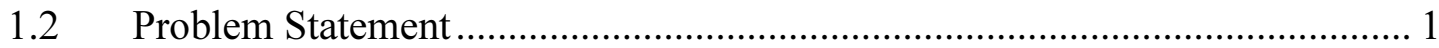

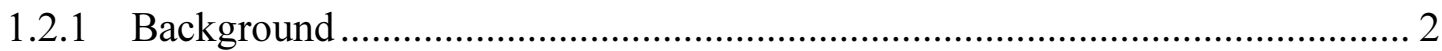

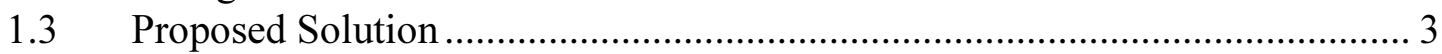

1.3.1 Goals and Objectives .............................................................................. 4

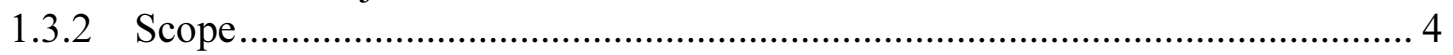

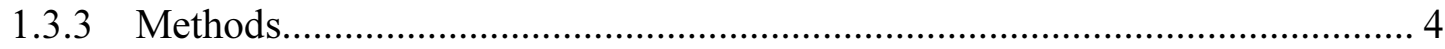

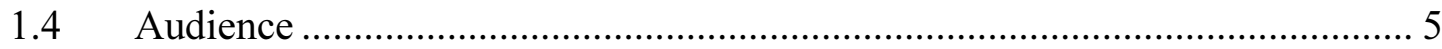

1.5 Overview of the Rest of this Report ........................................................... 5

Chapter 2 - Background and Literature Review .............................................................. 7

$2.1 \quad$ Inventory Management ...................................................................... 7

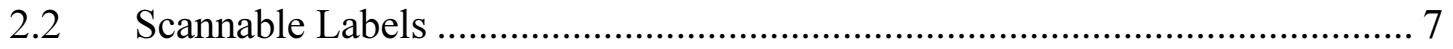

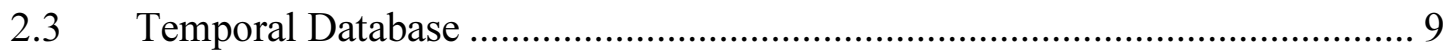

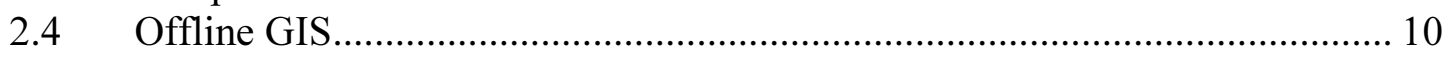

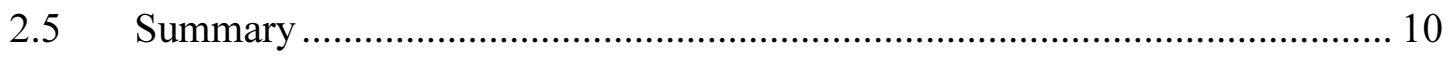

Chapter 3 - Systems Analysis and Design.................................................................... 13

$3.1 \quad$ Problem Statement ........................................................................... 13

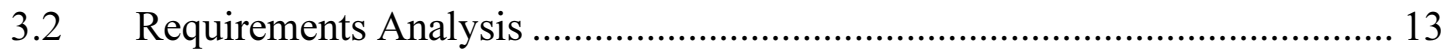

3.2.1 Operation Environment............................................................................ 13

3.2.2 Scale of Operation................................................................................... 14

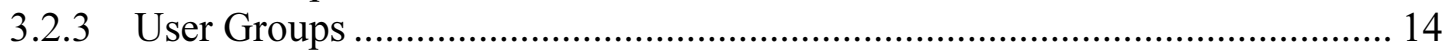

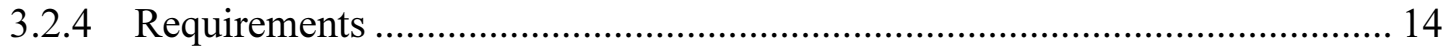

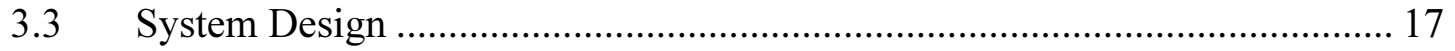

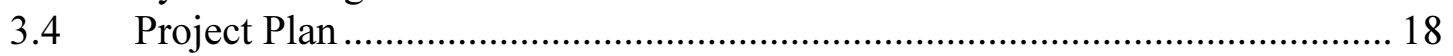

3.4.1 Technical Challenge.................................................................................. 18

3.4.2 Administrative Challenge ……………………......................................... 19

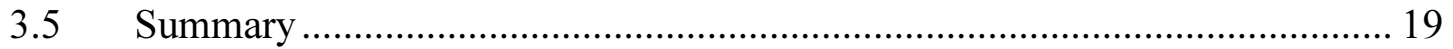

Chapter 4 - Database Design............................................................................................ 21

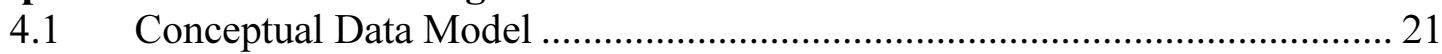

4.1.1 Temporal Model...................................................................................... 22

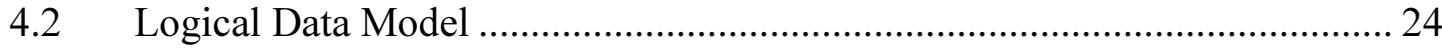

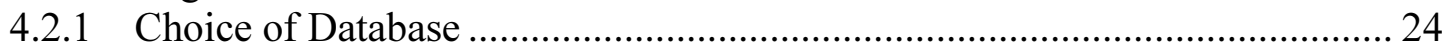

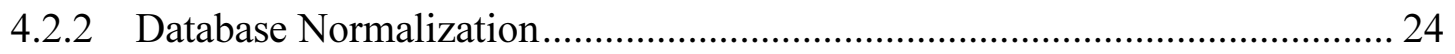

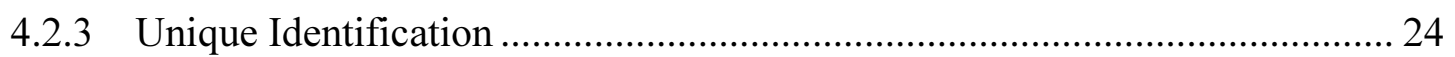

4.2.4 Database Schema ............................................................................. 25

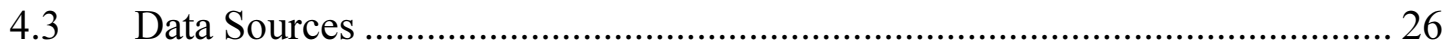

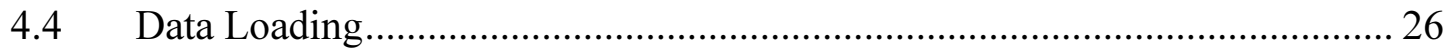

4.4.1 Automated File Geodatabase Creation ..................................................... 26

4.4.2 Publishing to ArcGIS Online .................................................................... 27

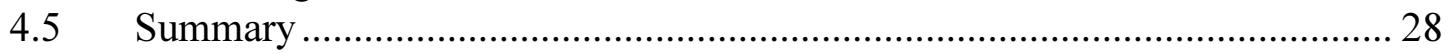

Chapter 5 - Implementation.......................................................................................... 29 
5.1 Design of Mobile Application User Interface (UI) ……………….............. 29

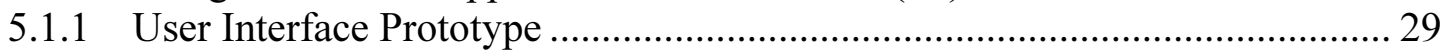

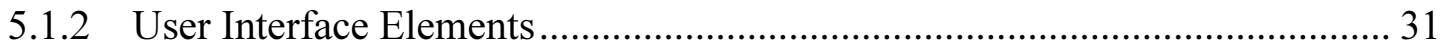

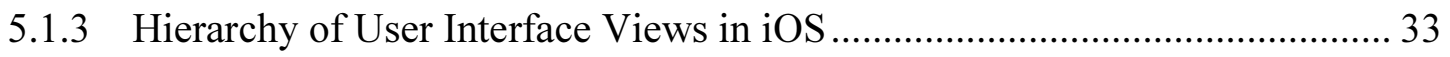

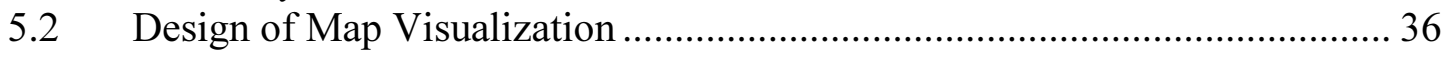

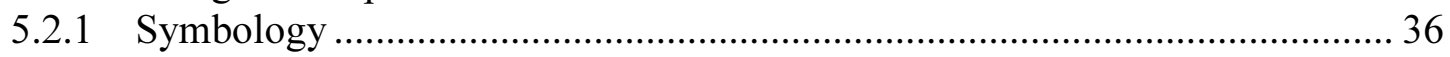

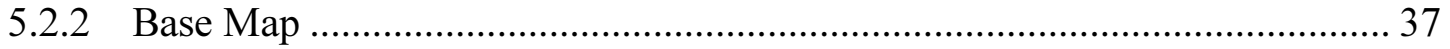

5.3 Setup of iOS Development Environment …………...................................... 37

5.3.1 Apple Development Account...................................................................... 37

5.3.2 Integrated Development Environment (IDE), ArcGIS Runtime SDK, and Mac

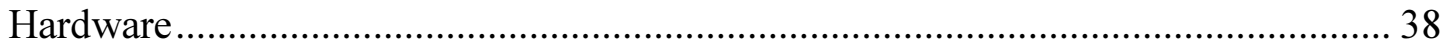

5.3.3 Version Compatibility …………………………................................. 39

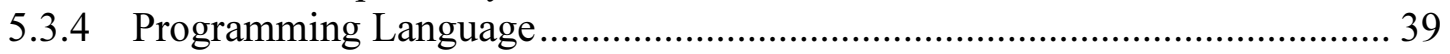

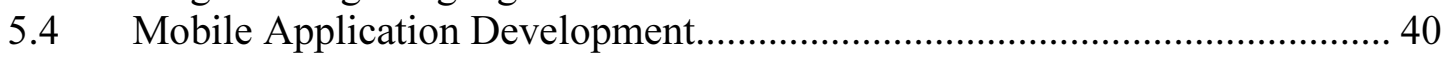

5.4.1 Sign into ArcGIS Online and Credential Caching ............................................. 40

5.4.2 Switching between Online and Local Modes .................................................. 42

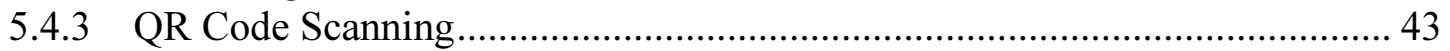

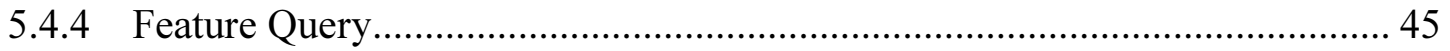

5.4.5 Integration with GPS Receiver ................................................................. 47

5.4.6 Useful Resources for iOS Development ..................................................... 47

5.5 Quick Response (QR) Code Generation ..................................................... 48

5.5.1 Creating QR Codes Images From IDs …………........................................ 48

5.6 Design and Configuration of Operations Dashboard........................................ 49

5.6.1 Dashboard Layout and Widgets.................................................................. 49

5.6.2 Dashboard Configuration............................................................................. 50

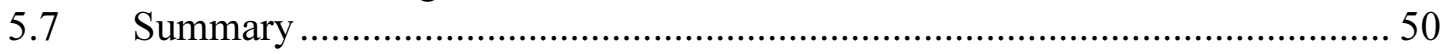

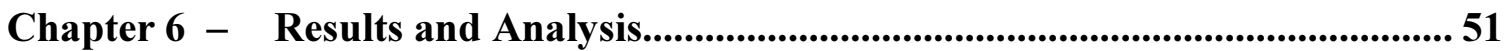

6.1 Requirement Traceability...................................................................... 51

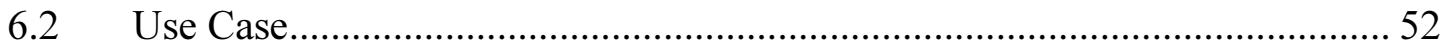

6.2.1 Sign Into ArcGIS Online ........................................................................ 52

6.2.2 Update Deployment ............................................................................... 53

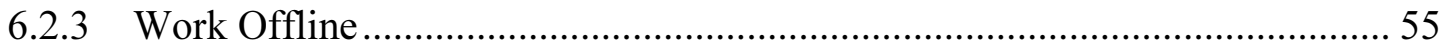

6.3 Analysis of Functionalities ........................................................................ 56

6.3.1 Management of Individually-labelled Items .................................................. 56

6.3.2 Mandatory Offline Preparation ..................................................................... 56

6.3.3 Periodic Database Integrity Checks .......................................................... 57

6.3.4 Dashboard Limitations................................................................................. 57

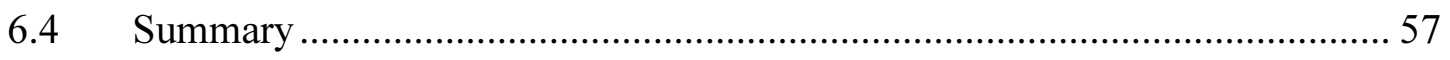

Chapter 7 - Conclusions and Future Work ................................................................. 59

$7.1 \quad$ Project Summary ………………………….................................... 59

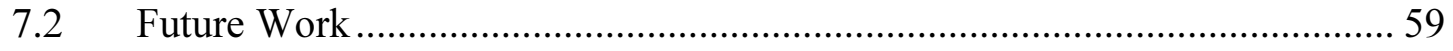

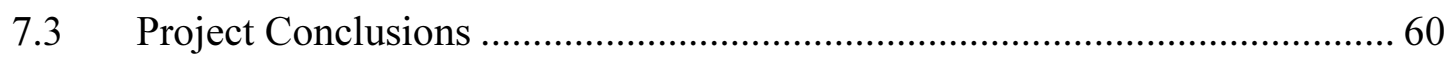

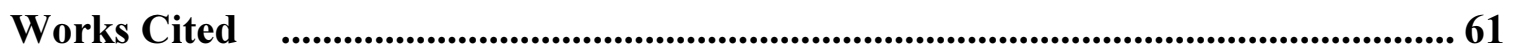

Appendix A. Planned Project Schedule ………………..................................................... 63 
Appendix B. Equipment-Deployment Schema ………….............................................. 65

Appendix C. Incident Schema _..............................................................................6 67

Appendix D. Prototype Views of Mobile Application ................................................... 68

Appendix E. Symbology ................................................................................................. 70

Appendix F. Installation Steps for CocoaPods and ArcGIS Runtime for iOS ...... 71

Appendix G. Procedures to Install Python Libraries for Windows (pip, pillow, and qrcode) $\quad$................................................................................................... 72

Appendix H. Source Code for Database Schema Creation .......................................... 73

Appendix I. Python Script to Generate QR Code Images ........................................... 88 



\section{Table of Figures}

Figure 1-1: Base Camp near Laytonville, CA (Photo provided by Abel Fire

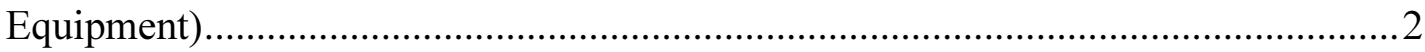

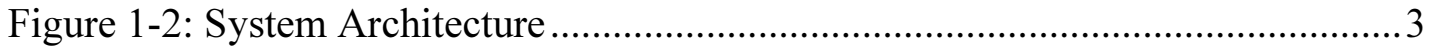

Figure 2-1: (a) 1 Dimensional Barcode (b) 2 Dimensional Barcode ...........................8

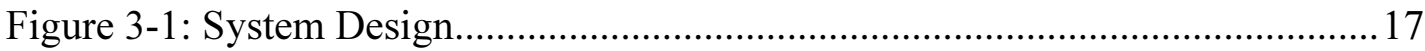

Figure 4-1: Conceptual Model of the Project ...........................................................22

Figure 4-2: Temporal Model to Track Past Deployment for a Single Equipment.....23

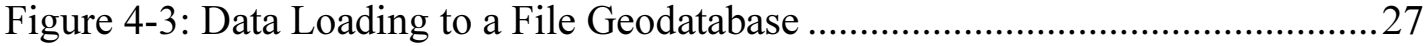

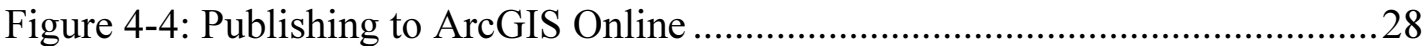

Figure 5-1: Overview of Mobile Application Prototype............................................. 30

Figure 5-2: Prototype of "Sign-In View" and "Map View" ................................... 31

Figure 5-3: A Table View with the sub-elements .................................................. 33

Figure 5-4: Example of the Hierarchy Within a View Controller ............................. 34

Figure 5-5: Navigation between View Controllers via the Navigation Controller.... 35

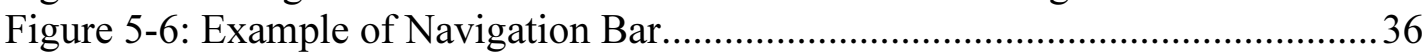

Figure 5-7: System Specifications of Development Environment ...........................39

Figure 5-8: Setting Deployment Target for Compatibility between SDK 8 and iOS

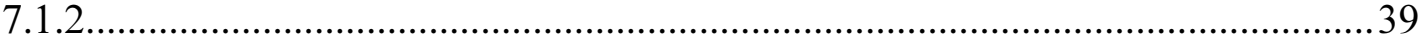

Figure 5-9: Code Snippet to Sign Into ArcGIS Online....................................... 40

Figure 5-10: Authentication Using AGSPortal Class .............................................. 41

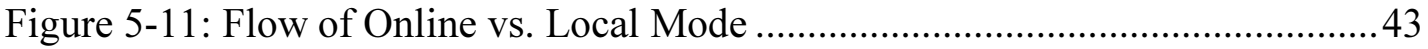

Figure 5-12: Code Snippet for QR Code Scanning ................................................4 44

Figure 5-13: Flow of QR Code Scanner .......................................................... 45

Figure 5-14: Flow of Executing a Feature Query on an Equipment-Deployment

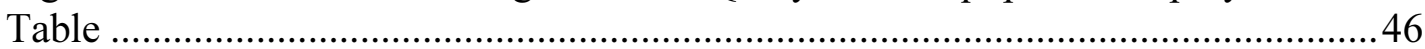

Figure 5-15: Code Snippet of Online and Local Feature Queries ............................47

Figure 5-16: Code Snippet to Query GPS Receiver Location ................................ 47

Figure 5-17: Code Snippet to Display AGSPoint in DMS .....................................47

Figure 5-18: Code Snippet for Creating QR Code Images From IDs........................48

Figure 5-19: Widget Layout for the Operations Dashboard ..................................49

Figure 5-20: Layer Filter for the Operations Dashboard .....................................50

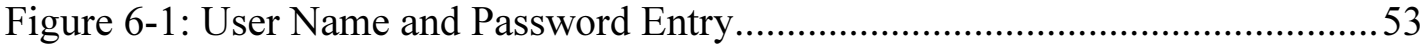

Figure 6-2: Equipment Scanning Process ............................................................... 54

Figure 6-3: Equipment-Deployment Details and Location Selection........................55

Figure 6-4: Deploying Equipment Offline......................................................5 



\section{List of Tables}

Table 2-1: Storage Capacity for a QR Code Error! Bookmark not defined.

Table 2-2: Seven Relationships Between Temporal Intervals ........................................... 9

Table 2-3: Comparison of Offline GIS Options …………………………………….... 10

Table 3-1: Requirements for Mobile Application............................................................ 15

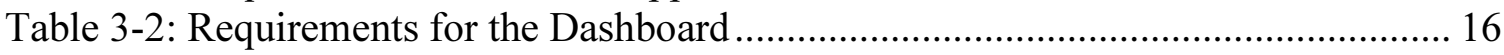

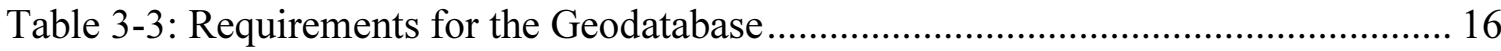

Table 3-4: Project Tasks by Phases .............................................................................. 18

Table 4-1: Section of Schema for Equipment-Deployment Feature Class ........................ 25

Table 4-2: Schema for Incident Feature Class ................................................................ 26

Table 5-1: Examples of User Interface Elements ............................................................... 32

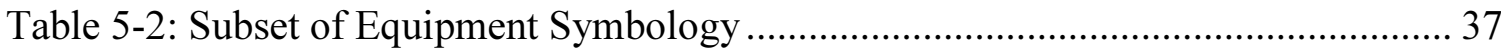

Table 5-3: Roles in an Organization Account (Extracted from developer.apple.com) .... 38

Table 6-1: Requirements for Mobile Application............................................................... 51 



\section{List of Acronyms and Definitions}

$\begin{array}{ll}\text { GIS } & \text { Geographic Information System } \\ \text { GPS } & \text { Global Positioning System } \\ \text { QR code } & \text { Quick Response code } \\ \text { HTTP } & \text { HyperText Transfer Protocol } \\ \text { REST } & \text { Representational State Transfer } \\ \text { UI } & \text { User Interface } \\ \text { URL } & \text { Uniform Resource Locator }\end{array}$





\section{Chapter 1 - Introduction}

Emergency incidents, such as wildfires, hurricanes, and earthquakes, cause serious damage to human lives and property. For example, the 2013 California Rim Fire, burned 402 square miles of land, and the cost involved was US\$127.35 million (U.S. Forest Service, 2013). The client for this project, Abel Fire Equipment, is a company that provides equipment and logistical support to government agencies handling emergency incidents. These incidents are time-critical and often span remote locations, making organized management of inventory challenging.

With the advancement of geographic information systems (GIS), mobile, and web technologies, field staff can potentially query inventory transactions using their mobile devices, in near real-time, even in areas of low cell service. This project analyzed the client's inventory management workflow to explore field inventory management from a spatio-temporal perspective. The project also integrated web and mobile technologies to develop a GIS inventory management prototype for the client.

This chapter introduces the problem and proposed GIS solution for this project. Section 1.1 introduces the client, the various point-of-contacts, and the staff configuration. Section 1.2 describes the challenges faced by the client in inventory management. Section 1.3 lists the overall goals and objectives of the GIS solution and summarizes the proposed solution. Section 1.4 addresses the intended audience for this report. Section 1.5 provides a brief summary of the rest of the report.

\subsection{Client}

The client is Abel Fire Equipment, a logistics company that provides equipment and logistic support to emergency incidents such as forest fires, earthquakes, and other natural disasters. The client has a wide spectrum of inventory, ranging from communication trailers and mobile kitchens to portable toilets, tables, and chairs.

The main point-of-contact was Ms. Elena Adams, the senior manager of the company. She manages the inventory accounting for the client, consolidates the financial billing of the logistics charges during each emergency incidents, among other roles. She defined the client's problem statement for this project, and provided the data required for the system development.

The client's GIS team has taken over the prototype for plans of future operationalization. The point-of-contact for the GIS team is Ms. Cassie Hanson. She is the Geographic Information Officer for Abel Fire Equipment.

There are two broad user groups: the management group, who requires overall awareness of the where equipment deployments are for an incident; and the executive group, who are the field staff deploying equipment. Chapter Three details the requirement differences of these two user groups.

\subsection{Problem Statement}

The client is spending substantial resources to locate and restock inventory that are lost at the conclusion of emergency incidents. This is mainly due to human error in keeping 
inventory records and partial dissemination of this information across staff. With the widespread usage of mobile devices, cloud solutions, and GIS technologies, it is possible to keep track of field deployments easily and efficiently. This project integrated technologies from the various domains to develop a prototype aimed at the management of field deployment information.

\subsubsection{Background}

A series of events happen for the logistic support of emergency incidents. First, a government entity selects one or more logistic support companies based on contractual agreements, cost effectiveness, and support terms. The companies then establish a base camp on an empty plot of land. Next, rapid deployments of assets, such as office trailers, shower units, GIS trailers, and helicopter support trailers are put together at a base camp similar to a miniature city almost overnight (Tavlian, 2013). Figure 1-1 shows a picture of a base camp near Laytonville, California.

Depending on how the situation changes, the agency may deploy smaller spike camps nearer to the disaster epicenter with additional logistic requirements. Usually spike camps are in remote places with very limited or no cell service. In addition, the government agency changes its logistic requirements according to the changes in the incident. Each time this happens, the client must deploy new equipment, redeploy equipment to a new location, or withdraw unused equipment.

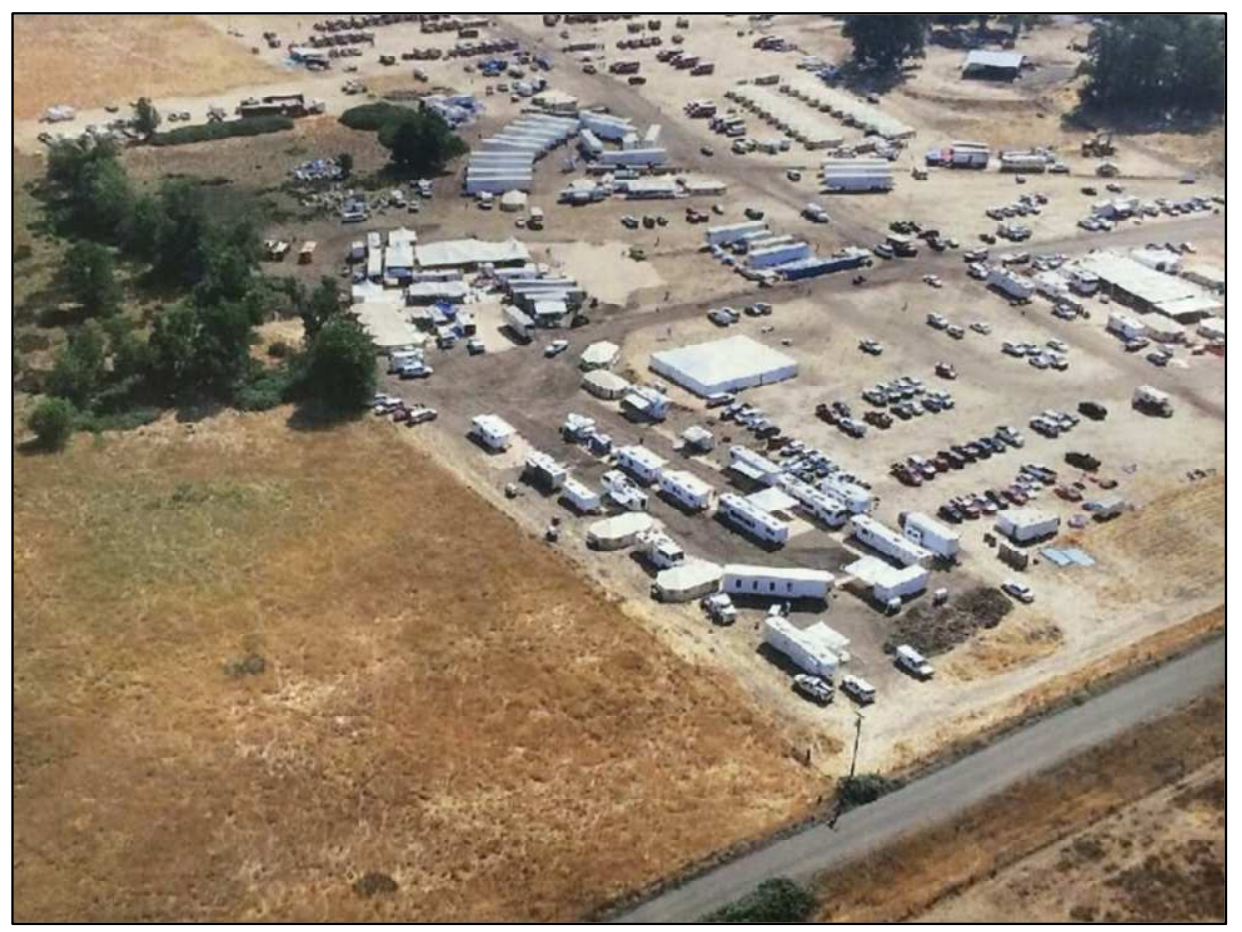

Figure 1-1: Base Camp near Laytonville, CA (Photo provided by Abel Fire Equipment)

The client keeps track of equipment deployment in the field via spreadsheets and schematic diagrams. This method is less than ideal in a few ways. Significant time and 
effort are required to ensure that the information is current and accurate, especially in a dynamic environment. Managers of each incident might not stay for the whole period of the incident, which means the outgoing manager needs to hand over deployment information to the incoming manager. The dissemination of deployment information in spike camps is delayed due to the lack of cell phone connectivity. This lapse increases the chance of human error in the sharing of deployment information.

The inventory management method results in inaccurate inventory information, which leads to incomplete situation awareness among the staff. This causes equipment to be misplaced or lost, especially from spike camps. The client thus has to spend substantial resources to locate or restock equipment. When the client supports multiple emergency incidents concurrently, the amount of resources spent is further increased.

Therefore, the client needed to reduce the resources spent due to the current inventory management method. To achieve this, this project proposed a GIS inventory management system that integrated GIS, cloud, and mobile technology.

\subsection{Proposed Solution}

This project focused on the prototype development of a mobile GIS application that allows managers and field staff to record and query inventory information. Due to the remoteness of the field environment, the prototype had an offline capability to allow users to use the application in areas without internet connectivity. Figure 1-2 summarizes the overall system architecture for the proposed prototype.

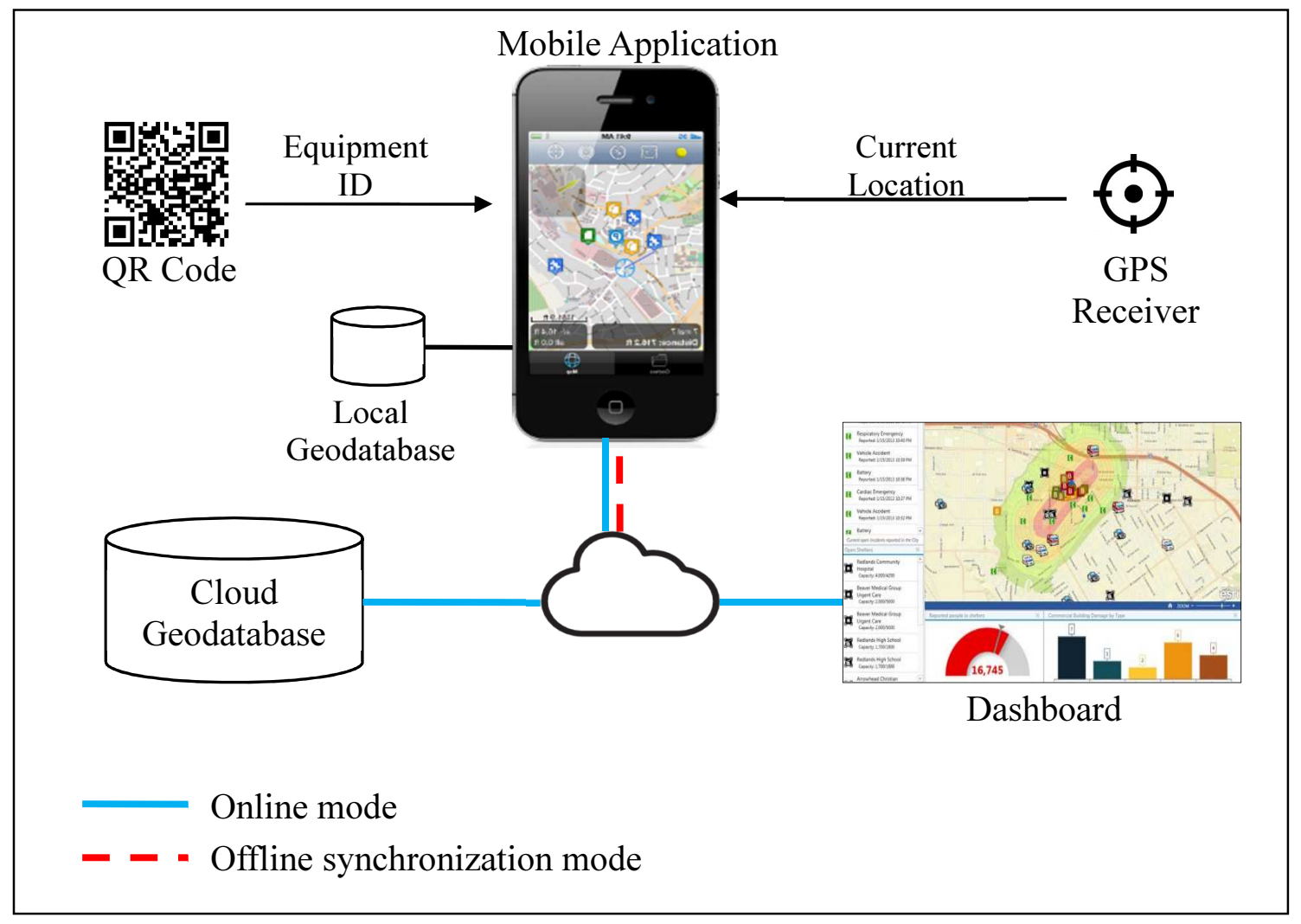

Figure 1-2: System Architecture 


\subsubsection{Goals and Objectives}

The goal of the project was to develop a GIS inventory management system to manage and track equipment deployment easily and accurately in both spatial and temporal aspects. This, in turn, would reduce the client's time and expense to restock or locate misplaced inventory.

There were three objectives for this project: create a central repository to store the spatio-temporal data from the field; allow users to easily input inventory deployments on the field via mobile devices; and enable users to view and query inventory locations quickly.

\subsubsection{Scope}

This project aimed to develop a prototype system to enable spatio-temporal inventory management in the field. The project was comprised of three main components. The first component was a spatial database. A suitable schema to house the client's inventory data enabled the various queries. The second component was an iOS map application. The mobile application made use of the device's global positioning system (GPS) and camera to enable field location data to be entered via Quick Reference (QR) code. The third component was a web dashboard for the presentation of the overall inventory deployments. A test scenario was also recreated using data from a previous incident near Laytonville, California.

\subsubsection{Methods}

The project implemented the database on a GIS cloud service, ArcGIS Online (organizational account). Although there are noted limitations in using ArcGIS Online as compared to an enterprise geodatabase, the client requested that the prototype be built using their existing resources. This design constraint mainly limited the amount of automated data consistency check the project could implement. This was due to the lack of trigger functionalities in ArcGIS Online that could apply custom rules to newly committed data. However, this was mitigated through the user interface design of the mobile application. The comparison between an enterprise geodatabase and ArcGIS Online is in Chapter Four.

Manual inventory records from a previous incident formed the test scenario. The client also provided a list of existing inventory. Not all the inventory had a unique identifier. To create unique equipment identification, the globally unique identifier (GUID) was selected to be the identification standard for this prototype.

The mobile platform targeted was an iPhone 4 running iOS 7.1.2. This was because the managerial staff was familiar with iOS devices. The mobile map application leveraged ArcGIS Runtime for iOS libraries for the GIS functions and data integration with ArcGIS Online. The mobile application recorded equipment using QR codes that depicted unique equipment identifiers. Each QR code was an image that represented the GUID of the equipment.

The dashboard interface was implemented using ArcGIS Operations Dashboard. This design decision was consistent with that of the database, aimed at utilizing the client's existing ArcGIS Online enterprise resources. The dashboard used various widgets 
to display the necessary inventory data, both on the map and as graphical/textual information.

\subsection{Audience}

The mobile application was designed for managers and field staff who do not have prior experience in GIS, but are proficient in using mobile devices and applications. The dashboard was designed for managerial uses with some basic GIS knowledge such as forming a spatial query. The database on ArcGIS Online required GIS technicians or administrators who have the knowledge of accessing, maintaining, and publishing feature classes.

This project report mainly addresses GIS/IT professionals who are looking at developing a similar system leveraging GIS, mobile, and cloud technologies using the suite of ArcGIS software products. As requested by the client, this project has no other infrastructural requirements except ArcGIS Online. End users who have similar requirements as the client may also be interested in this report to better define their needs.

\subsection{Overview of the Rest of this Report}

Chapter Two consists of the literature reviews for this project. They are categorized into the following technology areas: enterprise asset management systems, temporal databases, offline synchronization of databases, and visualization for situation awareness.

Chapter Three analyzes the client's requirements and organizes them into functional and non-functional requirements. It also gives an overview of the broad system architecture to achieve the requirements. Lastly, it discusses the project from a project management perspective, detailing the task-resource allocation, risks, and scheduled timelines.

Chapter Four explains the conceptual model and database designs, and compares the different database options. It also contains procedures to recreate the database schema with test data.

Chapter Five presents the detailed system architecture. It discusses the software architecture of the mobile application and the configuration behind the dashboard.

Chapter Six discusses the lessons learned while developing this system, from both a technical and managerial aspect. It also suggests functional improvements to the prototype system, especially for production purposes.

Chapter Seven concludes this report with three potential project scopes in the domains of inventory tracking and mobile technology. 



\section{Chapter 2 - Background and Literature Review}

This chapter presents research relevant to the scope of inventory management in the context of this project. Section 2.1 discusses the importance and various methods of managing inventory. Section 2.2 presents different ways that inventory can be quickly scanned and registered, and the possible applications to this project. Section 2.3 explains concepts in managing temporal data using temporal database designs, which is applicable in keeping track of the previous states of equipment deployments. Section 2.4 covers the options for implementing an offline GIS that can be accessible in remote deployments, such as spike camps. A summary of this chapter is in Section 2.6.

\subsection{Inventory Management}

Inventory management using mobile devices and networks was recognized as a significant class of e-commerce applications in the market (Varshney \& Vetter, 2002). These were applications that kept track of inventory movement to improve the quality of business. Generally, this class of applications tracked the movement of assets, in an attempt to optimize the time between order and receipt of product. The technology required included GPS, wireless networks, cellular networks, server middleware, GIS, and mobile devices.

There are many uses for mobile GIS technology, including park rangers accessing park satellite imagery from mobile devices, environmental scientists updating flora locations, and police officers sending reports back to their headquarters (Tsou, 2004). Water utility's asset management required the capability for assets editing, conducting quality checks, and editing by multiple users (Esri, 2014). These previous works have proven that these technologies are sufficiently mature and suitable in managing inventory, and invaluable lessons can be drawn from their workflows, technical implementations, and use cases.

\subsection{Scannable Labels}

Scannable labels such as one dimensional and two dimensional barcodes are used in supply chains for easy exchange of information on physical items. This is known as Electronic Data Interchange (EDI). These scannable labels exist in the EDI networks so that products can be tracked as they transited from storage facilities to customer locations (Wenninger, 1999). Figure 2-1 shows an example of (a) one dimensional barcode, and (b) two dimensional barcode (Wikipedia, 2015). Two dimensional barcodes can store more information, and because of this, have a higher error tolerance than one dimensional barcodes. The higher error tolerance also means that the barcode can sustain a certain amount of wear and tear before becoming unreadable by the scanner. 


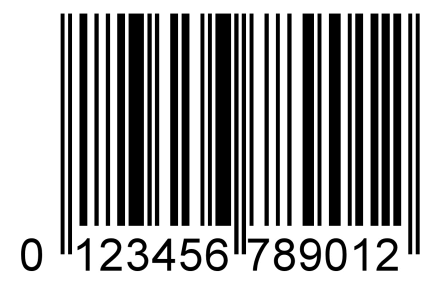

(a)

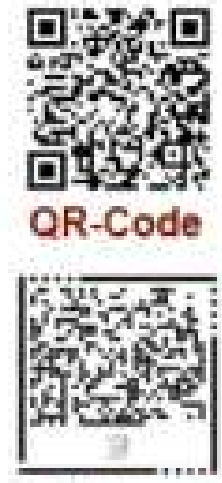

Trilicode

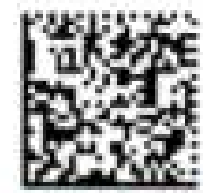

DataMatrix

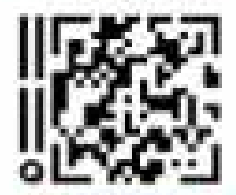

Quickmark

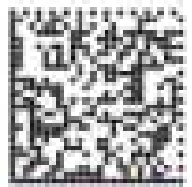

Cool-Data-Matrix

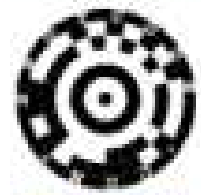

Shotcode

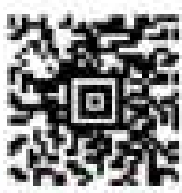

Aztec

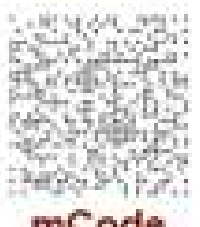

mCode
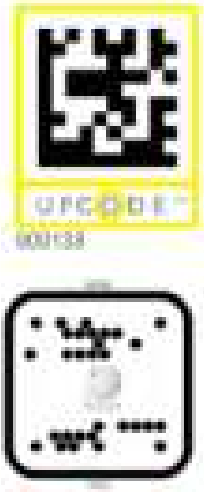

Beetagg

(b)

Figure 2-1: (a) 1 Dimensional Barcode (b) 2 Dimensional Barcode

There were many different variants of 2 dimensional barcodes such as QR code, DataMatrix, and Beetagg. In this project, QR code would be the main two dimensional barcode for discussion. This is based on the availability of open-source QR code libraries, the widespread availability of websites for QR code encoding and decoding, and the capacity to encode different types of data (Al-Khalifa, 2008). The QR code was first created for Japan's vehicle industry (Wikipedia, 2015), and can store 2,953 binary characters (8bits / character). Table 2-1 shows the storage capacity for a QR code.

Table 2-1: Storage Capacity for a QR Code

\begin{tabular}{|l|l|l|}
\hline Data Type & Max Characters & Possible Characters \\
\hline Numeric & 7,089 & $0,1,2,3, \ldots$ \\
\hline Alphanumeric & 4,296 & $0-9, \mathrm{~A}-\mathrm{Z}$, space, $\$, \%, \ldots$ \\
\hline Binary & 2,953 & Defined in ISO 8859-1 \\
\hline
\end{tabular}

QR code has a high error correction capability due to the inclusion of the ReedSolomon codes. This allows four levels of error correction to be achieved: L (7\%), M $(15 \%), \mathrm{Q}(25 \%)$, and $\mathrm{H}(30 \%)$. The number of squares (modules) in a $\mathrm{QR}$ code is called the symbol version, which ranges from $21 \times 21$ modules (version 1) to $177 \times 177$ 
modules (version 40). The higher the error correction level, the more squares are required to encode the data, hence a higher version of the $\mathrm{QR}$ code. Some of the benefits of using a QR code includes ability to be quickly scanned, highly readable even with error and distortion, and public QR code readers and generators are commonly available (Denso ADC, 2011). These benefits made $Q R$ code the main choice of labelling the assets in this project, due to the widespread usage and stability of the technology.

\subsection{Temporal Database}

Traditional data models in GIS focus on a snapshot representation of the real world. Current GIS systems were suggested to be lacking in modelling the temporal aspect of events, especially when it comes to dynamic spatio-temporal interactions (Yuan, n.d.). Previous works suggested keeping all historical states to enable temporal queries, and have temporal attributes to track state-changes (Langran \& Chrisman, 1988).

Fundamentally, time intervals could be used in cases where temporal knowledge is defined, rather than relative. Using intervals to record events via start time and end time, compared to using a single event time, is beneficial because temporal relationships between events can be defined. There are seven relationships for two events, A and B, shown in Table 2-2 (Allen, 1983).

Table 2-2: Seven Relationships Between Temporal Intervals

\begin{tabular}{|c|c|}
\hline Relation & Pictorial Depiction \\
\hline$A$ before $B$ & $<--$ A --> $\quad<--$ B --> \\
\hline$A$ equal $B$ & $\begin{array}{l}<-- \text { A --> } \\
<-- \text { B --> }\end{array}$ \\
\hline$A$ meets $B$ & $<--\mathrm{A}--><--\mathrm{B}-->$ \\
\hline$A$ overlaps $B$ & $\begin{array}{l}<-- \text { A --> } \\
\quad<-- \text { B --> }\end{array}$ \\
\hline$A$ during $B$ & $\begin{array}{c}<-- \text { A --> } \\
<------ \text { B --------> }\end{array}$ \\
\hline$A$ starts $B$ & $\begin{array}{l}<-- \text { A --> } \\
<------ \text { B --------> }\end{array}$ \\
\hline$A$ finishes $B$ & $\begin{array}{r}<-- \text { A --> } \\
<------ \text { B -------> } \\
\end{array}$ \\
\hline
\end{tabular}

By leveraging the relationships of temporal interval, the project could model equipment deployments and use them to check for temporal integrity and in the logic of updating deployments. A historical database, which contains data and their validity, would be suitable for implementation (Time Consult, 2005). This relationship could potentially be expanded to automatically calculate the financial accounting of the number of hired equipment hours based on the deployment status, start times, and end times.

By using points to represent each deployment, the amount of spatio-temporal data to be tracked was also simplified. There would be fewer issues in managing the change in spatial boundaries over time as mentioned by Langren and Chrisman (1988), where 
spatial boundaries, attributes, and temporal information may change independently. When this happens for polygons, it is difficult to conceptualize an effective model to perform dynamic queries across spatial boundaries, attributes, and time.

\subsection{Offline GIS}

An offline GIS, not just a software with all data pre-loaded in its hard drive for offline use, is a system that benefits from data and services online, and capable of downloading the necessary data to work offline. When connected back to the Internet, the offline GIS then disseminates and synchronizes the offline data back to the cloud.

One of the client's business use cases was to deploy equipment in areas with no internet connectivity. This section discusses the technical options available for offline workflow in a GIS application.

At the time of development there were four possible options for an offline mobile GIS solution: building offline capabilities into a web map application (GitHub, 2015a); using ArcGIS collector application out-of-the-box (Esri, 2015a); customizing a mobile application using ArcGIS Runtime (Esri, 2015b); and using GISCloud Offline Maps (GISCloud, 2015). The comparison is shown in Table 2-3.

\section{Table 2-3: Comparison of Offline GIS Options}

\begin{tabular}{|l|l|}
\hline Options & Remarks \\
\hline Offline Web Map & $\begin{array}{l}\text { Limited HTTPS support. Hence, only } \\
\text { intermittent offline is supported for editing. }\end{array}$ \\
\hline ArcGIS Collector Application & Not customizable. \\
\hline ArcGIS Runtime for iOS & Supported and highly customizable. \\
\hline GISCloud Offline Maps & Currently in experimental phase. \\
\hline
\end{tabular}

The offline web map stored downloaded data into the application cache. Although the edits could be downloaded to prepare for a full offline mode, the library did not support the secured HTTPS reconnection. Hence, the offline edits would not synchronize back to a secured feature service. In addition, when the browser cache is cleared, the local database would be deleted as well (GitHub, 2015b). The GISCloud offline capability is, at the development, in experimental phase, not quite suitable for a project of this scope and schedule.

Weighing the options, the most suitable approach for this project was to customize a mobile application using ArcGIS Runtime because it is the most supported and a proven solution in industries.

\subsection{Summary}

This chapter discussed the relevant technologies and domains for the project, specifically in the areas of inventory management, scannable labels, temporal databases, and offline GIS. The intent was to assess the feasibility of the broad objective of this project, the 
technologies that would be used, and the maturity and availability of these technologies or tools. Field assets management using mobile GIS has been around for years. This provides an opportunity for this project to re-assess the possibilities using the current advancement in technologies in this area by integrating the different domains and producing a simple and effective prototype solution. Chapter 3 discusses the detailed scope and project plan of how the project was completed. 



\section{Chapter 3 - Systems Analysis and Design}

This chapter analyzes the client's requirements and organizes them into functional and non-functional requirements. It also gives an overview of the system architecture to achieve the requirements. Lastly, it discusses the project from a project management perspective.

Section 3.1 restates the inventory management challenges faced by the client. Section 3.2 organizes the client's needs into functional and non-functional requirements. Section 3.3 describes the system architecture design for the mobile application, dashboard, and geodatabase, to address the client's requirements. Section 3.4 states the different processes within the design, development, and deployment phase of this project. Section 3.5 summarizes this chapter by providing a scope-schedule-cost perspective of this project.

\subsection{Problem Statement}

The client is spending substantial resources to locate and restock inventory that are lost or unrecorded, during or after emergency incidents due mainly to human error in keeping inventory records and partial dissemination of this information among staff, during a high tempo emergency environment. The current approach includes a constant update of spreadsheets and schematic diagrams to record inventory movements. This method requires a lot of effort to ensure accuracy and consistency and expects managers to perform perfect handing over of duties. The lack of communication networks in remote locations can cause information lapse. The client for this project required a GIS solution to store inventory deployment information in a central location accessible by the necessary staff, allowing field staff to enter deployment data easily, and enabling them to query the current inventory status.

\subsection{Requirements Analysis}

As part of the requirements analysis to define the client's needs, the project needed detail information about the client's operations, inventory management workflow, staff hierarchy, inventory information. After interviewing the client points-of-contact and analyzing their operations, it was possible to define their needs in the following categories: operation environment, scale of operation, and user groups.

\subsubsection{Operation Environment}

The client provides logistics support in the field for emergency incidents. Many of these locations do not have Internet connectivity, electrical power infrastructure, or a defined landmark description. During each deployment, a mobile device could record the deployment location using the on-board GPS receiver, and other deployment information such as resource order and remarks. Subsequently, staff could locate the deployment by retrieving these records and displaying them on a map. When deploying equipment in 
remote locations, staff could download the database for the mobile application beforehand, for use in an offline environment.

\subsubsection{Scale of Operation}

During an incident, the manager or staff deploys equipment, and then shares the information to the other staff in a timely manner. In reality, the rapid tempo of emergency incidents increases errors in information exchange.

The deployments range from large trailers to multiple stacks of chairs. Some inventory have identification markings on them. The identification markings are not easily accessible, or fade from wear and tear.

As such, a central information repository that stores all deployment information would enable easy tracking of individual items. Labels that can be electronically scanned by mobile devices, such as bar codes or QR (Quick Response) codes, could be placed on the equipment. The staff would then use the camera on the mobile devices to interpret the labels to retrieve equipment information. This would enable quick and correct recording of equipment information, thus reducing human error.

\subsubsection{User Groups}

The two main groups of users are the manager group and the field staff group. Staff could be located at the base camps, spike camps, in the middle of transporting, or deploying equipment. Most of the time, each manager is on duty for a limited time during an incident before another manager takes over. The workforce is on rotation shift to ensure ample rest.

The manager and field staff may deploy equipment together, or deployments could be delegated to the field staff. Generally, managers are interested in all the deployments for an incident. The field staff focuses on completing a list of deployments, and then closes the loop with the manager. Managers also have laptops to create documents or spreadsheets to store all the information. Hence, a dashboard with a map of deployments would be beneficial for managers to have an overview of deployments, and for both groups, a mobile map application would be extremely useful for data collection and for quick data reference.

\subsubsection{Requirements}

The project categorized the system requirements into functional and non-functional. Functional requirements specify the necessary behaviors of the system. Non-functional requirements specify the qualitative abilities of the system that can be used to gauge the quality of the system (Eide, 2005). The requirements for the three main components: mobile application, dashboard, and geodatabase are listed in Table 3-1, Table 3-2, and Table 3-3.

The mobile application was the focus of this project. The requirements for the mobile application are listed in Table 3-1. The application contained multiple functions to enable field staff to effectively enter deployment information, and upload to the cloud infrastructure. The requirements for the QR code minimized the time taken to record inventory information, and reduced the human error in manually reading of labels. The 
application also supported the downloading of database and offline editing capabilities so that field staff could use the application in areas with no cell phone service.

\section{Table 3-1: Requirements for Mobile Application}

\begin{tabular}{|l|l|}
\hline \multicolumn{1}{|c|}{ Functional Requirements } & \multicolumn{1}{|c|}{ Non-functional Requirements } \\
\hline $\begin{array}{l}\text { The mobile application shall allow } \\
\text { users to sign in to ArcGIS online with } \\
\text { valid organizational credentials. }\end{array}$ & $\begin{array}{l}\text { The mobile application runs on a } \\
\text { device with a minimum of iOS version } \\
7.1 .2, \text { camera device, and GPS } \\
\text { receiver. }\end{array}$ \\
$\begin{array}{l}\text { The mobile application shall allow } \\
\text { users to use the mobile phone GPS } \\
\text { location as the deployment location. }\end{array}$ & $\begin{array}{l}\text { The application allows the user to } \\
\text { zoom to the map area centered by the } \\
\text { GPS receiver location. }\end{array}$ \\
$\begin{array}{l}\text { The mobile application shall allow } \\
\text { users to scan a valid QR code (4" by } \\
\begin{array}{l}\text { ") to input inventory name, } \\
\text { description. }\end{array}\end{array}$ & $\begin{array}{l}\text { Users only need to sign in the first time } \\
\text { they start the application, until they } \\
\text { decide to sign out. }\end{array}$ \\
$\begin{array}{l}\text { The mobile application shall allow } \\
\text { users to create/edit/delete inventory } \\
\text { deployments. }\end{array}$ & $\begin{array}{l}\text { The mobile application supports both } \\
\text { online and offline viewing/editing. }\end{array}$ \\
$\begin{array}{l}\text { The mobile application shall allow } \\
\text { offline users to synchronize data with } \\
\text { the geodatabase when there is network } \\
\text { connectivity. }\end{array}$ & \\
$\begin{array}{l}\text { The mobile application shall present } \\
\text { clustered deployments into a single } \\
\text { group, depending on zoom extent. }\end{array}$ & \\
$\begin{array}{l}\text { The mobile application shall record the } \\
\text { starting time and ending time for each } \\
\text { deployments consistently. }\end{array}$ & \\
\hline
\end{tabular}


The dashboard enabled situation awareness of where the equipment deployments on a map. The dashboard requirements are listed in Table 3-2. It allowed users to perform basic queries on the past deployments and equipment details. The dashboard was designed to be used in an environment with internet connectivity, and would update itself as new information come in from the mobile application.

\section{Table 3-2: Requirements for the Dashboard}

\begin{tabular}{|l|l|}
\hline Functional Requirements & Non-functional Requirements \\
\hline $\begin{array}{l}\text { The dashboard shall show the number } \\
\text { of inventory deployments in the map } \\
\text { extent. }\end{array}$ & $\begin{array}{l}\text { The dashboard works only in an } \\
\text { environment with Internet connectivity. }\end{array}$ \\
$\begin{array}{l}\text { The dashboard shall allow users to sign } \\
\text { in to their ArcGIS Online } \\
\text { organizational account. }\end{array}$ & $\begin{array}{l}\text { The dashboard runs on a Chrome } \\
\text { desktop browser (version 43). Mobile } \\
\text { phone browsers are not supported. }\end{array}$ \\
$\begin{array}{l}\text { The dashboard shall allow users to } \\
\text { view an inventory's previous } \\
\text { deployment from a start time to an end } \\
\text { time. }\end{array}$ & \\
\hline
\end{tabular}

The geodatabase was the core of the project. The geodatabase requirements are listed in Table 3-3. It resided on the ArcGIS Online cloud infrastructure to receive and transmit data updates to both the mobile application and the dashboard. A mobile application could download a local version of the data and synchronize local updates to the geodatabase.

\section{Table 3-3: Requirements for the Geodatabase}

\begin{tabular}{|l|l|}
\hline Functional Requirements & Non-functional Requirements \\
\hline $\begin{array}{l}\text { The geodatabase shall allow only } \\
\text { authenticated users to access the data. }\end{array}$ & $\begin{array}{l}\text { The geodatabase runs as feature } \\
\text { services published to an ArcGIS Online } \\
\text { organizational account. }\end{array}$ \\
$\begin{array}{l}\text { The geodatabase shall allow } \\
\text { synchronized data between the } \\
\text { connected mobile application with the } \\
\text { dashboard. }\end{array}$ & \\
\hline
\end{tabular}




\subsection{System Design}

Based on the requirements analysis, a mobile application-dashboard solution supported by a geodatabase was proposed. The system design was also constrained by the client's requirement to use an ArcGIS Online organizational account to house the data instead of other database options. The three main components of this project were the mobile application, the dashboard, and the geodatabase. The system design is summarized in Figure 3-1. Each piece of equipment was labelled with a QR code logo that translated to a unique equipment identifier.

To record a deployment, the mobile application scanned and interpreted the QR code to identify the respective equipment. The current location was retrieved from the mobile phone's GPS receiver and used as the deployment location. In online mode, the information would be committed to the geodatabase on the cloud. In offline mode, the information was stored on the local geodatabase, to be synchronized with the cloud counterpart when there is connectivity.

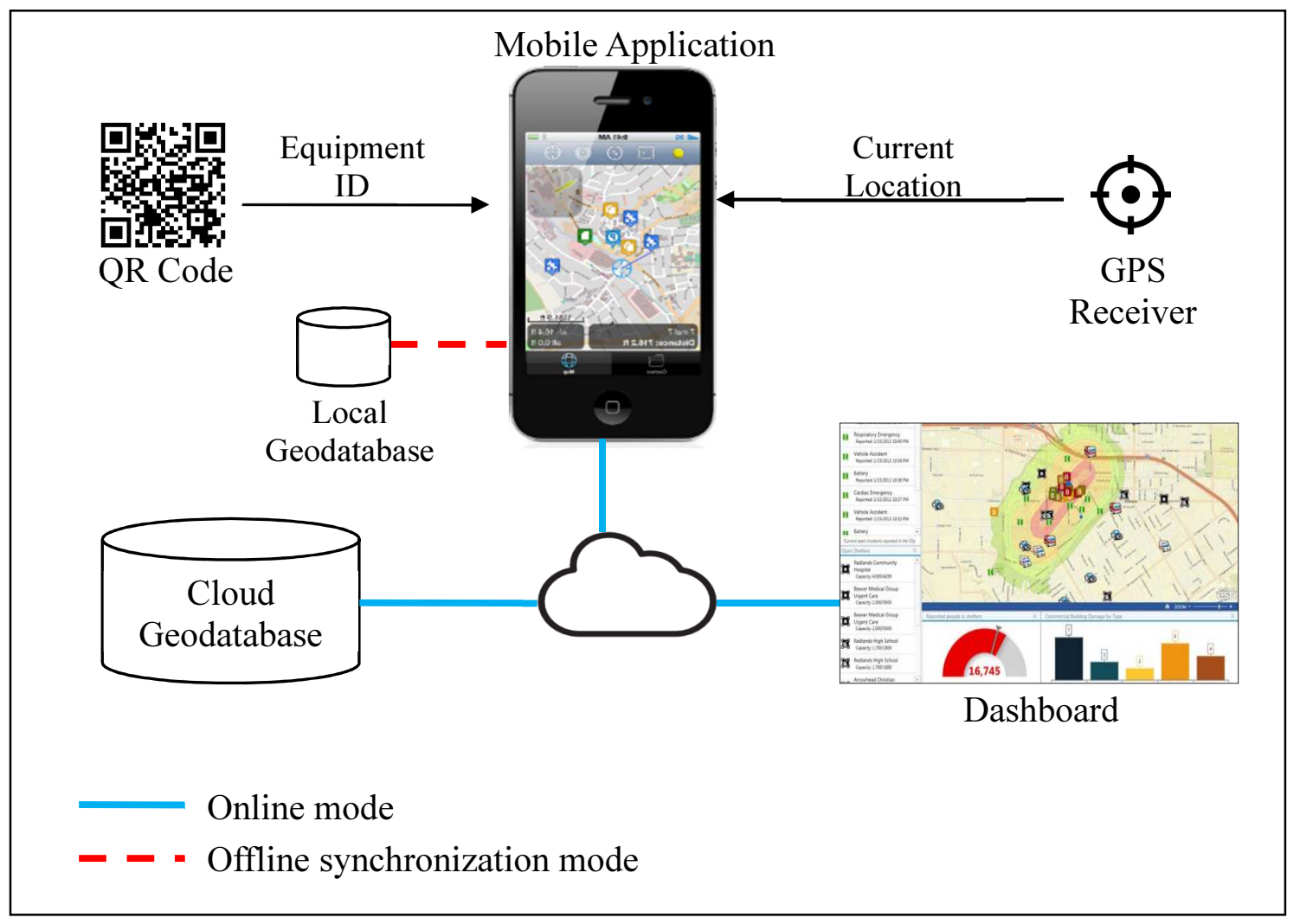

Figure 3-1: System Design

The dashboard received and presented the information from the geodatabase on the cloud. The dashboard allowed basic queries to refine the information presented. 


\subsection{Project Plan}

This project was planned in three phases over a period of six months (January to June 2015). The three main phases were Data Organization (Phase 1), App Customization (Phase 2), and Project Review (Phase 3). Reviews with the client were planned for each phase to gather feedbacks. Each of the three phases of the project was further broken down into three sub-phases, namely 'Design,' 'Development,' and 'Integration, Testing and Deployment.' The three phases were to run in a staggered manner. Table 3-4 showed the project tasks for each phase. The detailed project schedule is included in Appendix A.

Table 3-4: Project Tasks by Phases

\begin{tabular}{|c|c|c|}
\hline Phase & Task & Schedule \\
\hline $\begin{array}{c}\text { Data } \\
\text { Organization }\end{array}$ & $\begin{array}{l}\text { 1. Design conceptual model } \\
\text { 2. Design dashboard interface } \\
\text { 3. Create data model and scripts } \\
\text { 4. Populate database } \\
\text { 5. Integrate database, mobile COTS } \\
\text { application, and COTS dashboard } \\
\text { application }\end{array}$ & 8 weeks \\
\hline $\begin{array}{c}\text { App } \\
\text { Customization }\end{array}$ & $\begin{array}{l}\text { 1. Design mobile workflow } \\
\text { 2. Design mobile user interface } \\
\text { 3. Develop mobile app using } \\
\text { ArcGIS runtime } \\
\text { 4. Deploy and test on mobile device }\end{array}$ & 10 weeks \\
\hline Project Review & $\begin{array}{l}\text { 1. Design update } \\
\text { 2. Update database and app } \\
\text { 3. Training Materials } \\
\text { 4. Client Review }\end{array}$ & 5 weeks \\
\hline
\end{tabular}

\subsubsection{Technical Challenge}

The scope of this project spanned a number of technologies. This made the technical risk high, especially integrating the components together. The iOS development involved software architecture and tools such as the Cocoa framework, Xcode as the integrated development environment, and Objective $\mathrm{C}$ as the programming language. The learning curve to pick up these skillsets was steeper than expected. Initially, the software 
development tools required a significant amount of time to learn. However, follow-on development gradually became faster with the help of online technical forums.

\subsubsection{Administrative Challenge}

The mobile application was supposed to be developed under the client's iOS enterprise developer account. Deploying a mobile application under the enterprise account took longer than expected as there were more approvals required within the organization. Because of this, an individual developer account was used instead for rapid development and deployment of the application.

Given the above challenges, the project was able to meet both the schedule and the scope defined in the plan. This was made possible by the planned risk buffers identified during the planning phase.

\subsection{Summary}

The client's inventory management situation was the main focus of this project. After performing a thorough requirement analysis in Section 2 on the different aspects of the client's situation in inventory management, the project defined some of the client's needs based on the operation environment, user groups, and scale of operations. These needs were then translated to system functional and non-functional requirements, categorized by the three main components: mobile application, dashboard, and geodatabase. The project system design was discussed in Section 3, focusing on the how the project could improve on the current deployment workflow. The project plan and the technical risk were discussed in Section 4. 



\section{Chapter 4 - Database Design}

Organizing the client's inventory data and creating a suitable database schema was crucial for this project. Chapter 4 takes the reader through this design process in the following sections. Section 4.1 discusses the conceptual data model that was used to abstract the real-world scenario into entities. Section 4.2 explains the translation from the conceptual entities to an implementable database design. Section 4.3 covers the data sources from the client, from which the design was derived. Section 4.4 describes the process of creating and loading data into the database. The database design considerations are summarized in Section 4.5.

\subsection{Conceptual Data Model}

The conceptual data model was a representation of the client's inventory management in the real world. The central idea behind the conceptual data model was as follows: at all times, each equipment is deployed at a location, in a certain state of deployment, possibly supporting an incident. There were three main components in the conceptual model: equipment, incident, and deployment. The conceptual data model is represented in Figure 4-1.

Equipment represented the client's inventory. An equipment had attributes such as unique identifiers, equipment category, pictures, and text description. Equipment was categorized as large equipment and miscellaneous equipment. Large equipment consisted of trailers, tents, weed washers, and portable toilets. Miscellaneous equipment consisted of chairs, tables, generators, air conditioners, and light towers. The main difference between large equipment and miscellaneous equipment was that each piece of large equipment had a unique identifier, whereas miscellaneous equipment was uniquely identified by type with quantity. 


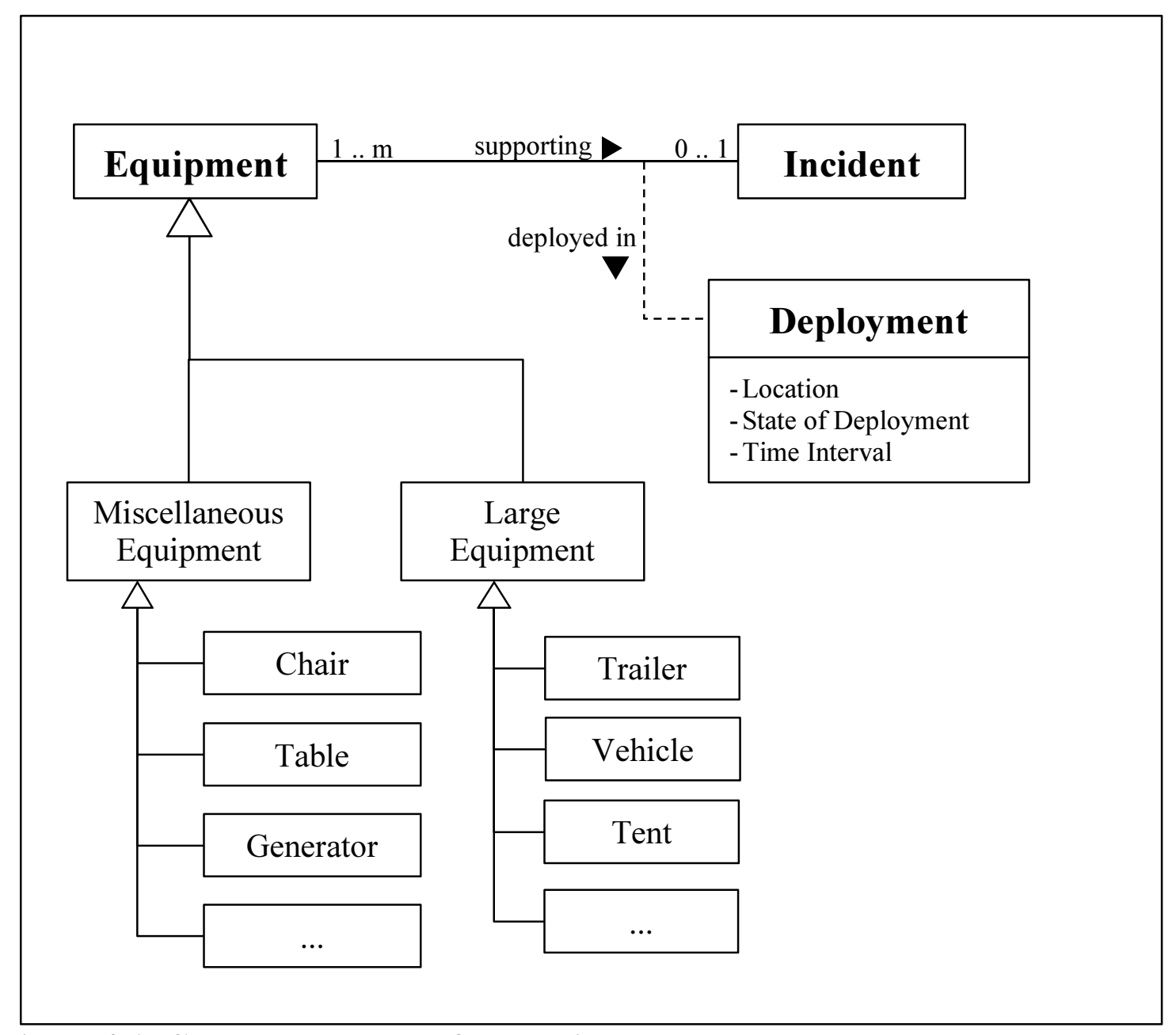

Figure 4-1: Conceptual Model of the Project

Incidents represented emergency events such as wildfires. An incident had attributes such as a unique identifier, the name of the incident, the period of the incident, and a location to represent the location of the incident. Each equipment was deployed in support of an incident.

A deployment represented the relationship of an equipment deployed to support an incident. A deployment consisted of attributes such as a location, state of deployment, and the time interval of deployment. There were four states of deployment: mobilized, demobilized, in-service, and under maintenance. Equipment that was in use by the hirer was considered 'mobilized'. Demobilized equipment was equipment that was not used, or equipment that was ready to be re-deployed. In-service equipment was equipment that was used by the client; for example, a clerical trailer used for the client's office work. Equipment under maintenance was not be usable until the maintenance was complete.

\subsubsection{Temporal Model}

The conceptual model consisted of time intervals for each deployment. The temporal model must be continuous and historical. Continuous intervals meant that deployments should consist of a start and an end time. Also, there should not be any gaps between 
intervals. Historical meant that past deployment information would remain in the database after updates. Hence, to record a change in deployment state, there were two processes that need to occur: to indicate an ending for the old record, and creating a new record with a starting time. Figure 4-2 illustrates this concept of updating deployment records for a single equipment.

This data model ended the previous deployment and created a new one, rather than only updating the past record. As a result, all the deployment information history remained. At any time interval, one can find out the state of deployment for an equipment using database queries.

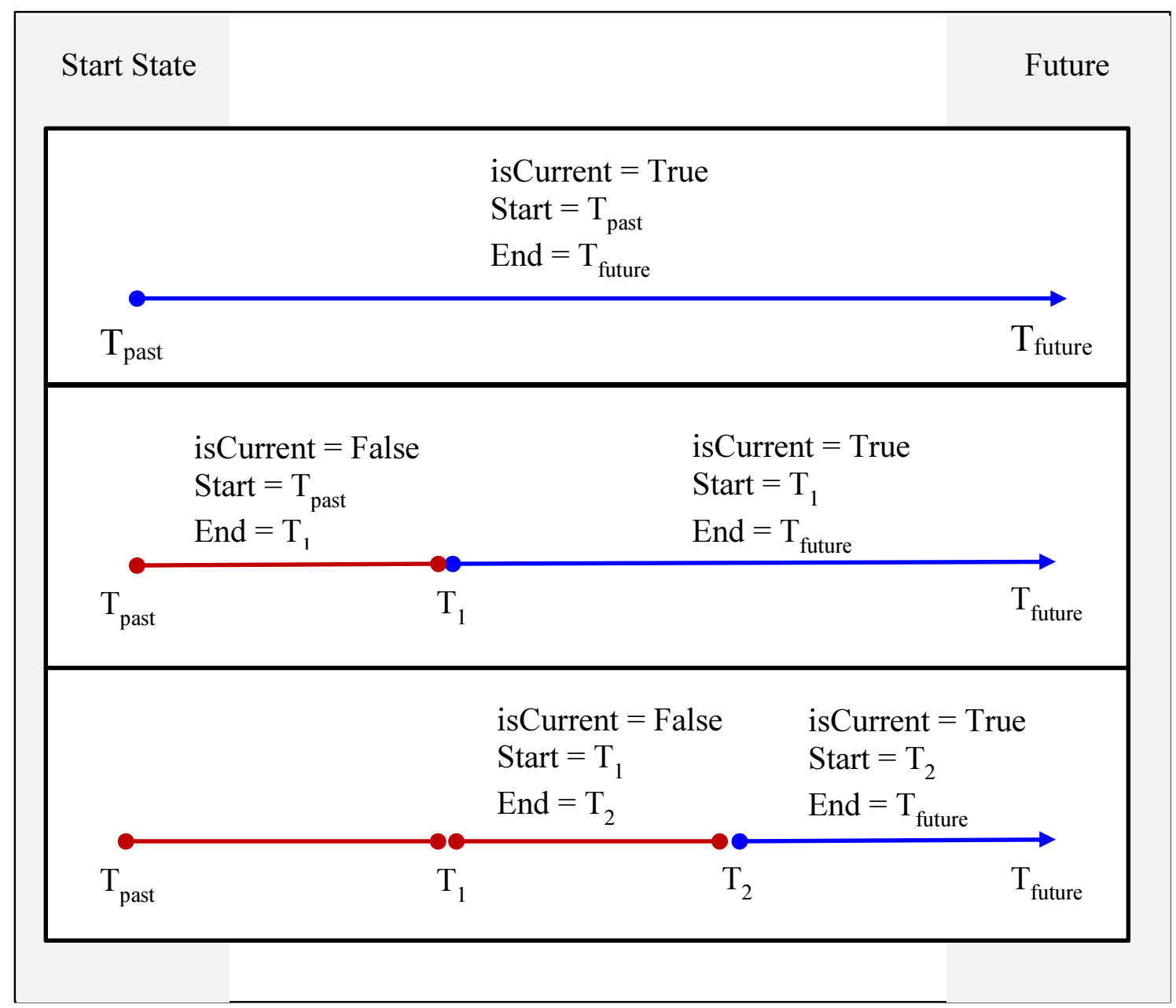

Figure 4-2: Temporal Model to Track Past Deployment for a Single Equipment

Three attributes were required in the deployment model to store interval information: start time, end time, and whether the record was current. In addition, arbitrary values for these variables were defined for the relative past and future. Since the deployments had to begin from an arbitrary start time, the temporal value "1/1/1901 01:00" was chosen to depict a relative start time. Similarly, the value "1/1/3901 01:00" was chosen to depict a relative future. A Boolean attribute was also used to keep track of whether the record was current. This Boolean attribute helped to form queries for current deployments. 


\subsection{Logical Data Model}

The logical data model represented the organization of data in the database. The database chosen was ArcGIS Online with a hosted geodatabase because it was a more cost effective option compared to utilizing an enterprise geodatabase with ArcGIS server. There were two spatial tables (feature classes) in the database: the equipment-deployment feature class and the incident feature class. The following sections discuss the selection of database, the normalization for the equipment-deployment feature class, the unique identifier used, and the schema supporting the database design.

\subsubsection{Choice of Database}

During design, there were two options for the geodatabase. The first was an enterprise geodatabase; the second was to use ArcGIS Online with a hosted geodatabase. There were several advantages to using an enterprise geodatabase, including more control over storage options, customization of powerful database scripts (known as triggers), and advanced functionalities such as versioning, archival, and backup. However, the client had an existing ArcGIS organizational account, which meant that it would be the more cost-effective solution. In addition, the client did not have to be concerned about server or database maintenance, which required considerable technical expertise and resources. Hence, the database choice was ArcGIS online with the hosted geodatabase.

\subsubsection{Database Normalization}

There are two spatial tables in the database implementation. Equipment and Deployment information were combined into the same table. This meant that this table is not in the second normal form (2NF) (Codd, 1971). Essentially, 2NF meant that the table should contain data of only one domain. In this case, the equipment-deployment table contained data from two domains: equipment and deployment.

This design decision was made because of two considerations: the performance of the mobile application when making multiple queries to form a related query, and the lack of support on related queries for the operational dashboard. For the mobile application, the method of querying related records was to perform a query to retrieve a list of object IDs, and then use the list of object IDs to query a related table. This means that each related table required a separate query, and a manual join operation was necessary to combine the various queries. This process potentially created high code complexity and was therefore avoided. As of the time of development, the operational dashboard only supported queries from a single table. In order to demonstrate the concept of querying information across equipment information and deployment information, both tables were combined into one.

\subsubsection{Unique Identification}

Based on the client's data, there were no appropriate fields to be used as a unique identification. Hence, the project created Globally Unique Identifiers (GUID) to index each incident, equipment, and deployment information. A GUID is a 128-bit integer number that is usually represented in the 32 hexadecimal characters $(0-F)$, separated by 
hyphens, and delimited by braces. An example of a GUID is \{496C7D9A-2AB9-450F9EB0-7600AF7D50EF\}. Random GUIDs have 122 random bits, and six fixed bits indicating that it is randomly generated. A GUID is used as the unique identifier because of the extremely low possibility $\left(\frac{1}{2^{122}} \times \frac{1}{2^{122}}\right)$ of two mobile applications generating the same GUID.

\subsubsection{Database Schema}

The two feature classes represented the equipment and its deployment, and the incident. Both of these feature classes were point feature types because the location information is representative in nature. The information is usually viewed at a relatively small scale (zoomed out), and the actual boundaries of the incident and equipment deployment are not necessary. Thus, point features were adequate in representing these locations. The detailed schema for the equipment-deployment and incident feature class are found in Appendix B and Appendix C respectively.

The equipment-deployment feature class captured two components: equipment information such as the equipment type and description, and deployment information such as state of deployment and time interval. Table 4-1 shows a section of the schema for the equipment-deployment feature class.

Table 4-1: Section of Schema for Equipment-Deployment Feature Class

\begin{tabular}{|c|c|c|}
\hline Field & Data Type & Description \\
\hline Equipment ID & GUID & GUID for Equipment \\
\hline Equipment_Type & Short Integer & $\begin{array}{l}\text { 1. Vehicles, Trailers } \\
\text { 2. Portable toilets } \\
\text { 3. Tents } \\
\text { 4. Weed washers } \\
\text { 5. Chairs } \\
\text { 6. Tables } \\
\text { 7. Generators } \\
\text { 8. AC } \\
\text { 9. Light Towers } \\
\text { 99. Others }\end{array}$ \\
\hline Equipment_Description & Text & Description for equipment \\
\hline DeployState & Text & $\begin{array}{l}\text { State of Deployment. } \\
\text { Coded Domain: } \\
\text { "Mobilized": "Mobilized" } \\
\text { "Demobilized": "Demobilized" } \\
\text { "In Service": "In Service" } \\
\text { "Under Maintenance": "Under } \\
\text { Maintenance" }\end{array}$ \\
\hline StartTime & Date & $\begin{array}{l}\text { Deployment start time. } \\
\text { Arbituary past: 1/1/1901 01:00 }\end{array}$ \\
\hline EndTime & Date & $\begin{array}{l}\text { Deployment end time. } \\
\text { Arbituary future: } 1 / 1 / 390101: 00\end{array}$ \\
\hline
\end{tabular}


The incident feature class contained the detailed information about incidents. Information in the feature class included the incident name, incident interval, and remarks. Table 4-2 shows the schema for the incident feature class.

Table 4-2: Schema for Incident Feature Class

\begin{tabular}{|l|l|l|}
\hline Field & Data Type & Description \\
\hline Incident_ID & GUID & GUID for Incident \\
\hline IncidentName & Text & Name of the incident \\
\hline StartTime & Date & $\begin{array}{l}\text { Incident start time. } \\
\text { Arbituary past: 1/1/1901 01:00 }\end{array}$ \\
\hline EndTime & Date & $\begin{array}{l}\text { Incident end time. } \\
\text { Arbituary future: 1/1/3901 01:00 }\end{array}$ \\
\hline Remarks & Text & Incident remarks \\
\hline POINT_X & - & $\begin{array}{l}\text { Internal data. Part of Point } \\
\text { object. X-coordinate in web- } \\
\text { mercator (m). }\end{array}$ \\
\hline & - & $\begin{array}{l}\text { Internal data. Part of Point } \\
\text { object. Y-coordinate in web- } \\
\text { mercator (m). }\end{array}$ \\
\hline
\end{tabular}

\subsection{Data Sources}

The client provided a spreadsheet of the equipment details, a schematic diagram of a previous deployment, and a document containing deployment instructions that were communicated during the incident over two weeks. The spreadsheet contained the list of equipment they have in the following categories: trailers, portable toilets, tents, and weed washers. The schematic diagram and word document were actual information captured during a previous incident. They included some deployment information, resource order references, and location references. This information is collectively used to design the categories of equipment and the attributes that were collected.

\subsection{Data Loading}

\subsubsection{Automated File Geodatabase Creation}

The client's equipment data were in the form of a spreadsheet, which was re-organized to represent the database schema for the equipment-deployment feature class and the incident feature class. Next, the spreadsheet was converted to a Comma Separated Value (CSV) file.

A data loading Python script performed three actions: create a file geodatabase, create the two feature classes using the schema from the CSV file, and populate data into these two feature classes. Variables for file paths and field names were used to abstract information from the main code. Figure 4-3 illustrates the data loading procedures using the Python script. By creating scripts to generate the initial database, any changes to the 
database schema or starting data could be easily done by re-running the script. This approach enabled rapid developmental changes throughout the project.

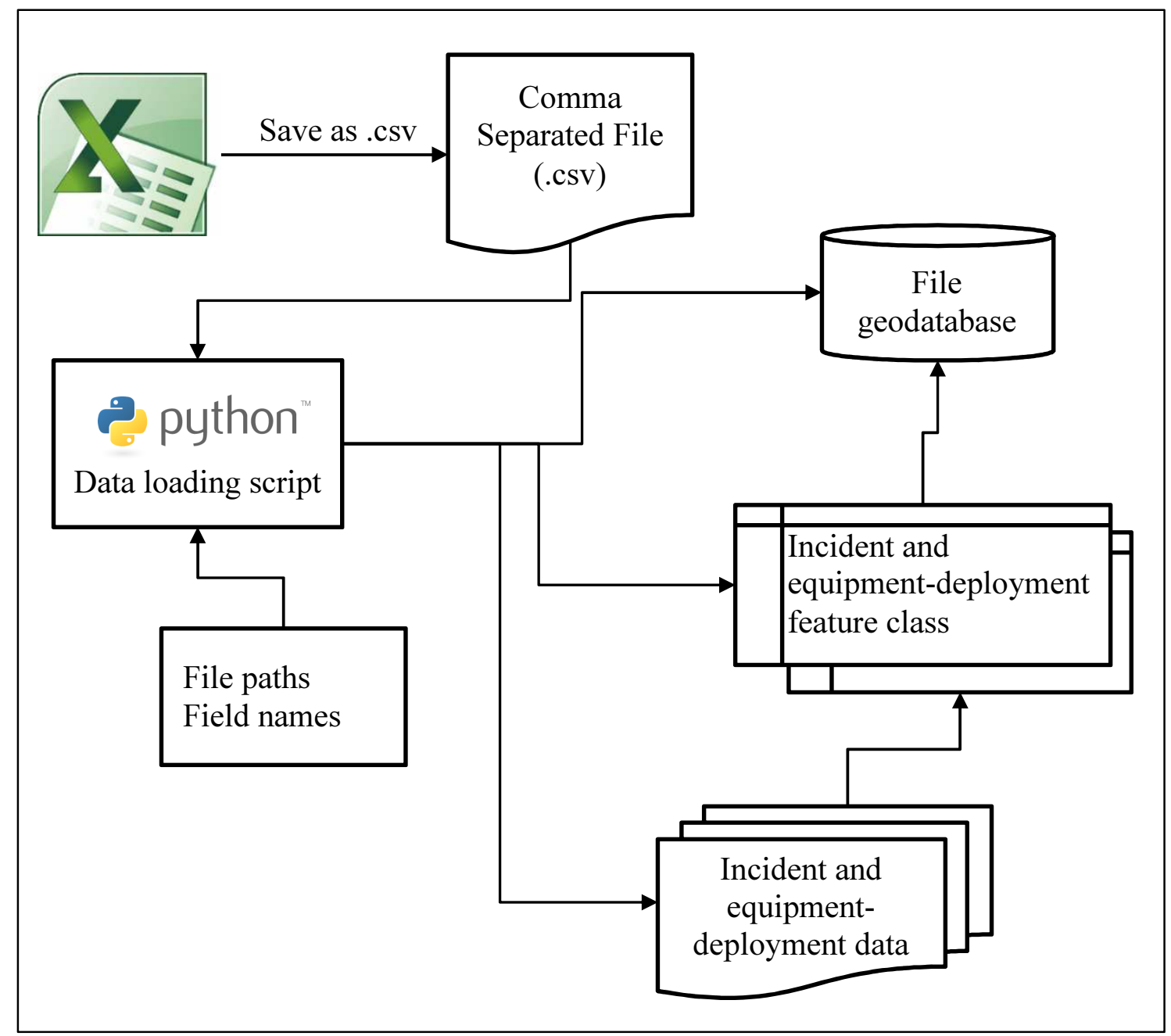

Figure 4-3: Data Loading to a File Geodatabase

\subsubsection{Publishing to ArcGIS Online}

Both the mobile application and the dashboard consumed data from feature services on ArcGIS Online. To achieve this, the data in the file geodatabase were loaded into a map document and published to ArcGIS Online as a feature service. The feature service was loaded onto the ArcGIS Online map as a web map. The dashboard accessed the data via the web map, and the mobile application accessed the data via the uniform resource locator (URL) of the feature services. Figure 4-4 illustrates the publishing workflow to ArcGIS online and the data access from both the dashboard and mobile application. 


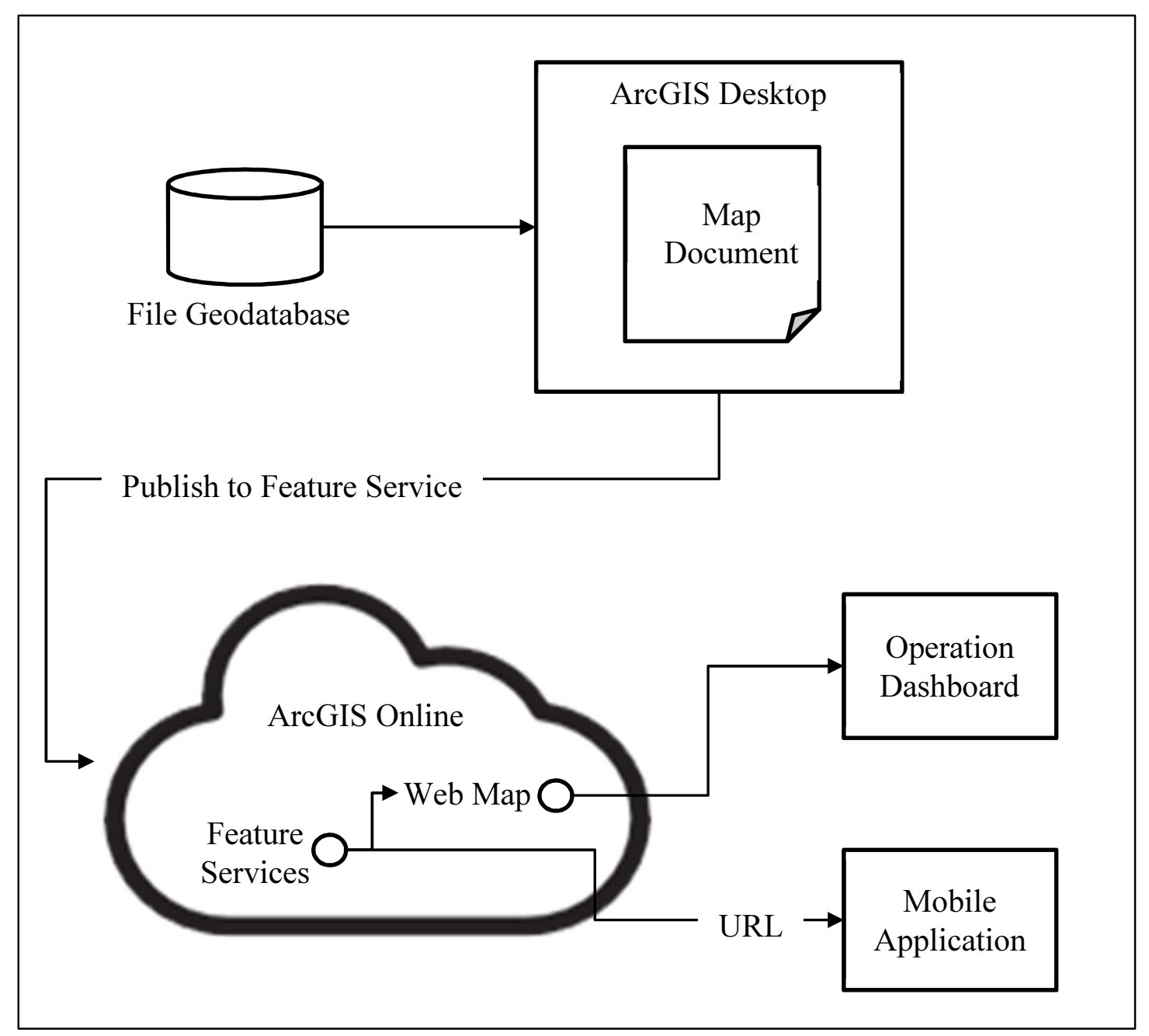

Figure 4-4: Publishing to ArcGIS Online

\subsection{Summary}

This chapter discussed the database design in depth, from the central idea supporting the conceptual data model, to the design choices supporting the logical data model. The design choices included selection of ArcGIS online over an enterprise geodatabase, a non-2NF (second order normal form) table, and unique identification using GUIDs. Sections 4.3 and 4.4 provided a walk through of the data provided by the client and the scripts that the project developed to populate the initial database. 


\section{Chapter 5 - Implementation}

This chapter explains the architecture blueprint of this system. This chapter aims to capture the key considerations in the implementation of a project of this scope and scale.

The various implementation phases are discussed, and decisions in both design and development are detailed. There were four main implementation phases: the design of the mobile application user interface and the map visualization (Sections 5.1 and 5.2); the setup and development of the iOS mobile application (Section 5.4); the Quick Response (QR) Code generation (Section 5.5); and configuration of the operations dashboard (Section 5.6).

\subsection{Design of Mobile Application User Interface (UI)}

For a mobile application, the amount of available screen space to present information and functionalities is very limited. The "iOS Human Interface Guidelines" (Apple Inc., 2015) emphasizes that user interfaces should focus on content clarity and present an easy understanding of the information. The development of the mobile application consisted of view controllers. Each view controller contained a main view, which contained UI elements such as text boxes and buttons. The main view presented the state of the application. In addition, each view controller could activate another view controller as the active view controller.

\subsubsection{User Interface Prototype}

Before the project proceeded deep into iOS programming, a user interface prototype was built using a web tool (www.fluidui.com). This web tool enabled rapid view prototyping of a mobile application using simple icons to build each view, and linked the different views together using interactions such as touching the "OK" button. Figure 5-1 shows the summary of the views created using the prototype builder. 


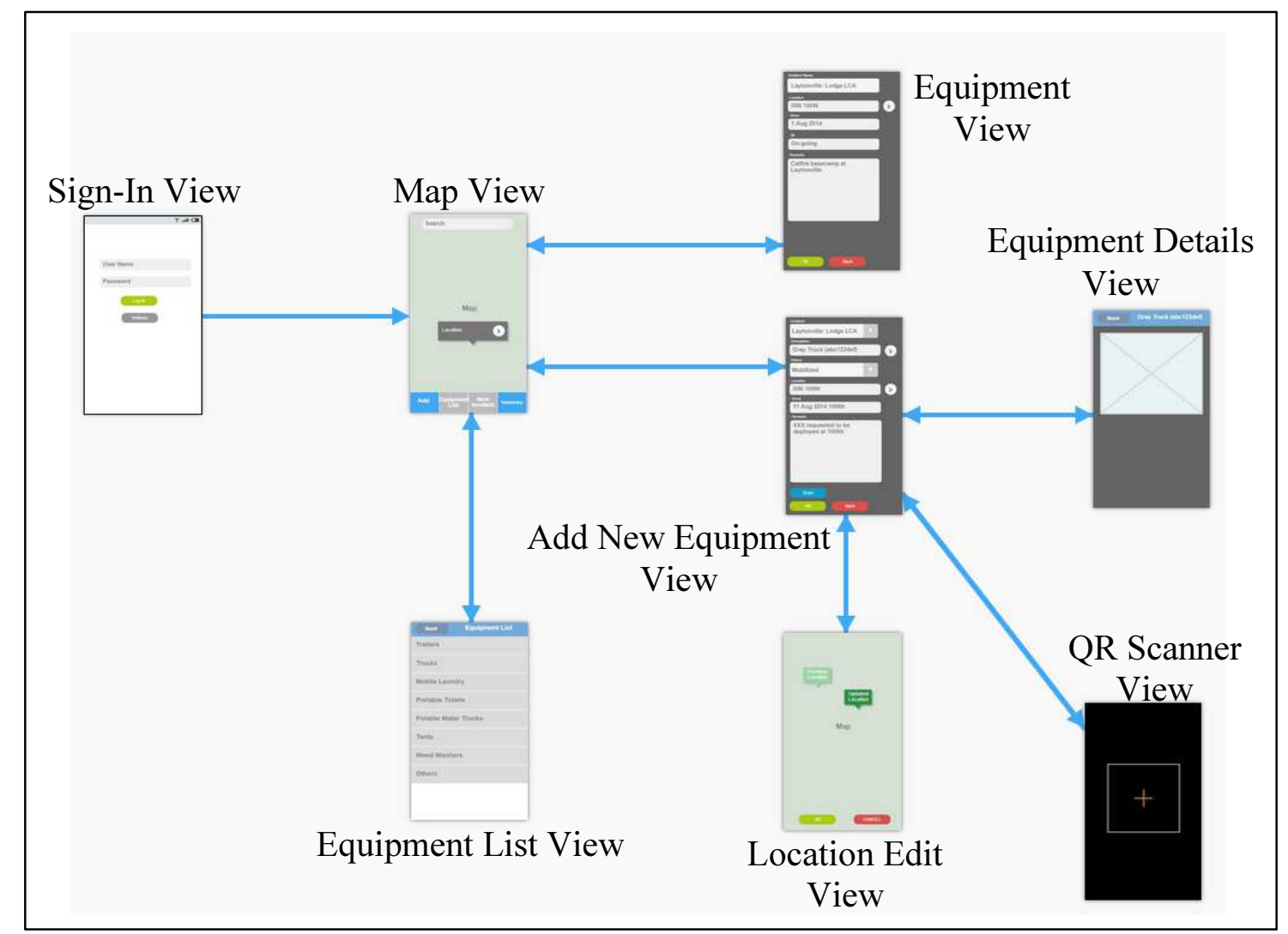

Figure 5-1: Overview of Mobile Application Prototype

Each view consisted of basic user interface elements which could be used to link to other views. An example was the "Log In" button. When the button was activated by a click or touch, the "Map View" would be shown (Figure 5-2). Similarly, an approximation user workflow could be created using this prototype. There were two main benefits of using this prototype builder: define the software use cases and workflow, and because this was a web tool, easily sharing this prototype with the client as a URL for project discussion. The client has view-only rights and not edit rights to the user interface prototype. 


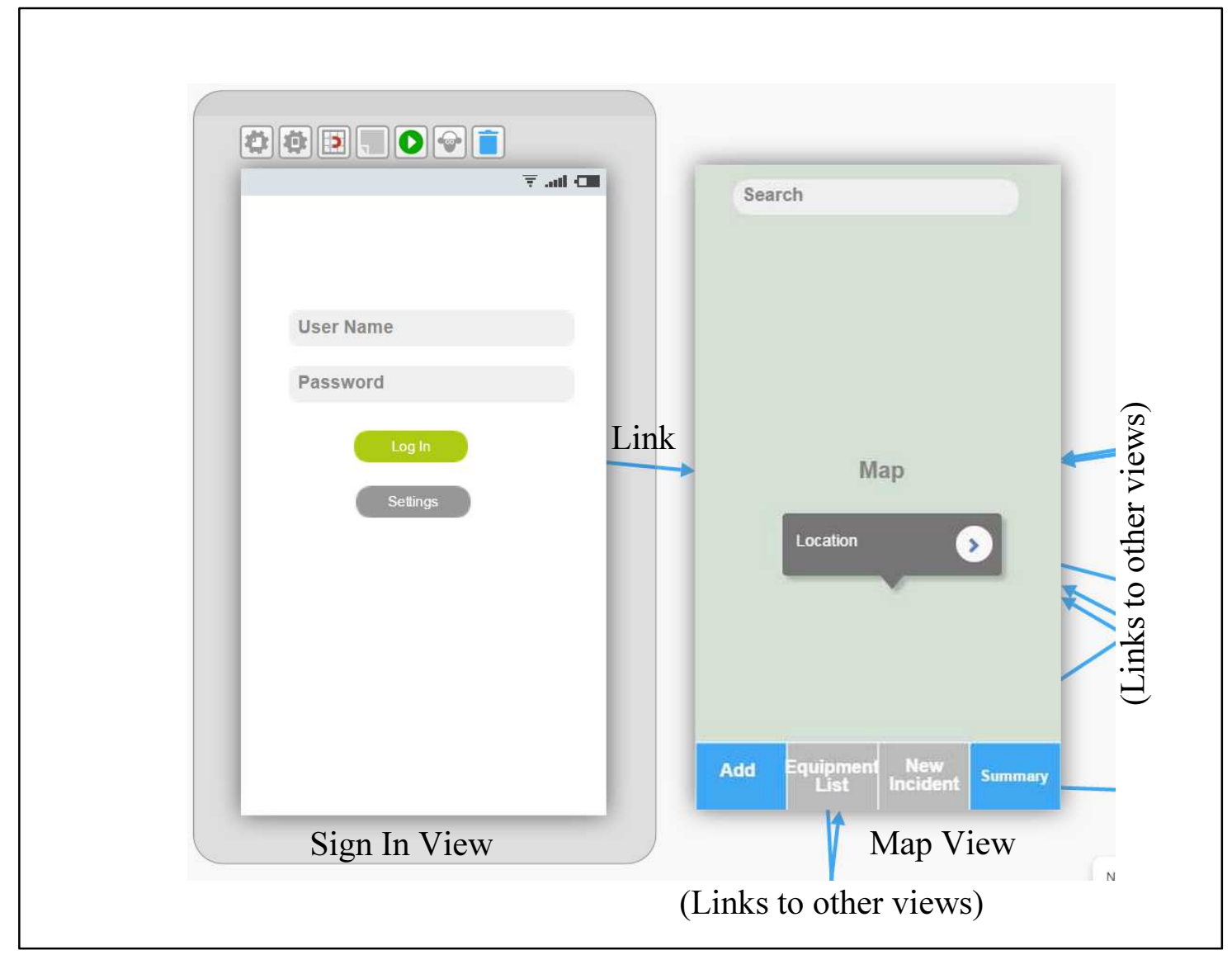

Figure 5-2: Prototype of "Sign-In View" and "Map View"

This prototype tool allowed the project team to discuss workflows with the client by providing a simple interface for them to try, without incurring substantial development time and effort. This was especially useful because the project team could produce the prototype without first learning the necessary programming language. The prototype views are available in Appendix D. The view-only link to the prototype is also included.

\subsubsection{User Interface Elements}

By building the prototype, the project team was able to narrow down some of the necessary UI elements available in iOS and ArcGIS Runtime SDK for iOS. Table 5-1 shows a subset of the user interface available in the iOS application framework. These user interface elements represent the common components in an information application with edit capabilities. The map view element was available in the ArcGIS Runtime SDK for iOS, whereas the rest of the elements were available in the iOS SDK. 
Table 5-1: Examples of User Interface Elements

\begin{tabular}{|c|c|c|c|}
\hline S/No. & Name of UI Element & Usage & Example \\
\hline 1 & Map View & Map presentation & \\
\hline 2 & Tool Button & $\begin{array}{l}\text { Represent user } \\
\text { actions }\end{array}$ & 0 \\
\hline 3 & Toolbar & $\begin{array}{l}\text { Organize tool } \\
\text { buttons }\end{array}$ & Download C + i0 signout 而 \\
\hline 4 & Navigation bar & $\begin{array}{l}\text { Navigate between } \\
\text { views }\end{array}$ & $\langle\operatorname{Back}(41) \quad \wedge \vee$ \\
\hline 5 & Date Picker & $\begin{array}{l}\text { Selection of a } \\
\text { date/time }\end{array}$ & 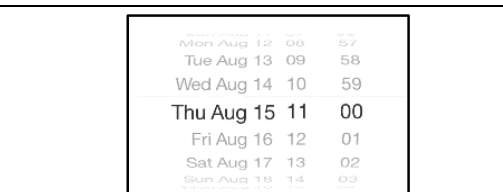 \\
\hline 6 & Alert View (Popup) & $\begin{array}{l}\text { Request for user } \\
\text { input OR show alert } \\
\text { message. }\end{array}$ & 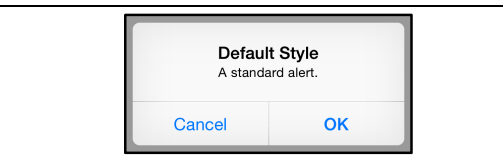 \\
\hline 7 & Table View & $\begin{array}{l}\text { Display a list of } \\
\text { information }\end{array}$ & 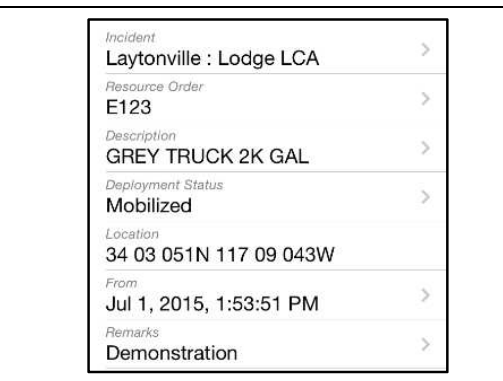 \\
\hline
\end{tabular}

The project team selected the table view to display detailed deployment information because of its versatility in presenting a list of structured data. The table view consisted of three sub-elements for each row that were useful to present specific information in context: text label, detail text label, and the accessory. The text label and detailed text label were used together to display the attribute field name, as well as the data for a field. The accessory was used to indicate whether the user could interact with a row, or to show drill-down details. Figure 5-3 shows the UI elements in a table view. 


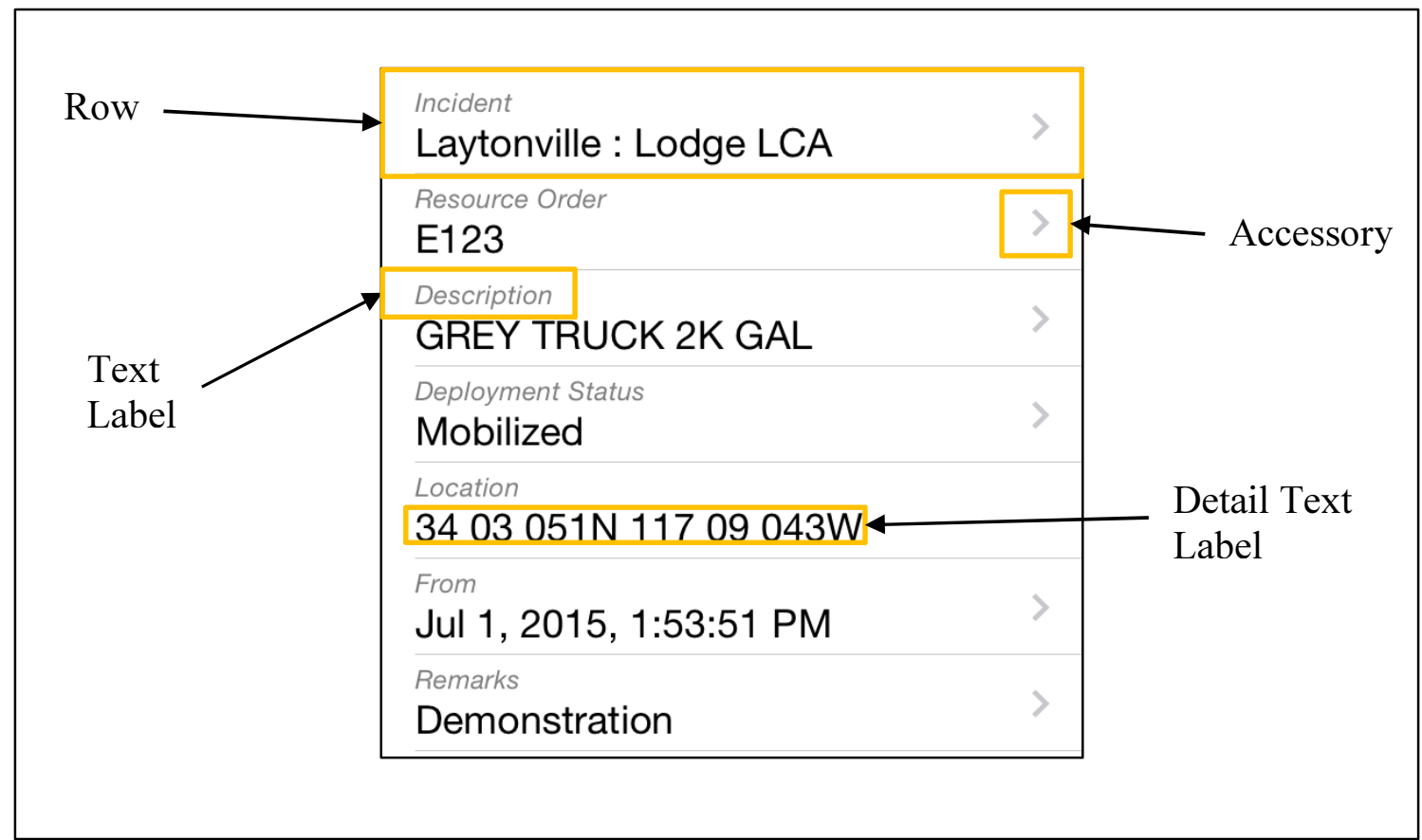

Figure 5-3: A Table View with the sub-elements

\subsubsection{Hierarchy of User Interface Views in iOS}

In iOS programming, view controllers are used to manage content displayed. A view controller consists of a main view and its UI elements. Figure 5-4 shows an example of the map view controller and the hierarchy of its elements. 


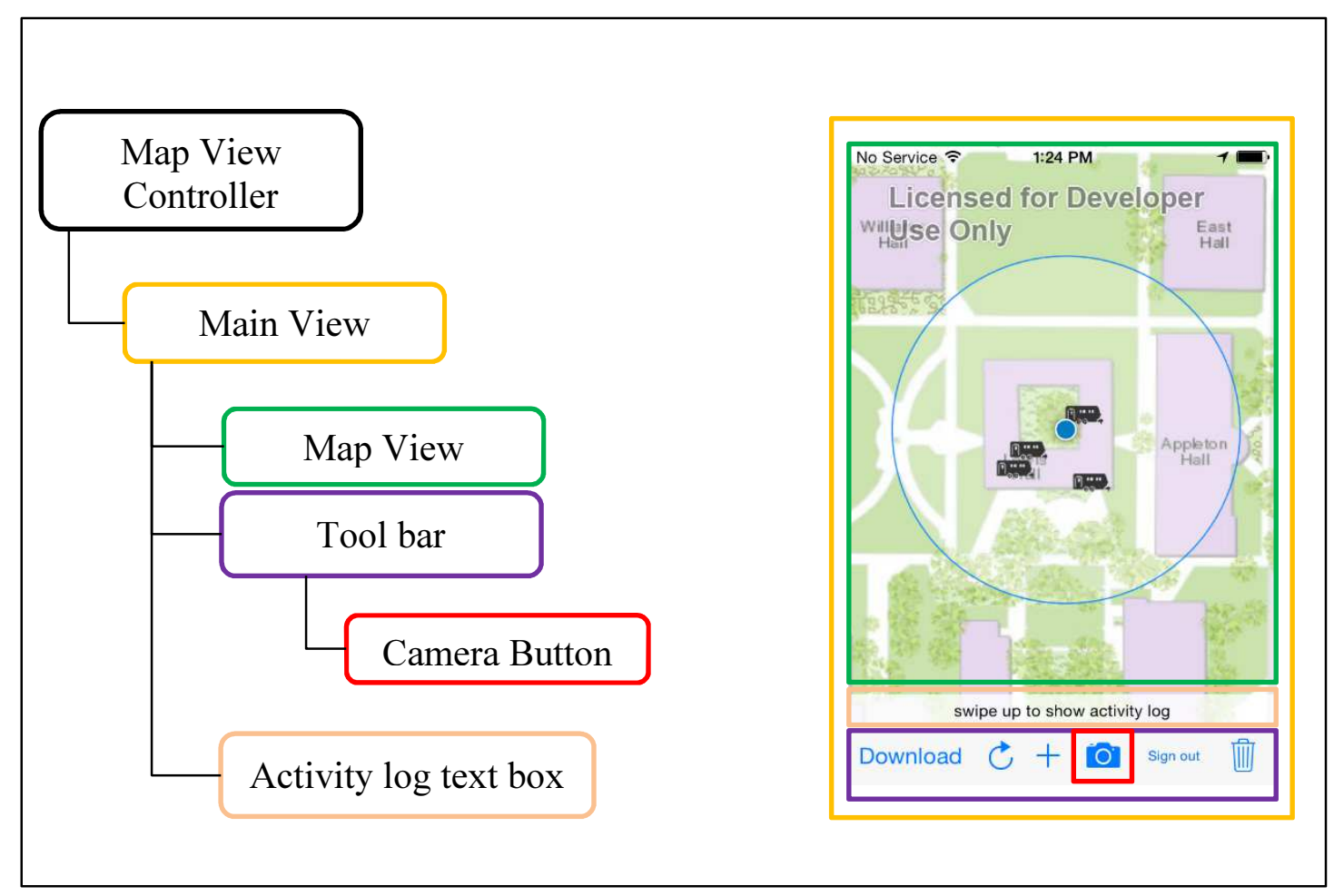

Figure 5-4: Example of the Hierarchy Within a View Controller

A method of navigating between view controllers in $\mathrm{IOS}$ is via the navigation controller. This is a UI manager that assists the developer in managing the current active view presented to the user, keeping track of the previous views, and organizing the view controllers available, using a stack. Figure 5-5 shows an example of the relationship between the navigation controller and the stack of view controllers. The navigation controller selects the sign-in view controller as the initial display when the user starts the application. The user is prompted to input the sign-in name and password. Upon authentication, the navigation controller is notified to present the map view controller as the current view controller. Similarly, when the camera button is touched by the user, the navigation controller activates the QR scanner view controller to scan the QR code. 


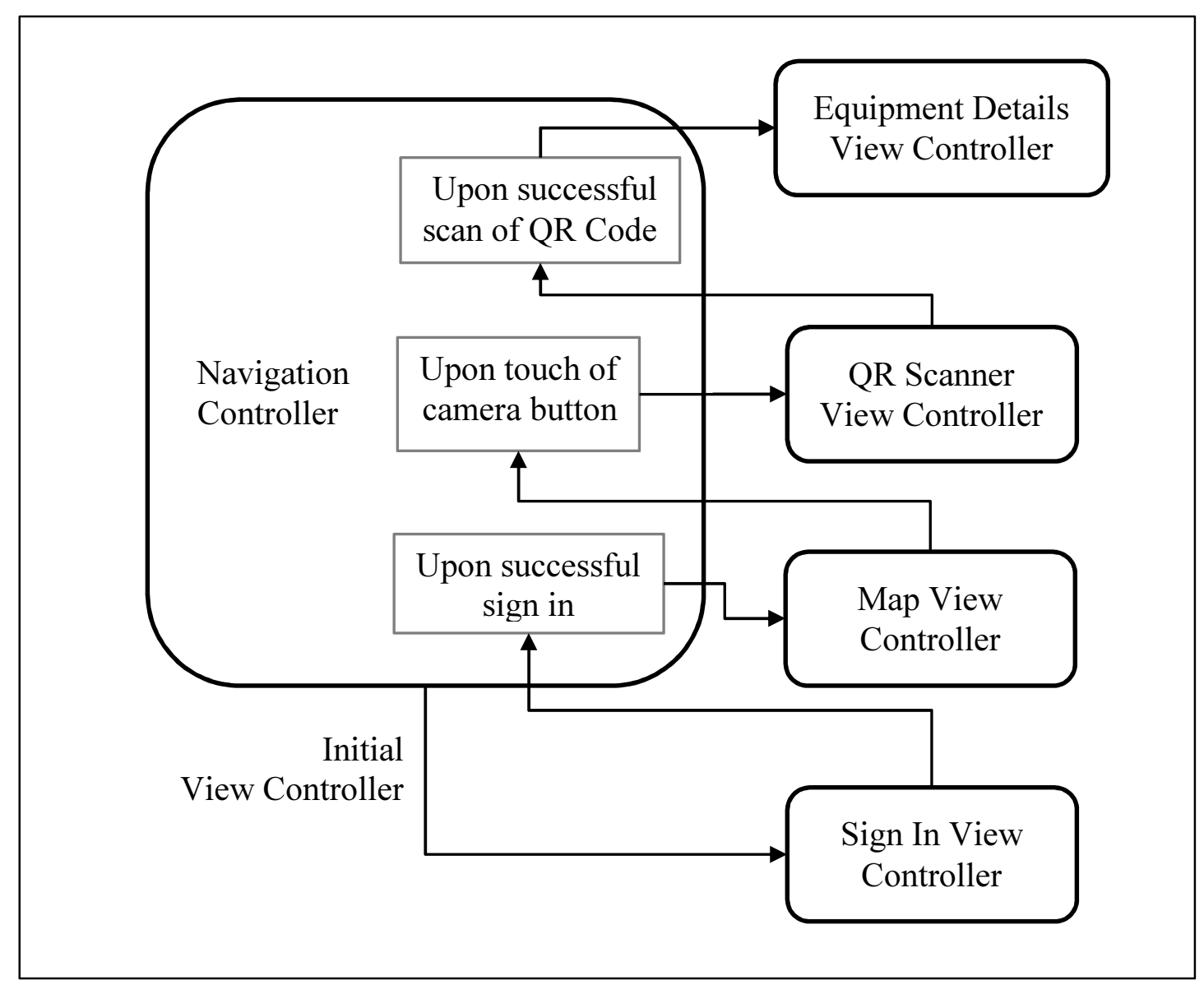

Figure 5-5: Navigation between View Controllers via the Navigation Controller

The additional benefit of using the navigation controller is that it provides navigational toolbar as a placeholder for top-left and top-right navigational buttons. As a convention for right-handers, the top-left button serves as a cancel action, whereas the top-right button serves as a change confirmation action. Figure 5-6 shows an example of the navigation bar and buttons used in the equipment detail view controller. In the equipment detail view controller, the top-left button is used as the cancel action, and the top-right button is used as the "save" action for confirming the changes to the application. 


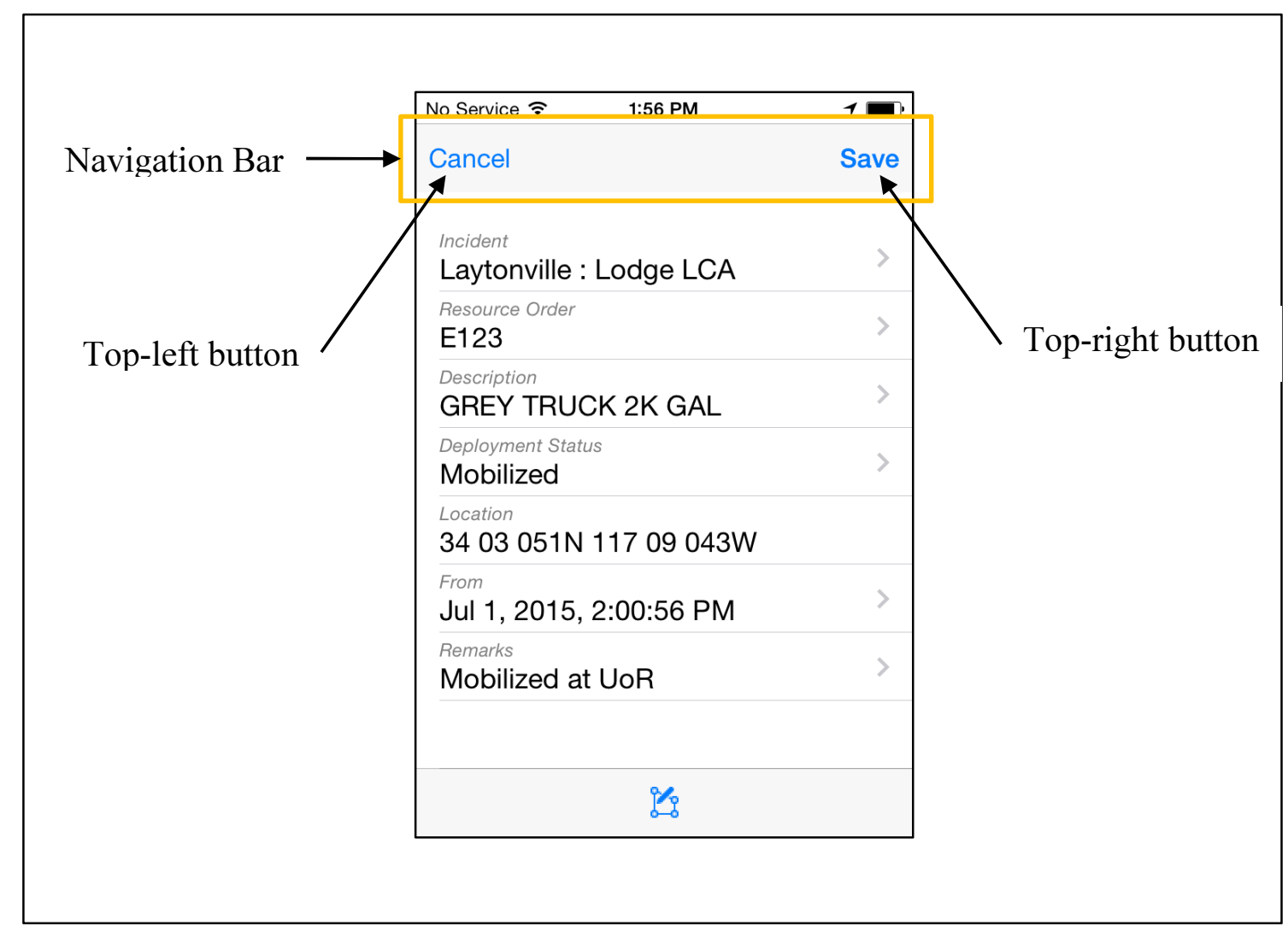

Figure 5-6: Example of Navigation Bar

\subsection{Design of Map Visualization}

There were two map products for this project: the map for the mobile application and the map for the operations dashboard. Both of these map products were supported by the same two published feature services as their main data sources: the incident feature service, and the equipment-deployment feature service. Two main map components that influenced the look and feel for the map products: the symbology used to represent the deployment information, and the base map.

\subsubsection{Symbology}

Different symbols were used to represent the incidents and equipment-deployments. Since the mobile application was the focus of the project, the symbols were designed to be simple and easily distinguishable on a small mobile device. The full list of symbols used in both maps can be found in Appendix E. Table 5-2 shows a subset of the symbols on the topographic base map. 
Table 5-2: Subset of Equipment Symbology

\begin{tabular}{|c|c|}
\hline Description & Symbol \\
\hline Trailer & \\
\hline Toilet & \\
\hline Tent & \\
\hline Generator & \\
\hline $\mathrm{AC}$ & \\
\hline Incident & \\
\hline
\end{tabular}

\subsubsection{Base Map}

The world topographic map from the ArcGIS gallery was selected as the default base map. At the time of development, there were ten base maps available from the base map gallery. The main factors influencing the base map selection were the amount of information and the clarity of the map. The topographic map was chosen because it had basic terrain information such as road information, river information, and contour lines. It was also visually less cluttered than the world street map and USA topographic map, which had similar amounts of details. This was important from the perspective of a mobile application with a small screen.

\subsection{Setup of iOS Development Environment}

Similar to most development framework, there are specific steps to set up a working development environment. This section lists the setup configuration that was used for this project.

\subsubsection{Apple Development Account}

For the iOS development framework, there were built-in controls to restrict the development and distribution of iOS mobile applications. This was done mainly via the iOS developer account registered with Apple. There are two types of developer accounts: the individual account and the organization account. From the perspective of an organization, the advantage of creating an organization account was the clear definition of administrator, agent, and member roles within a team. This demarcation of 
responsibilities also meant that actions during the development phase required approval from the correct personnel. For example, running an iOS application on a new device required two approvals: signing a development certificate for the application, and adding the new device to the list of devices (for the organization) so that the application could be installed. Table 5-3 explains the role descriptions within an organization account.

Table 5-3: Roles in an Organization Account (Extracted from developer.apple.com)

\begin{tabular}{|l|l|}
\hline Role & Description \\
\hline $\begin{array}{l}\text { Team } \\
\text { agent }\end{array}$ & $\begin{array}{l}\text { A team agent is legally responsible for the team and acts as the primary } \\
\text { contact with Apple. The team agent can invite team members and change } \\
\text { the access level of any other team member. There (is) only one team agent. }\end{array}$ \\
\hline $\begin{array}{l}\text { Team } \\
\text { admin }\end{array}$ & $\begin{array}{l}\text { A team admin can set the privilege levels of other team members, except } \\
\text { the team agent. Team admins manage all assets used to sign your apps, } \\
\text { either during development or when your team is ready to distribute an app. } \\
\text { Team admins are the only people on a team who can sign apps for } \\
\text { distribution on nondevelopment devices. Team admins also approve } \\
\text { signing certificate requests made by team members. }\end{array}$ \\
\hline $\begin{array}{l}\text { Team } \\
\text { member }\end{array}$ & $\begin{array}{l}\text { A team member can sign apps during development, but only after he or she } \\
\text { makes a request for a development signing certificate and has that request } \\
\text { approved by a team admin. }\end{array}$ \\
\hline
\end{tabular}

The individual account was the simpler alternative for this context because the individual had the rights to manage the device assets, sign application certificates, and submit distribution requests. Thus, this project requested the individual account for development of this prototype.

\subsubsection{Integrated Development Environment (IDE), ArcGIS Runtime SDK, and Mac Hardware}

The IDE used for this project was Xcode 6 running on Mac OS X (Yosemite). A Mac OS is a necessity for iOS application development. ArcGIS Runtime SDK for iOS was installed using CocoaPods (cocoapods.org). CocoaPods was the tool used by iOS projects to install external libraries. The detailed steps to install CocoaPods and subsequently install ArcGIS Runtime SDK are explained in Appendix F. The hardware used was a Mac Mini (2012). Figure 5-7 shows the system specifications used for this project. 


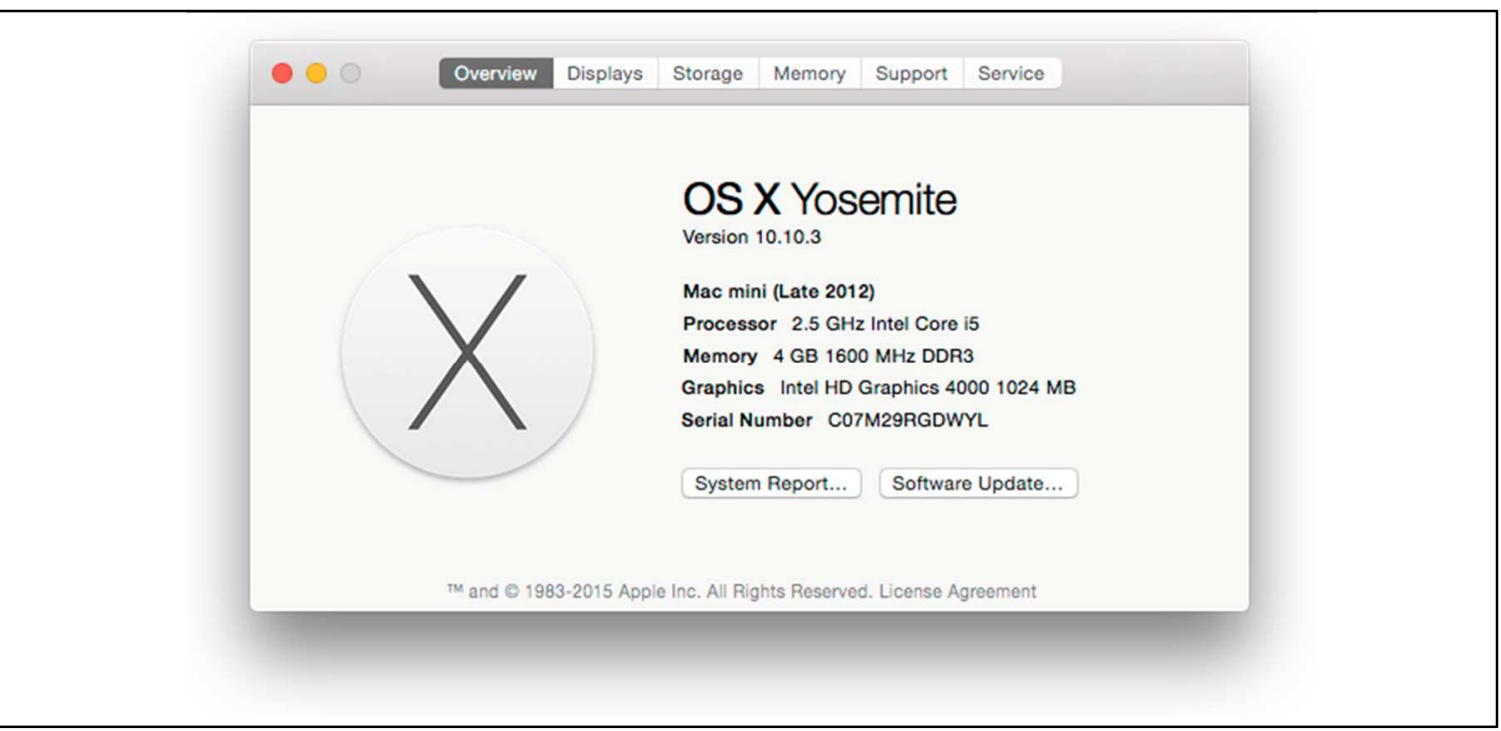

\section{Figure 5-7: System Specifications of Development Environment}

\subsubsection{Version Compatibility}

When developing within the iOS framework with ArcGIS Runtime, there are many version compatibilities to verify. This project was developed on an iPhone 4 running iOS version 7.1.2, ArcGIS Runtime SDK for iOS version 10.2.4. Xcode 6 was used as the IDE with iOS SDK 8. When compiling the program, the iOS deployment target was chosen to be iOS 7.1 so that the application could run on iOS 7.1.2 (see Figure 5-8).

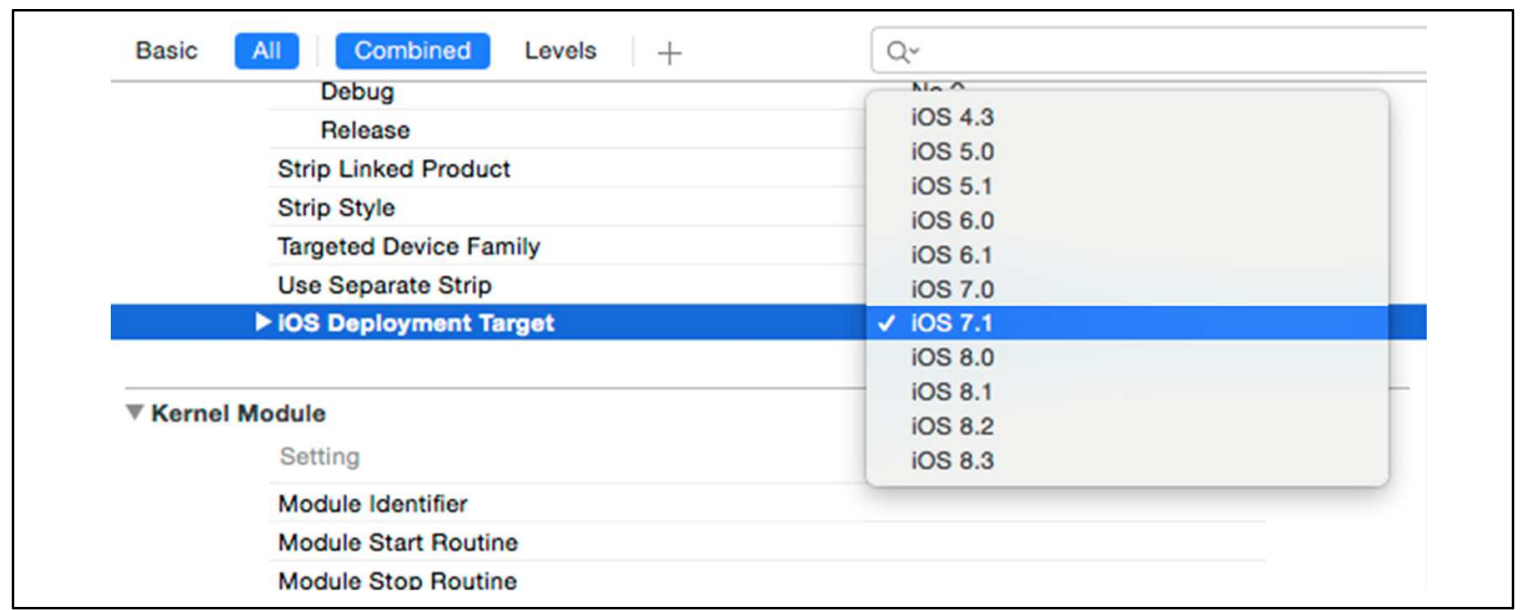

Figure 5-8: Setting Deployment Target for Compatibility between SDK 8 and iOS 7.1.2

\subsubsection{Programming Language}

Objective $\mathrm{C}$ was chosen as the programming language for this project. The latest programming language for iOS, Swift, was an alternate option. This decision was made due to the existing community support available for Objective C. However, both Esri and 
Apple are promoting the use of Swift to developers, especially in the development of new applications.

\subsection{Mobile Application Development}

This section discusses on the implementation of several functionalities of the project. The code snippets included serves as a pseudo-code reference, rather than the actual code in the software.

\subsubsection{Sign into ArcGIS Online and Credential Caching}

ArcGIS Online used the OAuth Framework to authenticate users. The AGSPortal class was responsible for abstracting the authentication process. Four parameters were required to sign into ArcGIS Online: the portal URL, the token URL, the user name, and the password. During initiation, the AGSPortal object authenticates against the portal URL. Upon successful authentication, a valid token is generated for subsequent transactions. After a successful authentication, the AGSPortal delegate's portalDidLoad method is called. Figure 5-9 shows a code example of signing into ArcGIS Online.

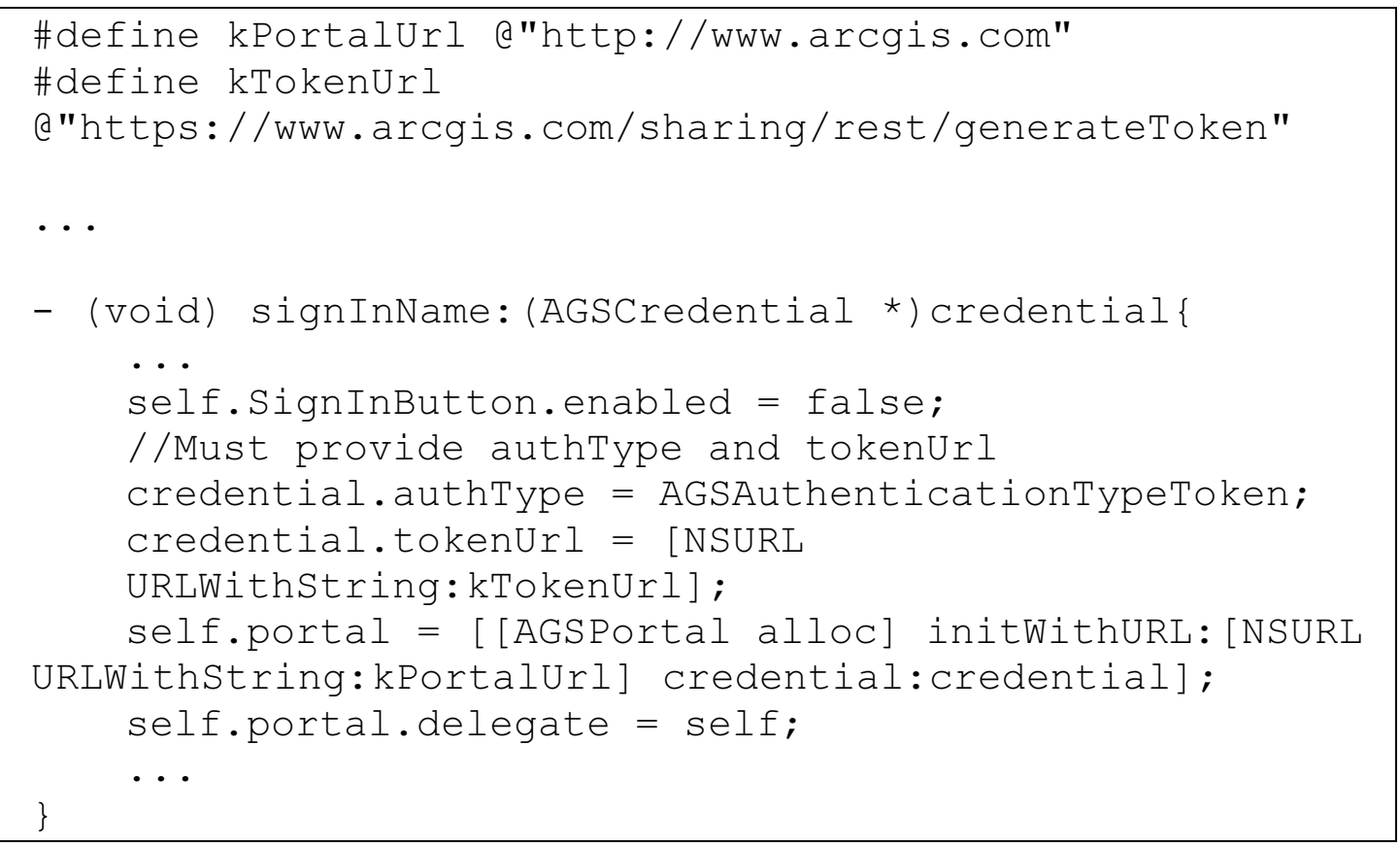

Figure 5-9: Code Snippet to Sign Into ArcGIS Online

After successful sign-in, the credentials are cached on the device so that the user does not have to key in his user name and password every time the application starts up. "Keychains" were used to store credentials locally. Valid credentials were stored as a "keychain" with an associated identifier. When the application started up, it checked for existing cached credentials to be used for authentication. Three methods were developed to save credentials to the keychain, fetch credentials from the keychain, and remove 
existing credentials from the keychain. Figure 5-10 shows an overview of the authentication process using the AGSPortal object.

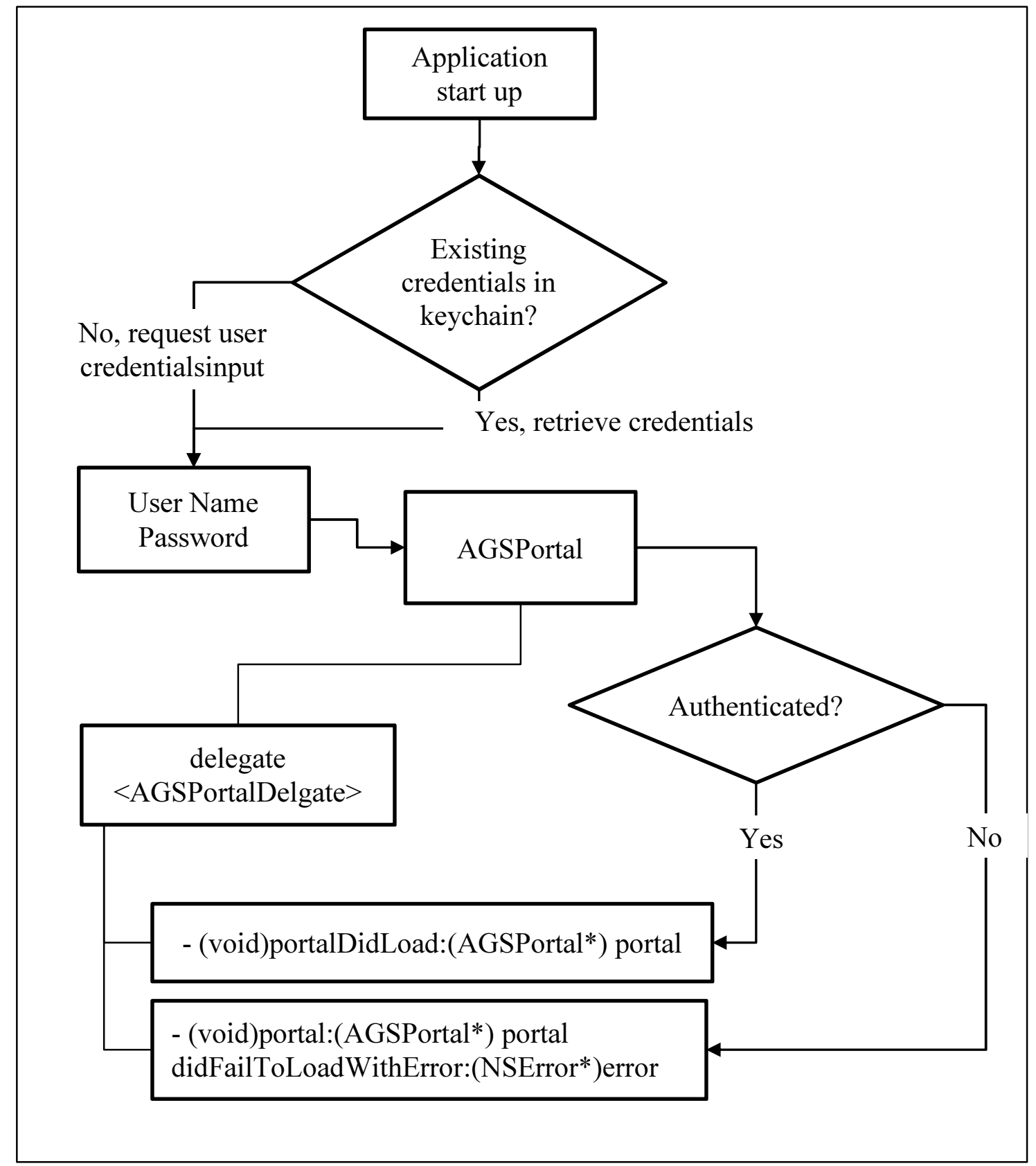

Figure 5-10: Authentication Using AGSPortal Class 


\subsubsection{Switching between Online and Local Modes}

Two separate classes were used to represent a layer of features, depending on whether the data source was online or local. When switching to online mode, a feature layer with the equipment-deployment features was created using the AGSFeatureLayer class. By passing in the equipment-deployment feature service URL, the AGSFeatureLayer would be populated with the data and symbolized according to how it was published. Subsequently, the equipment-deployment feature layer (AGSFeatureLayer) was displayed on the mobile application by adding the AGSFeatureLayer to AGSMapView.

When switching to local mode, the local geodatabase was downloaded using the AGSGDBSyncTask. The download process was asynchronous, meaning that the application was free to perform other activities while downloading occurred. When the download of the local geodatabase was completed, a feature table layer with the equipment-deployment features was created using the AGSFeatureTableLayer class. The feature table layer was initiated using the equipment-deployment feature table from the downloaded geodatabase. Similar to online mode, the equipment-deployment feature table layer (AGSFeatureTableLayer) was displayed on the mobile application by adding it to the AGSMapView. Figure 5-11 summarizes the display of the equipmentdeployment information in both online and local modes. 


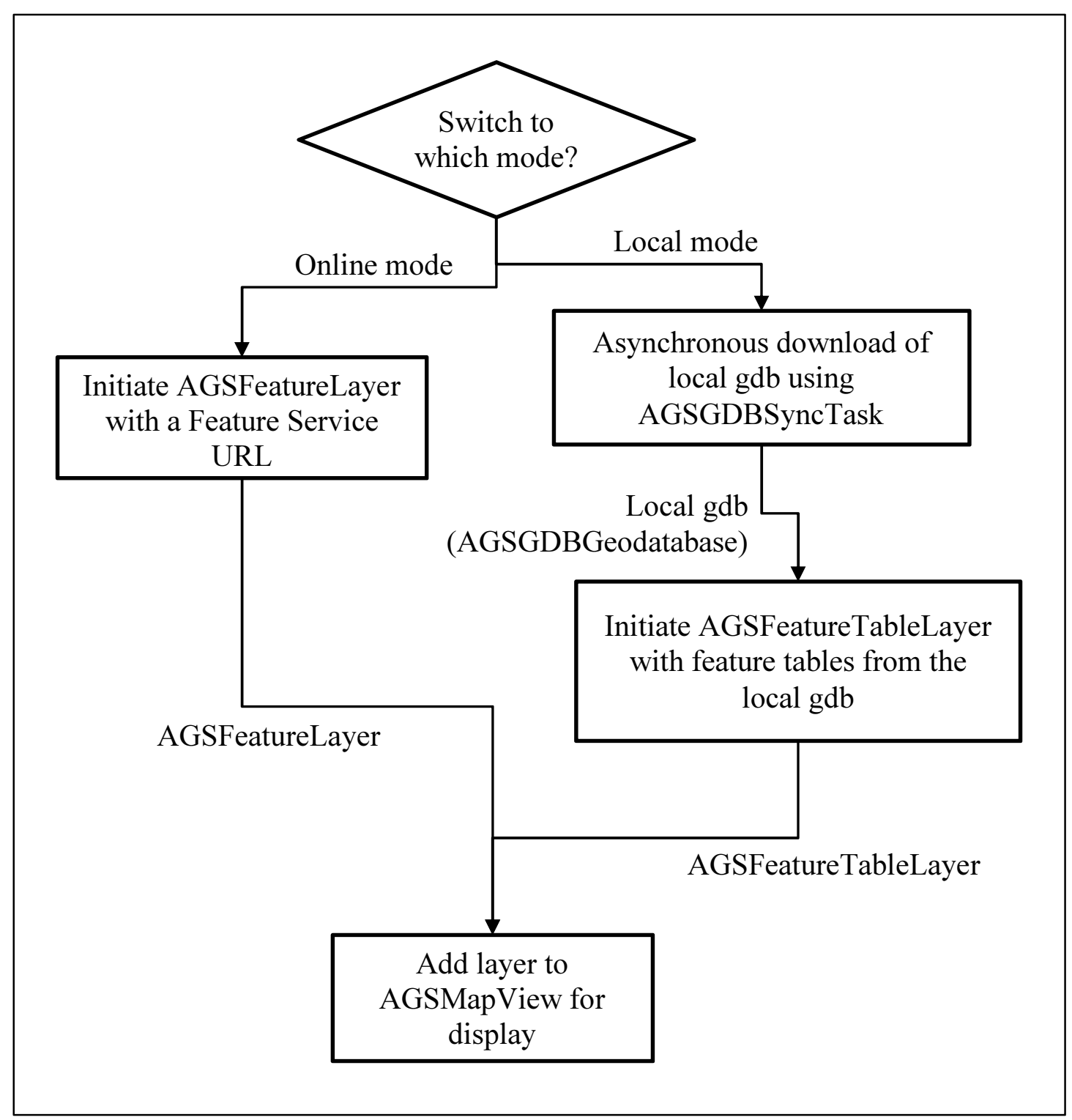

\section{Figure 5-11: Flow of Online vs. Local Mode}

\subsubsection{QR Code Scanning}

The mobile application made use of the on-device camera as a QR code scanner to translate a valid picture to an equipment ID, which in turn was used for querying the database. The component responsible for QR code scanning was the Scanner View Controller. The view controller had to display to the user what the camera was capturing, and notify the application when a valid QR code was scanned. Figure 5-12 shows a code example of the initialization of some of the components in preparation of capturing a valid QR code. 


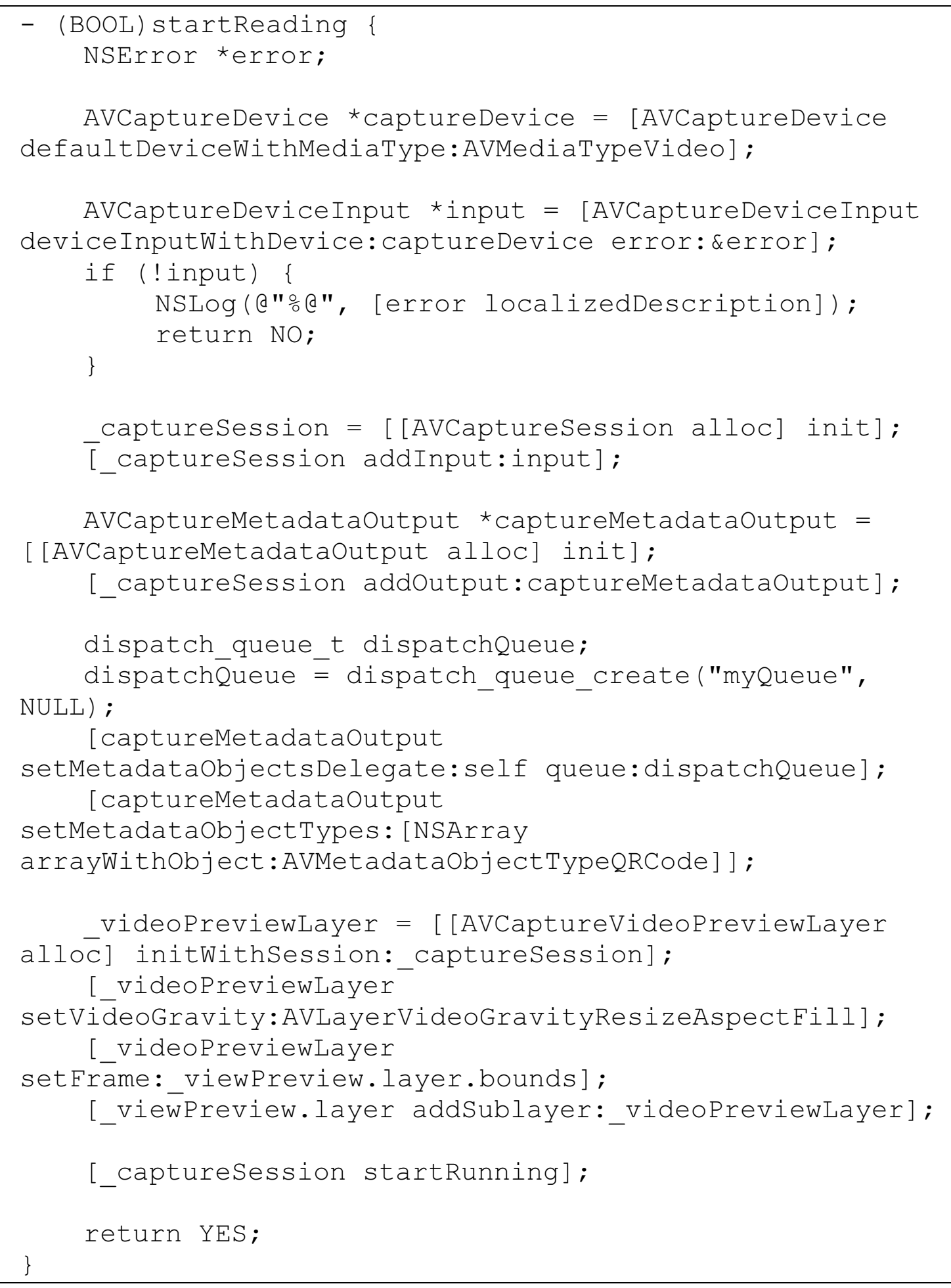

\section{Figure 5-12: Code Snippet for QR Code Scanning}

When the camera button was activated, the Scanner View Controller performed several procedures. First, the camera of the mobile device was initialized to be ready for video capture. Second, a video preview layer was initialized. The purpose of the video 
preview layer was to show the user what the camera was capturing. This helped guide the user to point the camera towards the QR code. Third, a capture session was started to analyse the video taken using image libraries to detect a valid QR image, and translate the image to an ID text string. When a valid QR image was detected and translated, the delegate would be informed with an event (captureOutput: didOutputMetadataObjects: fromConnection). Figure 5-13 shows the overview of how the QR code scanner worked.

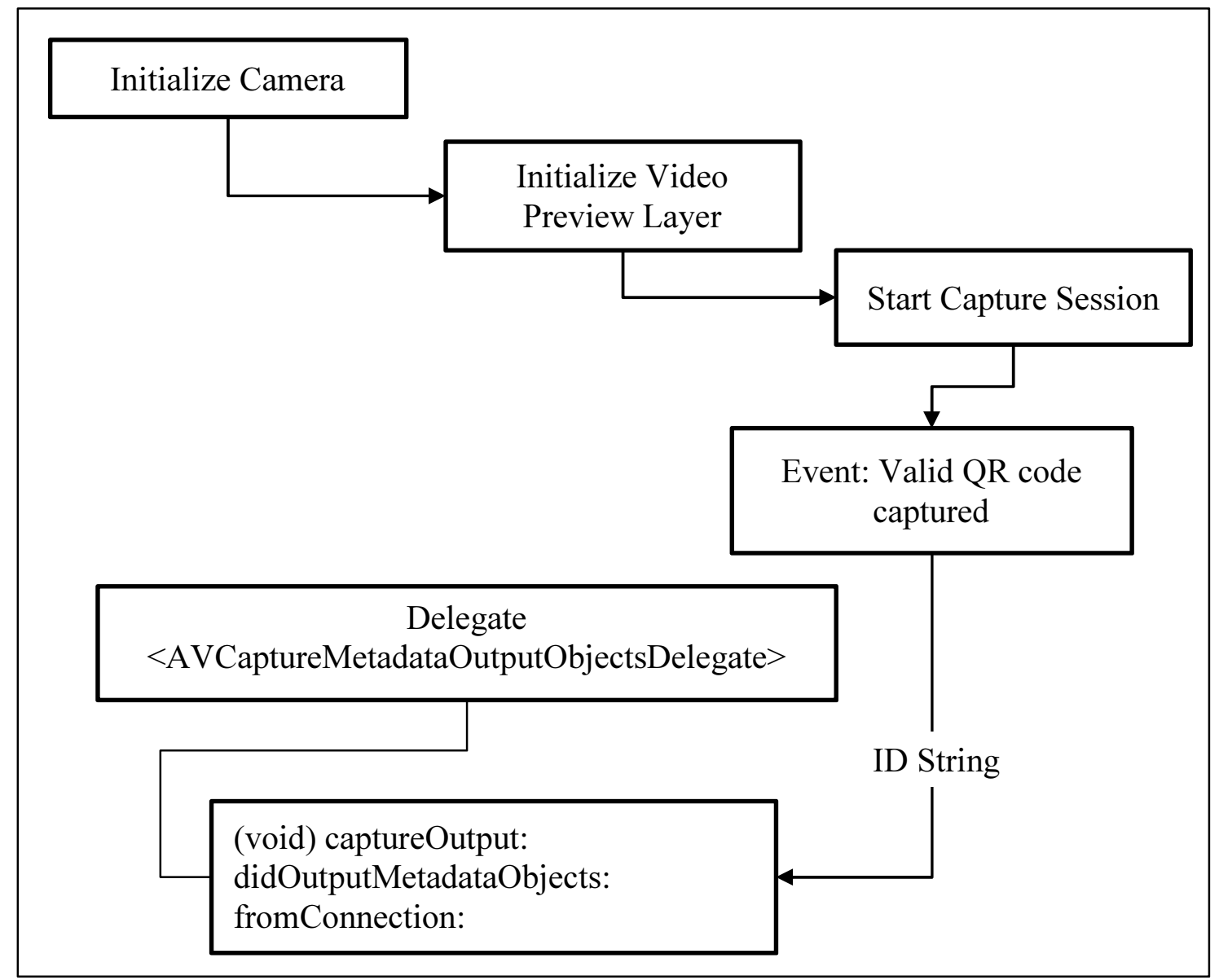

Figure 5-13: Flow of QR Code Scanner

\subsubsection{Feature Query}

After a valid QR code was scanned and translated to an equipment ID, the application queried the database for the corresponding equipment-deployment feature. The resulting feature was then used to populate the details in the table view. Feature query for both online and local modes differed slightly in code, but shared a similar concept. Figure 5-14 shows the summary flow of performing feature queries. 


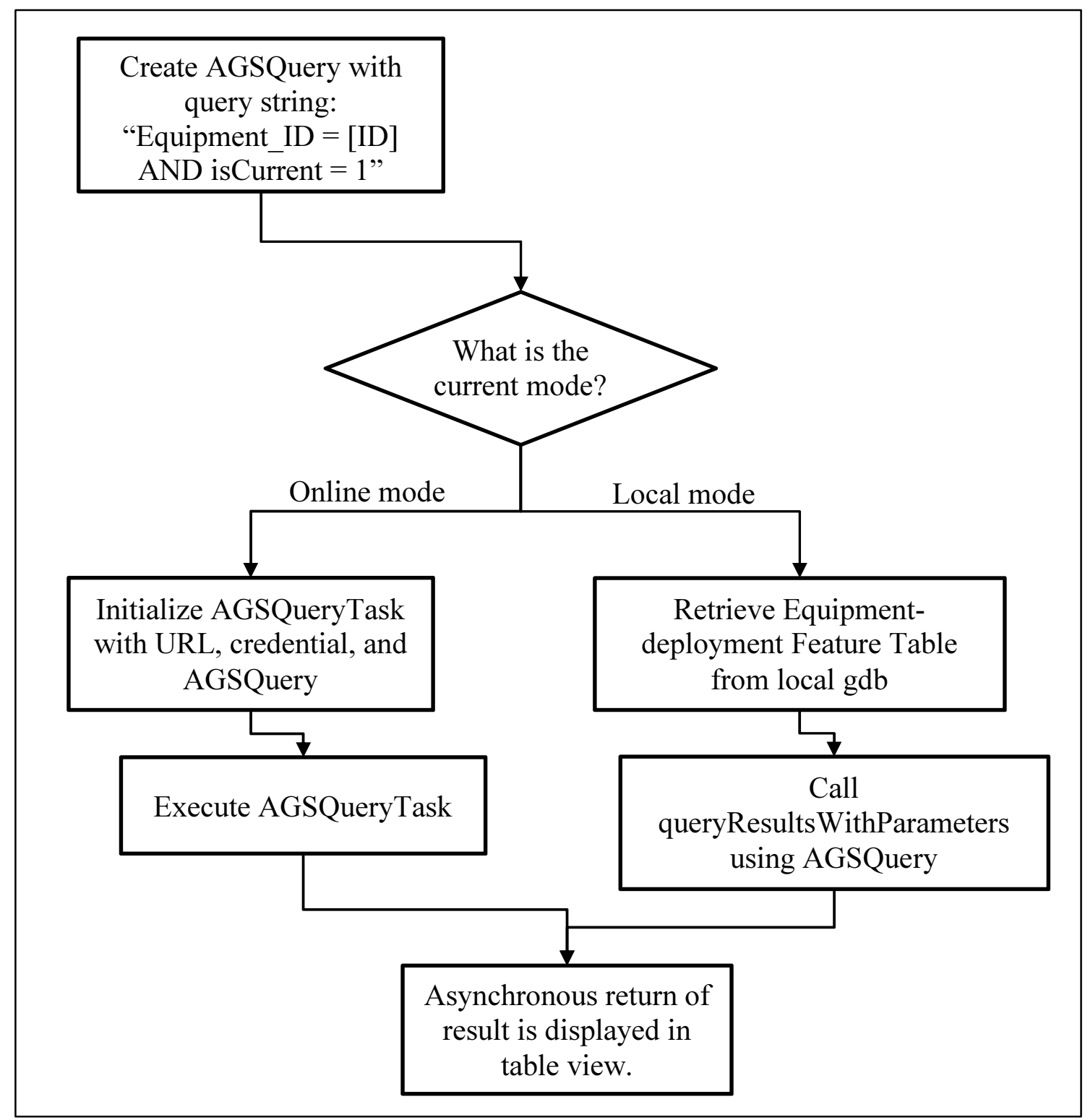

Figure 5-14: Flow of Executing a Feature Query on an Equipment-Deployment Table

For the online mode, the AGSQueryTask was created and initialized with the equipment-deployment feature service URL and credentials. An AGSQuery was created that contained the query text:

Equipment_ID $=[$ ID_from_QR_Scan $]$ AND isCurrent $=1$

After the asynchronous return of the query result, the table view was activated and populated with the equipment-deployment feature.

For the offline mode, an AGSQuery was created that contained the same query text. The query was made against the corresponding table from the local geodatabase, using the queryResultsWithParameters method of AGSFeatureTable (Figure 5-15). 


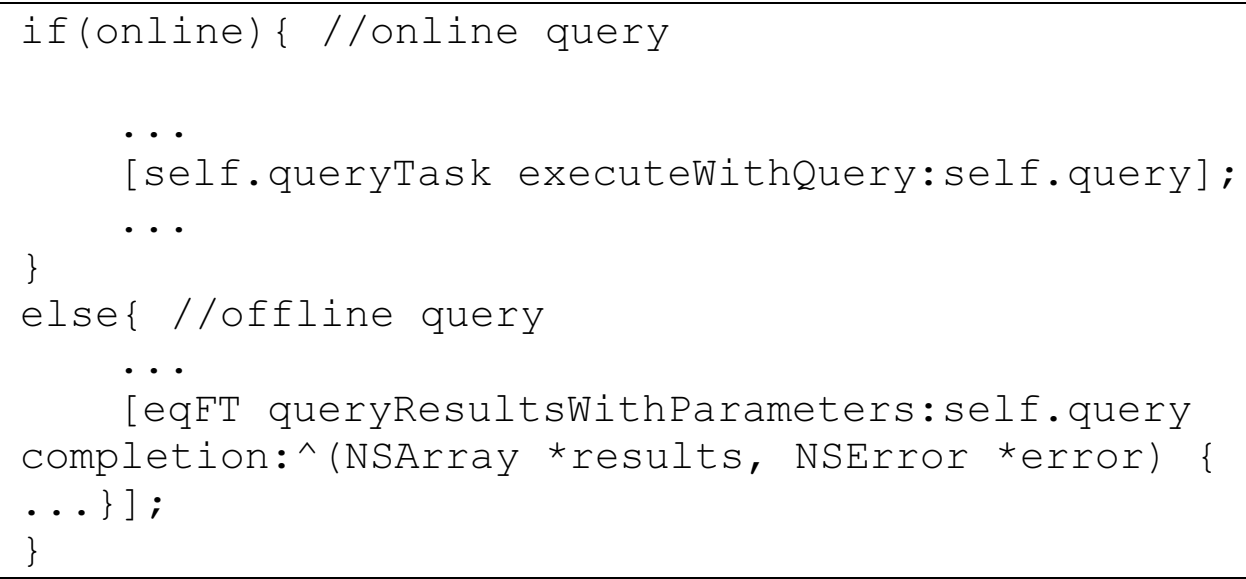

\section{Figure 5-15: Code Snippet of Online and Local Feature Queries}

\subsubsection{Integration with GPS Receiver}

When creating a new deployment entry, the mobile application used the current GPS receiver location as the default deployment location. The GPS receiver acted as a datasource to the map element. The GPS receiver datasource had to be started before the application could query the GPS receiver location. After starting the datasource, the GPS receiver location could be queried from the map element. Figure 5-16 shows a code example of querying the GPS receiver location as an AGSPoint.

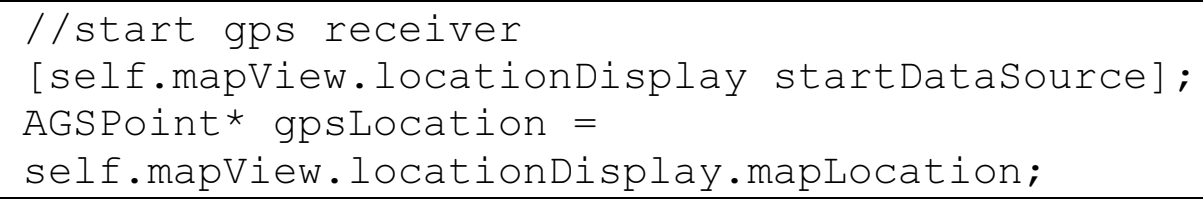

\section{Figure 5-16: Code Snippet to Query GPS Receiver Location}

Since the map used a Web Mercator projection, the AGSPoint defaulted to Web Mercator coordinates. For the purpose of display, the coordinates were converted to degree-minutes-seconds (DMS) format to the nearest second. Figure 5-17 shows the code example of displaying a Web Mercator point in DMS format.

displayed_text $=$ [point

degreesMin̄utessecondsStringWithNumDigits:0 ] ;

\section{Figure 5-17: Code Snippet to Display AGSPoint in DMS}

\subsubsection{Useful Resources for iOS Development}

There were many online community supports for general iOS application development. Resources on ArcGIS runtime for iOS were mostly from Esri's contribution to Github (esri.github.io/\#iOS) and ArcGIS for Developers (developers.arcgis.com). Github 
contained many sample applications which could be downloaded, compiled, or modified. Each sample application normally demonstrated one or more concepts. This project integrated and adapted samples from the Offline Feature Editing Sample (github.com/Esri/arcgis-runtime-samples-ios/tree/master/OfflineFeatureEditingSample), the Query Task Sample (github.com/Esri/arcgis-runtime-samplesios/tree/master/QueryTaskSample), and Save to Keychain Sample (github.com/Esri/tipsand-tricks-ios/tree/master/DevSummit2015_TipsAndTricksDemos/Tips-AndTricks/SaveToKeychain).

In terms of learning Objective $\mathrm{C}$, some of the resources used by this project included Apple's Developer website, Ry's Objective-C Tutorial, Stack Overflow, and AppCoda.

\subsection{Quick Response (QR) Code Generation}

An objective of this project was for the mobile application to scan each equipment's QR code. So it was necessary to have a method of generating the QR code for all equipment. A Python code was written to read a list of equipment IDs and output a QR code image that corresponds to each ID. The qrcode library from Python Package Index (PyPI) was used. The qrcode library depended on the Pillow library, a branch of the Python Imaging Library (PIL). The libraries were installed using Pip (a Python package manager). Procedures of installing Pip, Pillow, and qrcode are documented in Appendix G.

\subsubsection{Creating QR Codes Images From IDs}

The following code snippet (Figure 5-18) looped through the CSV file of equipment IDs, and created a QR code image in PNG format for each ID. The equipment ID is a GUID string, for example:

\{7588141F-9B06-4F26-921C-5564020A7D88\}

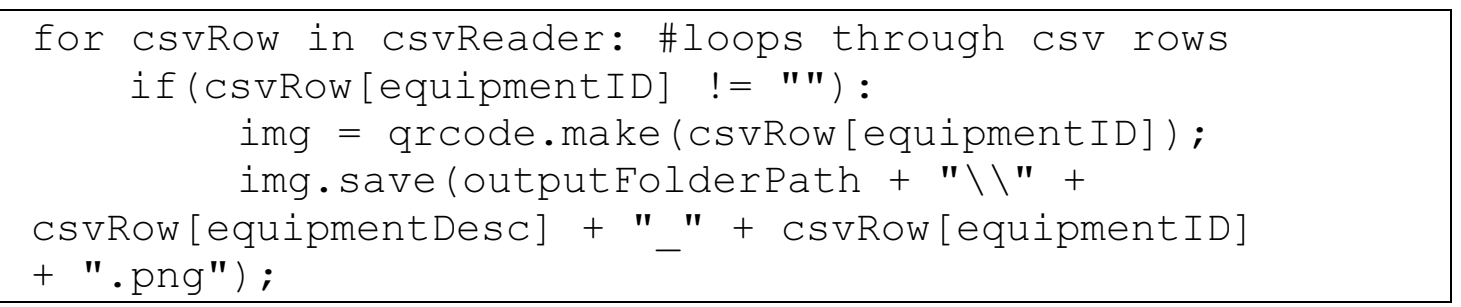

Figure 5-18: Code Snippet for Creating QR Code Images From IDs 


\subsection{Design and Configuration of Operations Dashboard}

The Operations Dashboard for ArcGIS was a configurable tool used to author a dashboard view to be consumed in either a Windows desktop native environment or a web browser. Authoring an operations dashboard view was done on a Windows desktop. There were two types of operations dashboard view: the single-display view and the multi-display view. At the time of development, the multi-display view had more layout customizability compared to the single-display view. However, only the single-display view could be accessed from a web browser.

\subsubsection{Dashboard Layout and Widgets}

One limitation of the operational dashboard was the lack of related query capabilities. Hence, the operational dashboard could only query the current incident name for an equipment-deployment, but not the incident details. This consideration was included in the layout design for the operation dashboard. Figure 5-19 shows the layout of the operations dashboard for both the equipment-deployment query widgets and the incident query widgets.

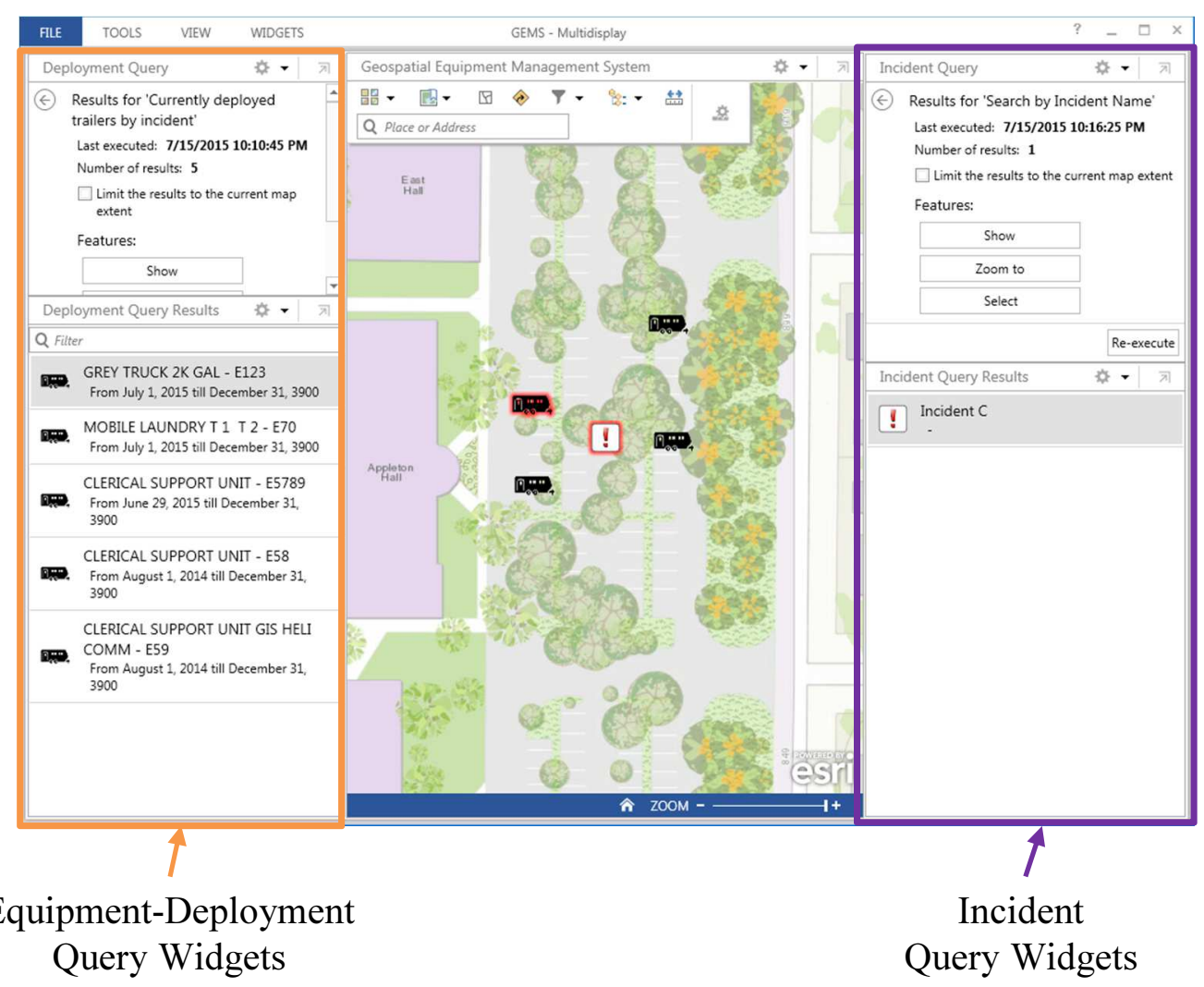

Figure 5-19: Widget Layout for the Operations Dashboard 


\subsubsection{Dashboard Configuration}

To allow automatic update of the equipment-deployments to the dashboard, the refresh interval was set to 0.1 minute, or six seconds. This meant that every six seconds, the equipment-deployment layer would refresh and update with the latest information. In addition to the automated refresh, each map interaction, such as zoom or pan, would also refresh the data.

Layer filters were added to allow users to view only the current deployments or historical deployments. The filter can be further refined by including the time period of interest. Figure 5-20 shows the layer filter options in the operations dashboard.

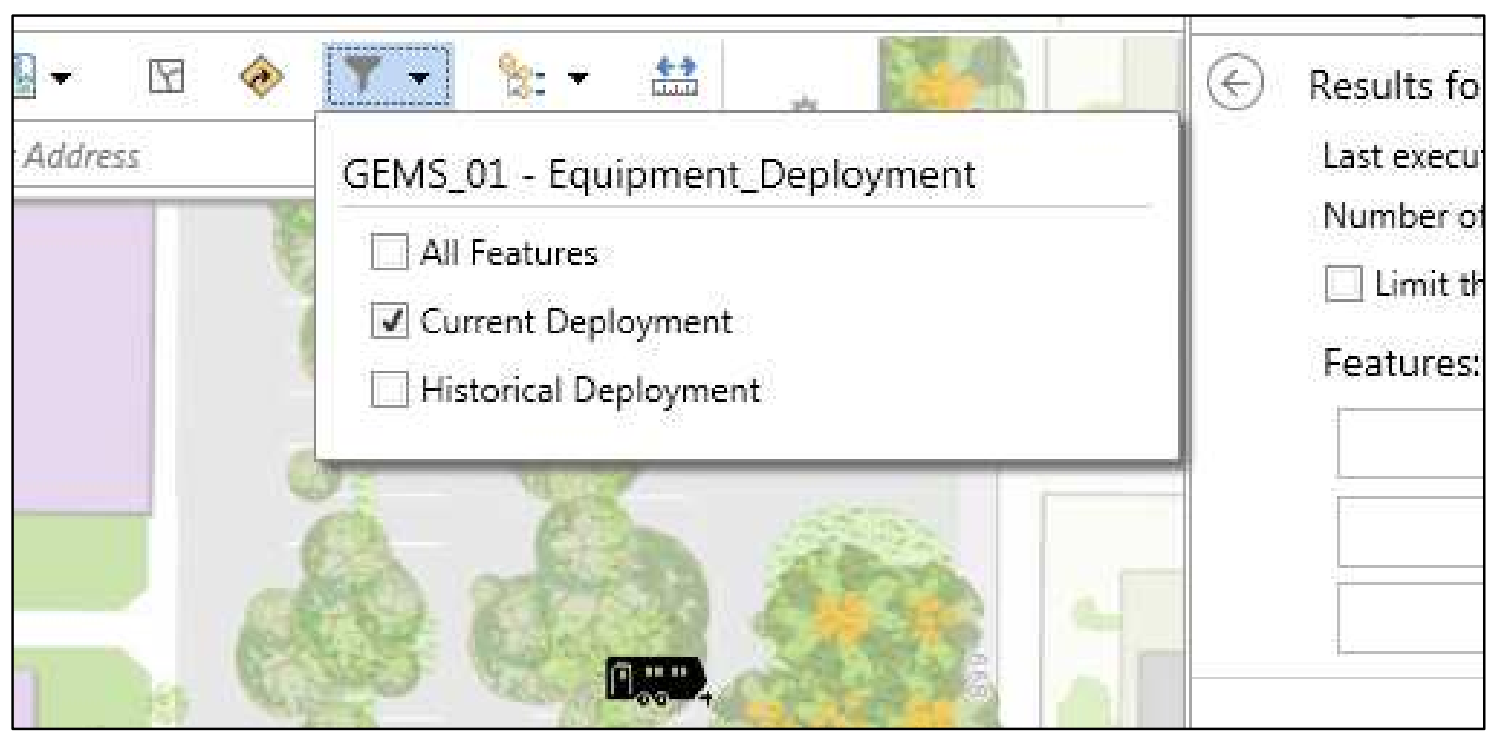

Figure 5-20: Layer Filter for the Operations Dashboard

\subsection{Summary}

This chapter discussed the developmental procedures for creating the project. The four phases of development included the design of the mobile application user interface and map visualization; the coding of Objective $\mathrm{C}$ within the iOS framework and leveraging the ArcGIS runtime libraries; QR code generation using Python libraries; and configuration of the operations dashboard for situation monitoring. Some of the design decisions made were based on the best course of action during the time of development. Section 5.4.6 discussed on the resources adapted to develop this project. The Appendix sections contain more implementation details for this project. 


\section{Chapter 6 - Results and Analysis}

This chapter describes the final product developed, revisits the requirements defined earlier in the project phase, and summarizes the completion of the requirements of this project. In Section 6.2 walks through the mobile application functionalities using test cases. Section 6.3 analyses the limitations of the application and recommends some functional areas of improvement. Section 6.4 provides a summary for this chapter.

\subsection{Requirement Traceability}

Table 6-1 shows the functional and non-functional requirements for the mobile application. All of the requirements were met except for the clustering of deployments into a single group. The intent of this requirement was to reduce the cluttering of symbols on the map by grouping close symbols together into a single symbol. This was not implemented due to the clustering library available for the ArcGIS iOS library. The library provided clustering for only the AGSFeatureLayer class, but working with offline downloading required the use of both AGSFeatureLayer and AGSFeatureTableLayer classes. It was decided that the offline download function was more useful to the client than the clustering function, and there was insufficient time to implement a customized clustering library. The recommendation would be to modify the existing clustering library, where its source code was available on Github, to perform clustering on the required classes.

\section{Table 6-1: Requirements for Mobile Application}

\begin{tabular}{|l|l|}
\hline \multicolumn{1}{|c|}{ Functional Requirements } & \multicolumn{1}{c|}{ Non-functional Requirements } \\
\hline $\begin{array}{l}\text { The mobile application shall allow } \\
\text { users to sign in to ArcGIS online with } \\
\text { valid organizational credentials. }\end{array}$ & $\begin{array}{l}\text { The mobile application runs on a } \\
\text { device with a minimum of iOS version } \\
7.1 .2, \text { camera device, and GPS } \\
\text { receiver. }\end{array}$ \\
$\begin{array}{l}\text { The mobile application shall allow } \\
\text { users to use the mobile phone GPS } \\
\text { location as the deployment location. }\end{array}$ & $\begin{array}{l}\text { The application allows the user to } \\
\text { zoom to the map area centered by the } \\
\text { GPS receiver location. }\end{array}$ \\
$\begin{array}{l}\text { The mobile application shall allow } \\
\text { users to scan a valid QR code (4" by } \\
4 \text { ") to input inventory name, } \\
\text { description. }\end{array}$ & $\begin{array}{l}\text { Users only need to sign in the first time } \\
\text { they start the application, until they } \\
\text { decide to sign out. }\end{array}$ \\
$\begin{array}{l}\text { The mobile application shall allow } \\
\text { users to create/edit/delete inventory } \\
\text { deployments. }\end{array}$ & $\begin{array}{l}\text { The mobile application supports both } \\
\text { online and offline viewing/editing. }\end{array}$ \\
\end{tabular}




\begin{tabular}{|l|l|}
\hline \multicolumn{1}{|c|}{ Functional Requirements } & Non-functional Requirements \\
\hline $\begin{array}{l}\text { The mobile application shall allow } \\
\text { offline users to synchronize data with } \\
\text { the geodatabase when there is network } \\
\text { connectivity. }\end{array}$ & \\
$\begin{array}{l}\text { The mobile application shall present } \\
\text { clustered deployments into a single } \\
\text { group, depending on zoom extent. (Not } \\
\text { completed) }\end{array}$ & \\
$\begin{array}{l}\text { The mobile application shall record the } \\
\text { starting time and ending time for each } \\
\text { deployments consistently. }\end{array}$ & \\
\hline
\end{tabular}

\subsection{Use Case}

\subsubsection{Sign Into ArcGIS Online}

When the user starts the application, it requests the user's name and password. A valid ArcGIS Online account would bring up the map view. When there is no internet connection, the user is given the option to work offline, and work with a previously downloaded geodatabase, if any. These two views are shown in Figure 6-1. 


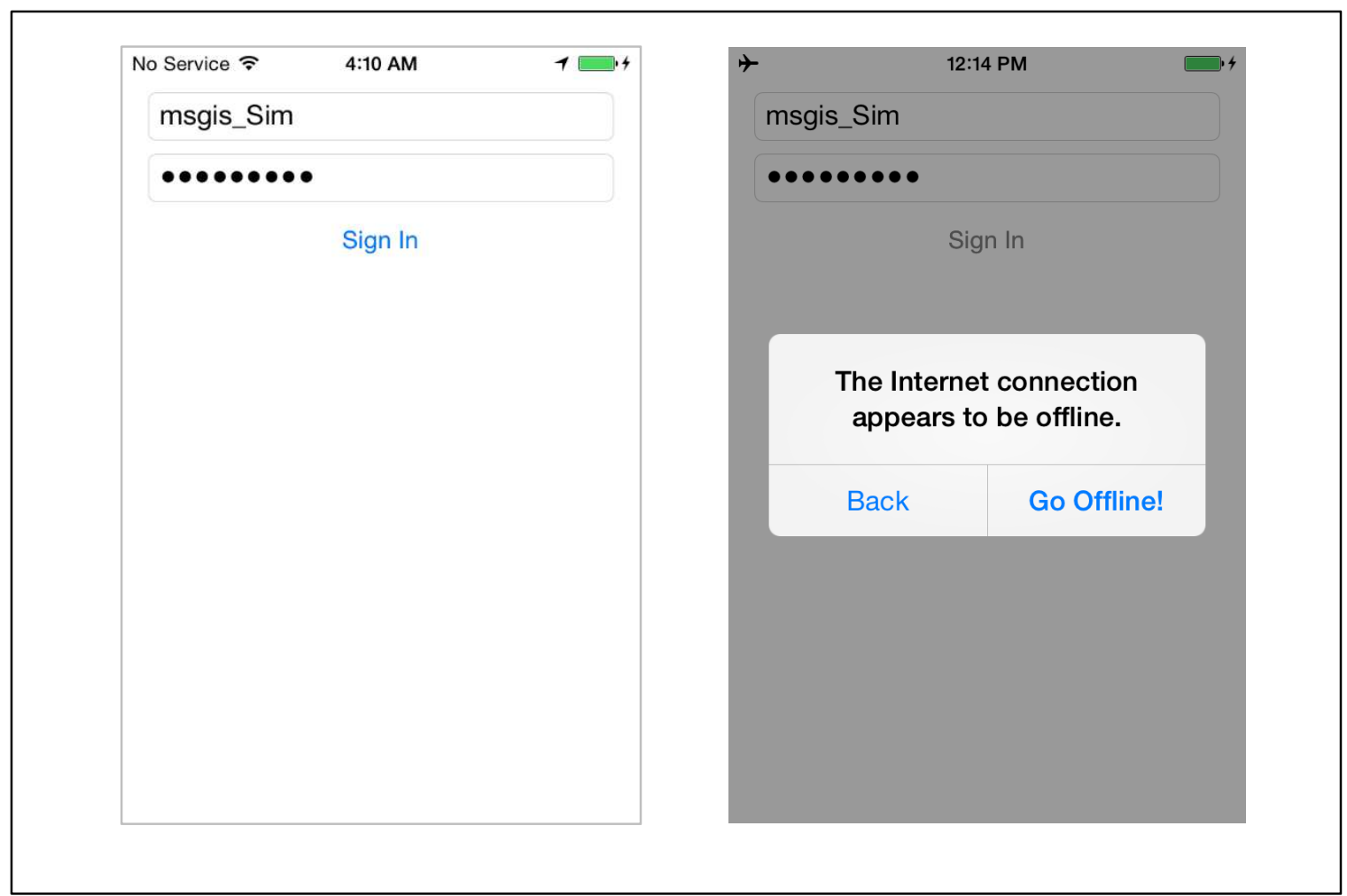

Figure 6-1: User Name and Password Entry

\subsubsection{Update Deployment}

In the map view, the user can pick the scan tool, indicated by the camera icon, to begin scanning an equipment. Figure 6-2 shows the map view with the scan tool, and the mobile application when scanning a physical QR code label. 


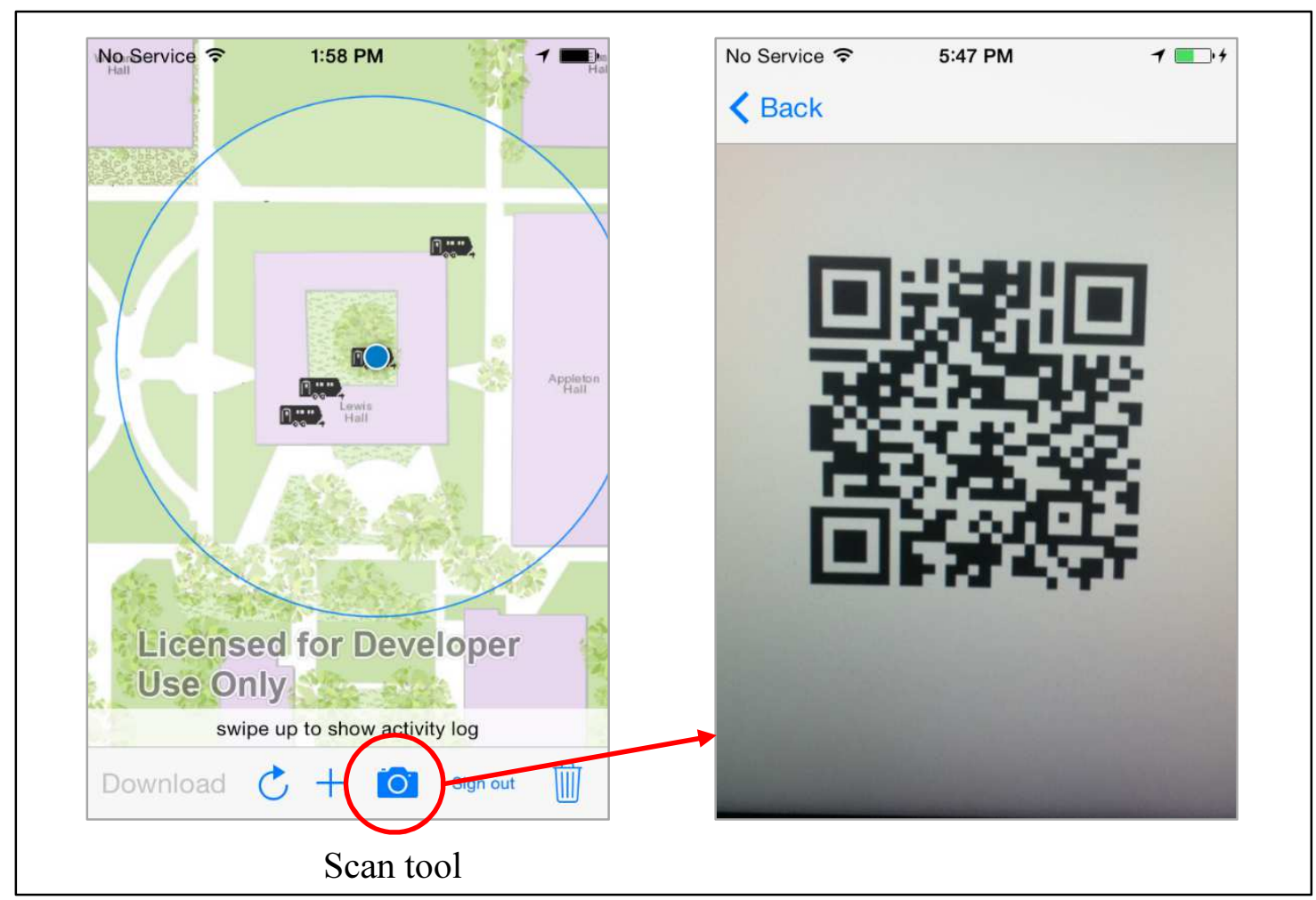

Figure 6-2: Equipment Scanning Process

After a successful scan of a valid QR code, the equipment details are shown for the user to update the information by touching the respective attribute. The user can also update the deployment location by touching the location button at the bottom of the screen to show the map. The user can then select the new location on the map, indicated as a red dot. Figure 6-3 shows the details screen and the location selection. 


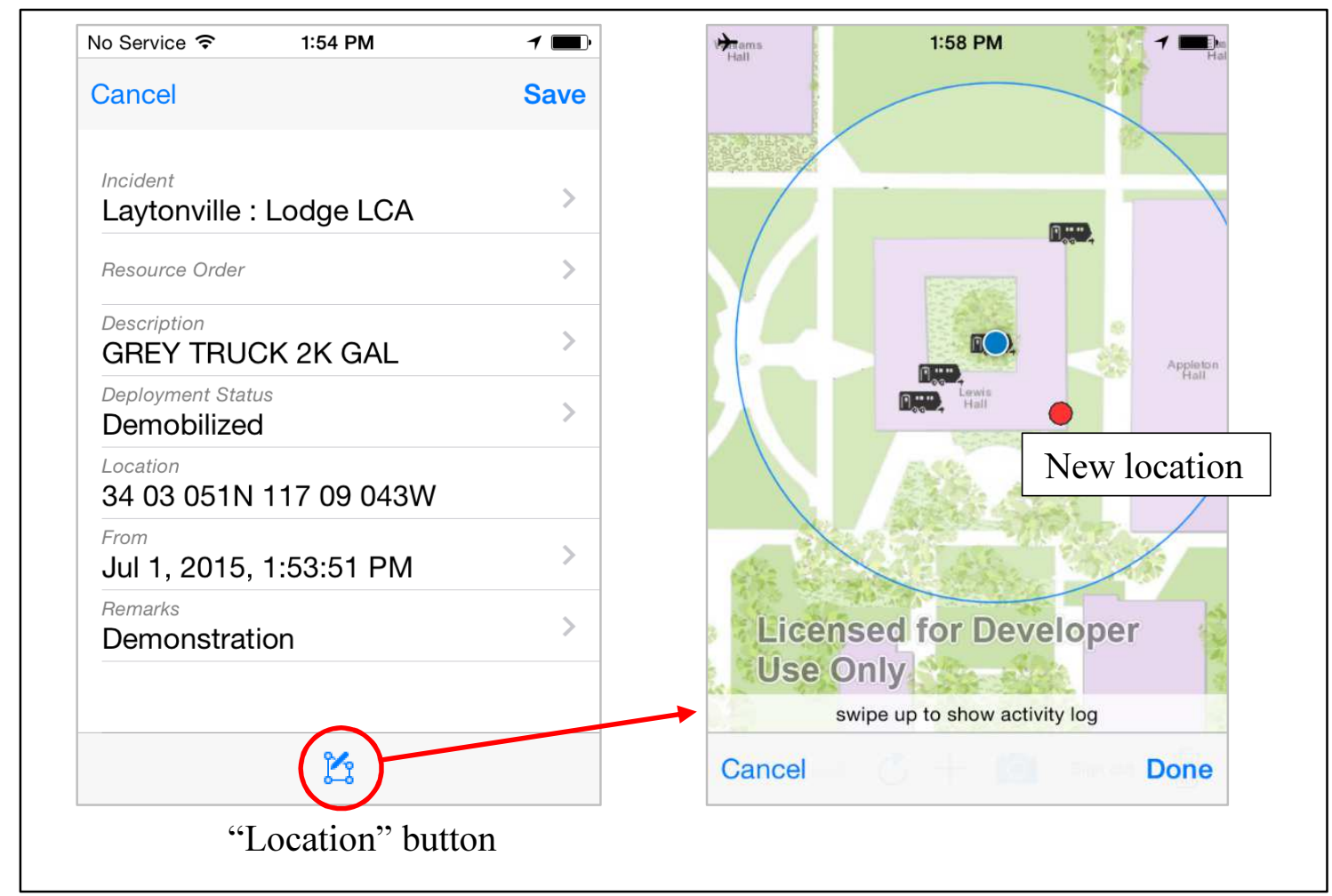

Figure 6-3: Equipment-Deployment Details and Location Selection

\subsubsection{Work Offline}

When the user plans to deploy an equipment to a remote location, he or she needs to download the latest geodatabase while there is internet connection. To download the geodatabase, the user touches the download button to initiate the download. After the download completes, application works in an offline mode. Any updates are made to the local geodatabase, and the number of offline updates is indicated by a number over the synchronize button. When the user is connected back to the Internet, he can touch the synchronize button to update the changes back to ArcGIS Online. Figure 6-4 shows the process of working offline. 


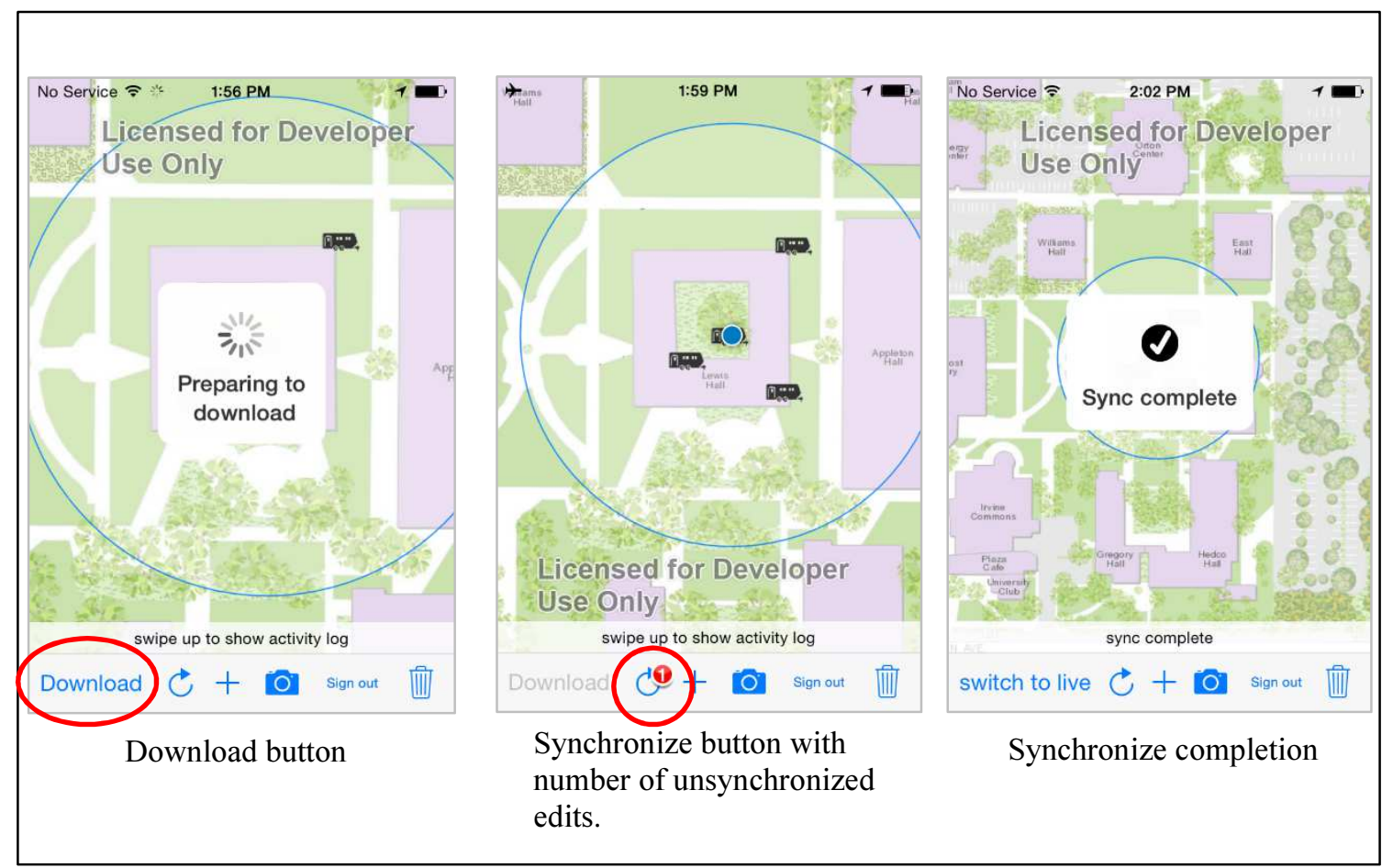

Figure 6-4: Deploying Equipment Offline

\subsection{Analysis of Functionalities}

The functionalities developed under this project allowed basic equipment deployment updates using an iPhone in remote locations. This section analyses the limitations of the application, and recommends advanced asset management functionalities as areas of improvements for operational consideration.

\subsubsection{Management of Individually-labelled Items}

One assumption at the start of this project was that every equipment is individually labelled. This assumption holds true for assets that are easily countable. For smaller items such as accessories, there should be a way for a group of items to be tracked and recorded. The complexity for this advanced functionality is the management of identity. Two concepts to be explored are the splitting of items into groups, and the merging of groups. To fully track the identity of the groups, one may have to track the history of all the splitting and merging using parent and child relationships. Hornsby and Egenhofer (2000) are among the researchers who have studied the possible identity permutations and coherence in spatio-temporal information.

\subsubsection{Mandatory Offline Preparation}

The current offline workflow required the user to download the database before leaving Internet connectivity. The base map for working offline also had to be pre-loaded into the mobile device. This presented a specific scenario causing the application to be ineffectual: if the user did not pre-download the database before leaving Internet 
connectivity, the application would have to rely on the database that was last downloaded, potentially providing obsolete updates. To overcome this, an advanced offline workflow could be designed to have a more seamless offline experience. For example, as the user uses the mobile application, the download could be initiated automatically in the background and synchronized periodically. The base map could be gradually cached as the user uses the mobile application. In this way, the user can work from a remote location and would probably have the relevant information to work with. In addition, when the user connects back to the Internet, the application could automatically synchronize the changes with ArcGIS Online. The challenge to implementing this is a deeper exploration with the ArcGIS Runtime SDK on automatic periodic background updates, and checking for legitimate network connectivity.

\subsubsection{Periodic Database Integrity Checks}

The temporal integrity for this project was implemented on the mobile application. As part of the database maintenance, scripts should be run to ensure the temporal consistency of the database information. This could be in the form of scripts or database stored procedures. An example would be to run a temporal check on all equipment to ensure the deployments line up temporally without any gaps or overlaps. Any exceptions would be highlighted for the data administrator's attention.

\subsubsection{Dashboard Limitations}

The dashboard was configured using the ArcGIS Operations Dashboard, a suitable rapid prototyping tool for situational awareness. It provided basic capabilities: a map with incident and equipment deployment locations; filter functions to show some a certain portion of each layer; and query functions show a list of equipment deployments based on parameters such as deployment dates. However, it could not readily display nearby deployments as clusters, and perform a single query across multiple data sources. This resulted in a potential visual clutter of near deployments and multiple queries to correlate incidents to equipment deployments. The recommended approach to overcome these limitations is to develop a customized dashboard using the JavaScript API, so that advanced functionalities could be built into the dashboard. The challenge for this would be to define a practical scope of functionalities and information to be integrated into the dashboard, and the development on a web platform.

\subsection{Summary}

This project was a proof-of-concept to use mobile GIS for the rapid deployment of equipment in remote locations. QR code was used to enable rapid data entry, and an iOS mobile application was developed to manage assets in a central geodatabase.

Functionally, the prototype achieved the objective of concept exploration. This was discussed in Sections 6.1 and 6.2. In Section 6.3, the application was analysed for functional limitations, and scenarios which may cause to application to be not effective was discussed. Some recommendations were also presented in the section. Chapter 7 consolidates the specific recommendations into broader areas for future work, and 
provides insights to the possible evolution of inventory management in the emergency disaster domain. 


\section{Chapter 7 - Conclusions and Future Work}

This chapter draws the project to an end by summarizing the entire planning and development process in Section 7.1. In Section 7.2, possible project ideas are discussed for future development. Section 7.3 concludes by extrapolating the development and analysis possibilities that can be achieved in the domain of logistics support for emergency incidents.

\subsection{Project Summary}

The client was Abel Fire Equipment, a logistics support company that specializes in emergency incidents. This project analysed the client's challenges in field assets management, and proposed a mobile GIS solution to easily collect and organize deployment information in the field (Chapter 1). Relevant literature from various publications was discussed and referenced to support the proposed solution (Chapter 2). The project team proceeded to interview the points-of-contact from the client company to crystalize the requirements for the prototype. After the requirements analysis was completed, a project plan was finalized to manage scope and schedule (Chapter 3). The project team further detailed the design process of abstracting equipment deployments into models in the conceptual data model and logical data model (Chapter 4). Focusing on developing an integrated iOS mobile application, the implementation phase included user interface design, translation of information exchanges into Objective C programming language, QR code generation in Python, and configuration of the dashboard (Chapter 5). The project achieved all but one of the originally planned functional requirements, and the final result was a successful proof-of-concept that had the potential to be productized into an inventory management system for the field (Chapter 6).

\subsection{Future Work}

This project tackled field asset management from a spatio-temporal perspective, leveraging on mobile, GIS, and cloud technologies. Extending this idea, there are three new project ideas that may complement this solution.

The first project idea is to manage ambiguous groupings of assets spatially and temporally. Small equipment, such as repair components or small furniture, is difficult to track because of its lack of consistent identity. A thousand chairs deployed ten times in ten places can generate many permutations. Unless each chair is uniquely identified, which will drastically increase overhead costs, groups of items must be managed in areas of merging groups, splitting groups, parent-child group relationship, etc.

The second project idea is to optimize maintenance routines of equipment and personnel support. By tracking personnel movement and maintenance schedules, the number of people required for maintenance and logistics support may be reduced, resulting in a cost-saving for the company.

The third project idea is to track equipment directly in real time by placing location transmitters on large assets such as trailers. By doing this, the transportation process can 
be tracked live. The asset management process will be more seamlessly integrated because each piece of equipment collects its own location without human intervention. For remote locations without Internet, the equipment can still record its own GPS location locally and synchronize back at a later time.

\subsection{Project Conclusions}

This project simply started the first step in equipment management for emergency incidents. There are many opportunities for technological innovations in this domain. With advancements in GIS, mobile, web, and sensor technology, there will definitely be many new approaches to mitigate organizing of field equipment deployment.

To raise the challenge to the next level, after organizing the raw data, one may begin developing prediction models to anticipate the trending of logistics needs when emergency incidents occur, or about to occur. For example, depending on where and when tsunamis are projected to happen, trailers and other equipment can already start setting off to the impacted areas.

Further extending this idea, once the trends are modelled, the optimization of emergency resources allocation can be studied in depth to reference past incidents. These are actually everyday GIS challenges of trying to best estimate what to allocate, when to allocate, and where to allocate. What makes the domain especially challenging will be the small time window of early warnings possible, and the direct impact the analysis may have on lives and property. 


\section{Works Cited}

Al-Khalifa, H. (2008). Utilizing QR Code and Mobile Phones for Blinds and Visually Impaired People. Computers Helping People with Special Needs, 11th International Conference. Linz, Austria.

Allen, J. F. (1983). Maintaining Knowledge about Temporal Intervals. Communications of the ACM, 26(11).

Apple Inc. (2015, April). iOS Human Interface Guidelines. Retrieved from iOS Developer Library:

https://developer.apple.com/library/ios/documentation/UserExperience/Conceptua 1/MobileHIG/index.html

Codd, E. F. (1971). Further Normalization of the Data Base Relational Model. San Jose, California: IBM Research Report.

Denso ADC. (2011). QR Code ${ }^{\circledR}$ Essentials. Retrieved from Denso ADC - White Paper: http://denso-adc.com/

Eide, P. L. (2005). Department of Computer and Information Science - Norwegian University of Science and Technology. Retrieved from http://www.ntnu.edu/idi/: http://www.idi.ntnu.no/grupper/su/fordypningsprosjekt-2005/eide-fordyp05.pdf

Esri. (2014, August). Implementing ArcGIS for Water Utilities. Retrieved from Esri White Papers: http://www.esri.com/library/whitepapers/pdfs/implementingarcgis-for-water-utilities.pdf

Esri. (2015a). Collector for ArcGIS. Retrieved from ArcGIS: http://doc.arcgis.com/en/collector/

Esri. (2015b). Sync offline edits. Retrieved from ArcGIS Runtime SDK for iOS: https://developers.arcgis.com/ios/objective-c/guide/sync-offline-edits.htm

Fluid Software. (n.d.). Fluid UI Mobile Prototyping. Retrieved from Fluid UI: https://www.fluidui.com/

GISCloud. (2015). Offline Maps are out! Retrieved from GISCloud: http://www.giscloud.com/blog/offline-maps-are-out/

GitHub. (2015). offline-editor-js. Retrieved from GitHub: https://github.com/Esri/offlineeditor-js

GitHub. (2015). offline-editor-js FAQ. Retrieved from GitHub: https://github.com/Esri/offline-editor-js/wiki/FAQ

Hornsby, K., \& Egenhofer, M. (2000). Identity-based change: a foundation for spatiotemporal knowledge. International Journal of Geographical Information Science, 14(3), 207 - 224.

Langran, G., \& Chrisman, N. R. (1988). A Framework For Temporal Geographic Information. Cartographica: The International Journal for Geographic Information and Geovisualization, 25(3).

Snodgrass, R. T. (1992, September). Temporal Databases. Theory and Methods of SpatioTemporal Reasoning in Geographic Space (pp. 22-64). Pisa, Italy: LNCS. Retrieved from University of Arizona: http://www.cs.arizona.edu/people/rts/publications.html\#generaltemporal

Tavlian, A. E. (2013, October 4). Risky work: Vendors for firefighting camps face revenue swings. Retrieved from Sacramento Business Journal: 
http://www.bizjournals.com/sacramento/print-edition/2013/10/04/risky-workvendors-for-firefighting.html

Time Consult. (2005, May). What are Temporal Databases? Retrieved from Time Consult: http://www.timeconsult.com/TemporalData/TemporalDB.html

Tsou, M.-H. (2004). Integrated Mobile GIS and Wireless Internet Map Servers for Environmental Monitoring and Management. Cartography and Geographic Information Science, 31(3), 153-165.

U.S. Forest Service. (2013, 10 25). Rim Fire. Retrieved from InciWeb - Incident Information System: http://inciweb.nwcg.gov/incident/3660/

Varshney, U., \& Vetter, R. (2002). Mobile Commerce: Framework, Applications and Networking. Mobile networks and Applications, 7(3), 185-198.

Wenninger, J. (1999, June). Business-to-Business Electronic Commerce. Current Issues in Economics and Finance, 5(10).

Wikipedia. (2015, February). Mobile tagging. Retrieved from Wikipedia: https://en.wikipedia.org/wiki/Mobile_tagging

Wikipedia. (2015, July). QR code. Retrieved from Wikipedia.

Yuan, M. (n.d.). Temporal GIS and Spatio-Temporal Modeling. Retrieved from National Center for Geographic Information and Analysis:

http://ncgia.ucsb.edu/conf/SANTA_FE_CD-ROM/sf_papers/yuan_may/may.html 


\section{Appendix A. Planned Project Schedule}

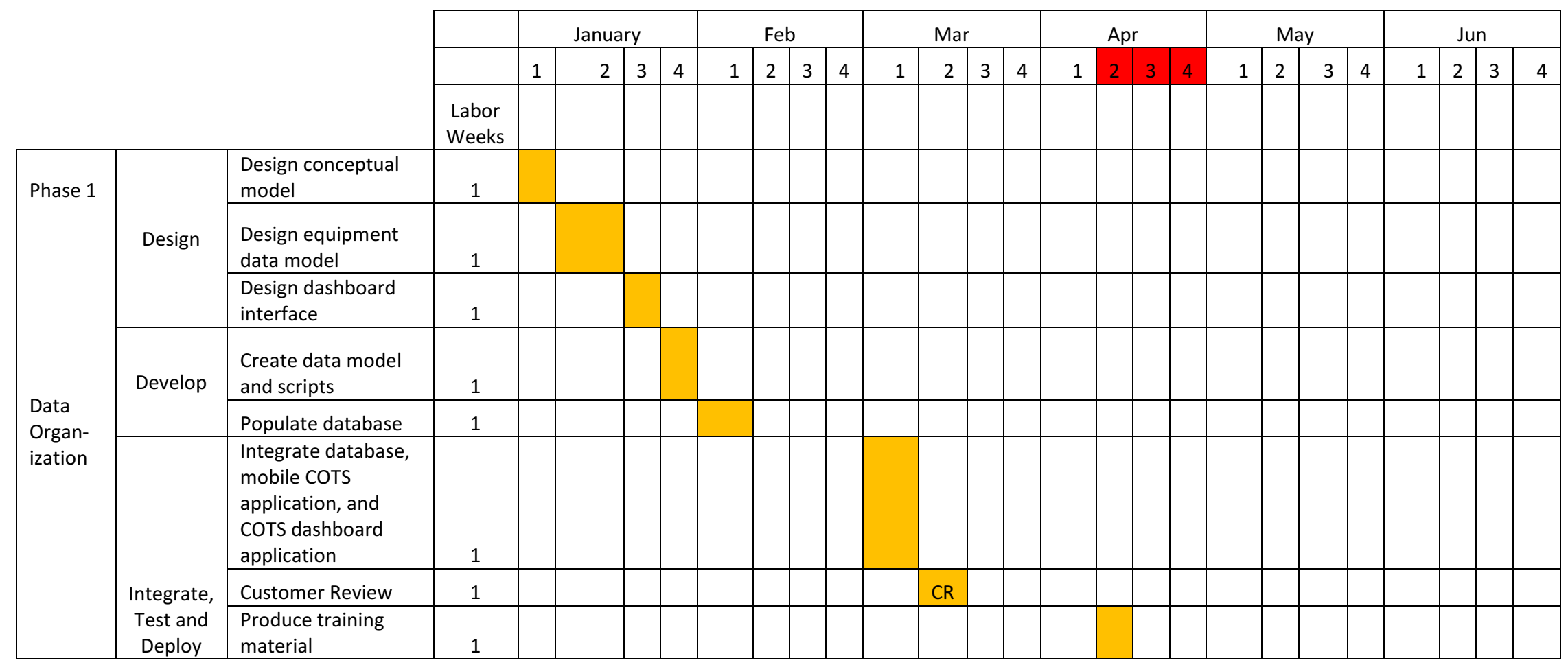




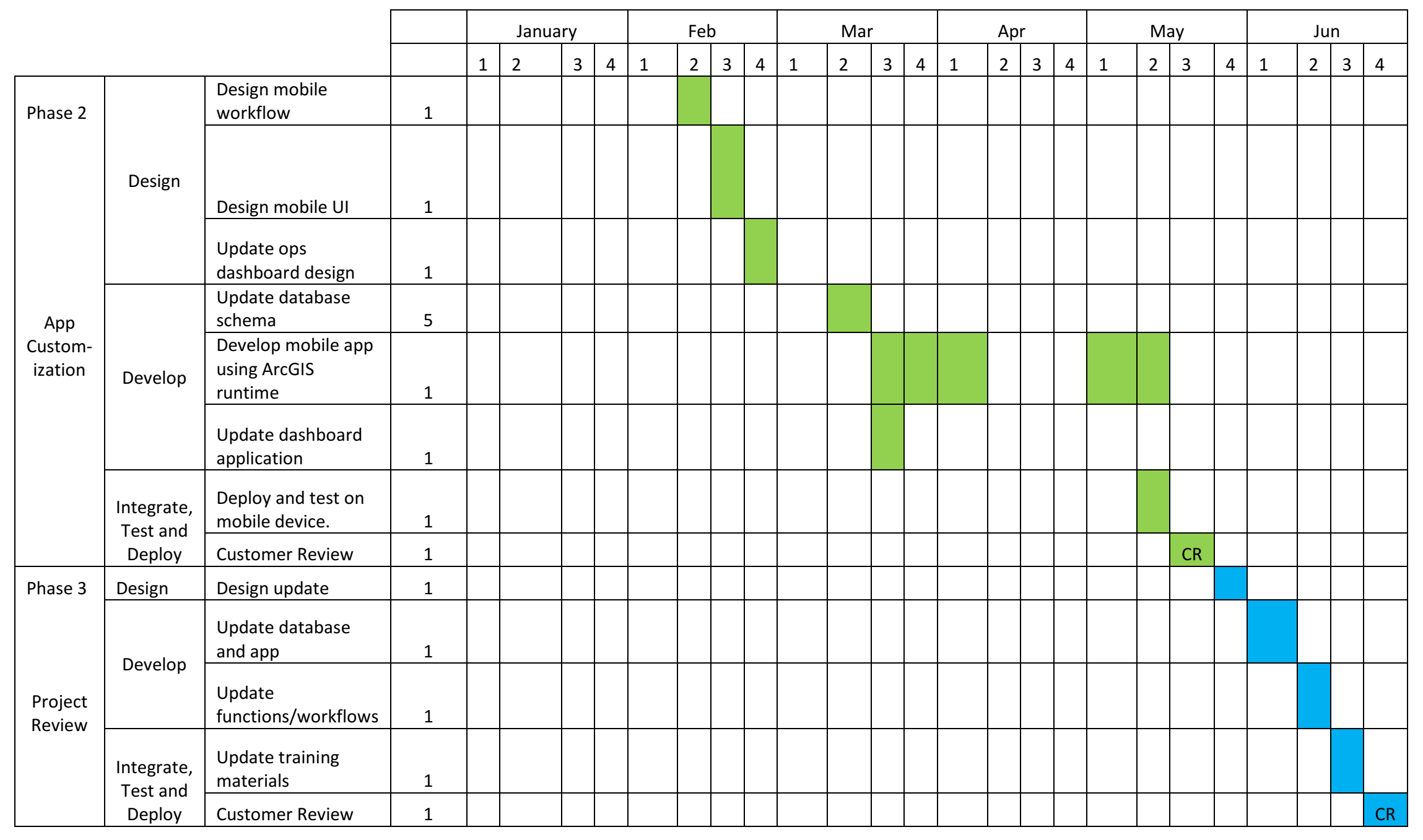




\section{Appendix B. Equipment-Deployment Schema}

\begin{tabular}{|c|c|c|c|}
\hline SNo & Field & Description & Data Type \\
\hline 1 & Equipment_ID & GUID for Equipment & GUID \\
\hline 2 & Equipment_Type & $\begin{array}{l}\text { 1. Vehicles, Trailers } \\
\text { 2. Portable toilets } \\
\text { 3. Tents } \\
\text { 4. Weed washers } \\
\text { 5. Chairs } \\
\text { 6. Tables } \\
\text { 7. Generators } \\
\text { 8. AC } \\
\text { 9. Light Towers } \\
\text { 99. Others }\end{array}$ & Short Integer \\
\hline 3 & Equipment_Description & Description for equipment & Text \\
\hline 4 & Location VIPR & Contractual location & Text \\
\hline 5 & VIN & Vehicle Identification Number & Text \\
\hline 6 & Last4Lic & Last 4 characters of license plate & Text \\
\hline 7 & VehicleYear & Year of vehicle manufacture & Text \\
\hline 8 & VehicleMake & Vehicle Make & Text \\
\hline 9 & isClericalTrailer & Boolean flag for clerical trailer & Short Integer \\
\hline 10 & isGISTrailer & Boolean flag for GIS trailer & Short Integer \\
\hline 11 & isCommTrailer & $\begin{array}{l}\text { Boolean flag for communication } \\
\text { trailer }\end{array}$ & Short Integer \\
\hline 12 & isHeliTrailer & Boolean flag for heli-trailer & Short Integer \\
\hline 13 & ToiletIdentifier & Identifier for portable toilet & Text \\
\hline 14 & ToiletDescription & Descriptor for portable toilet & Text \\
\hline 15 & TentName & Name of Tent & Text \\
\hline 16 & WWName & Name of Weed washer & Text \\
\hline 17 & WWIdentifier & Identifier of weed washer & Text \\
\hline 18 & Deployment_ID & GUID for deployment & GUID \\
\hline 19 & Parent_ID & Parent ID for commodities & GUID \\
\hline 20 & ResourceOrder & Resource Order Reference & Text \\
\hline 21 & Quantity & Quantity of commodities & Float \\
\hline 22 & LocationName & Name of deployment location & Text \\
\hline 23 & DeployState & $\begin{array}{l}\text { State of Deployment. } \\
\text { Coded Domain: } \\
\text { "Mobilized": "Mobilized" } \\
\text { "Demobilized": "Demobilized" } \\
\text { "In Service": "In Service" } \\
\text { "Under Maintenance": "Under } \\
\text { Maintenance" }\end{array}$ & Text \\
\hline
\end{tabular}




\begin{tabular}{|l|l|l|l|}
\hline 24 & StartTime & $\begin{array}{l}\text { Deployment start time. } \\
\text { Arbituary past: } 1 / 1 / 190101: 00\end{array}$ & Date \\
\hline 25 & EndTime & $\begin{array}{l}\text { Deployment end time. } \\
\text { Arbituary future: } 1 / 1 / 390101: 00\end{array}$ & Date \\
\hline 26 & IsCurrent & Boolean flag for current deployment. & Short Integer \\
\hline 27 & TransactionTime & Time when data was added. & Date \\
\hline 28 & Remarks & Deployment remarks & Text \\
\hline 29 & Incident_ID & GUID for Incident. & GUID \\
\hline 30 & Incident_Name & Name of incident. & Text \\
\hline 31 & POINT_X & $\begin{array}{l}\text { Internal data. Part of Point object. X- } \\
\text { coordinate in web-mercator }(m) .\end{array}$ & Float \\
\hline 32 & POINT_Y & $\begin{array}{l}\text { Internal data. Part of Point object. Y- } \\
\text { coordinate in web-mercator }(\mathrm{m}) .\end{array}$ & Float \\
\hline
\end{tabular}




\section{Appendix C. Incident Schema}

\begin{tabular}{|l|l|l|l|}
\hline SNo & Field & Description & Data Type \\
\hline 1 & Incident_ID & GUID for Incident & GUID \\
\hline 2 & IncidentName & Name of the incident & Text \\
\hline 3 & StartTime & $\begin{array}{l}\text { Incident start time. } \\
\text { Arbituary past: } 1 / 1 / 190101: 00\end{array}$ & Date \\
\hline & & $\begin{array}{l}\text { Incident end time. } \\
\text { Arbituary future: } 1 / 1 / 390101: 00\end{array}$ & Date \\
\hline 5 & EndTime & Incident remarks & Text \\
\hline 6 & POINT_X & $\begin{array}{l}\text { Internal data. Part of Point object. } \\
\text { X-coordinate in web-mercator }(\mathrm{m}) .\end{array}$ & - \\
\hline 7 & POINT_Y & $\begin{array}{l}\text { Internal data. Part of Point object. } \\
\text { Y-coordinate in web-mercator (m). }\end{array}$ & - \\
\hline
\end{tabular}




\section{Appendix D. Prototype Views of Mobile Application}

URL to view-only UI prototype:

https://www.fluidui.com/editor/live/preview/p_sxfTbkB24i4SlkexB9Cr5brW8Fx0vvTX.1436896457380

QR Code to view UI prototype:

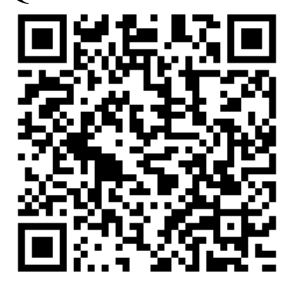

Prototype View 1:

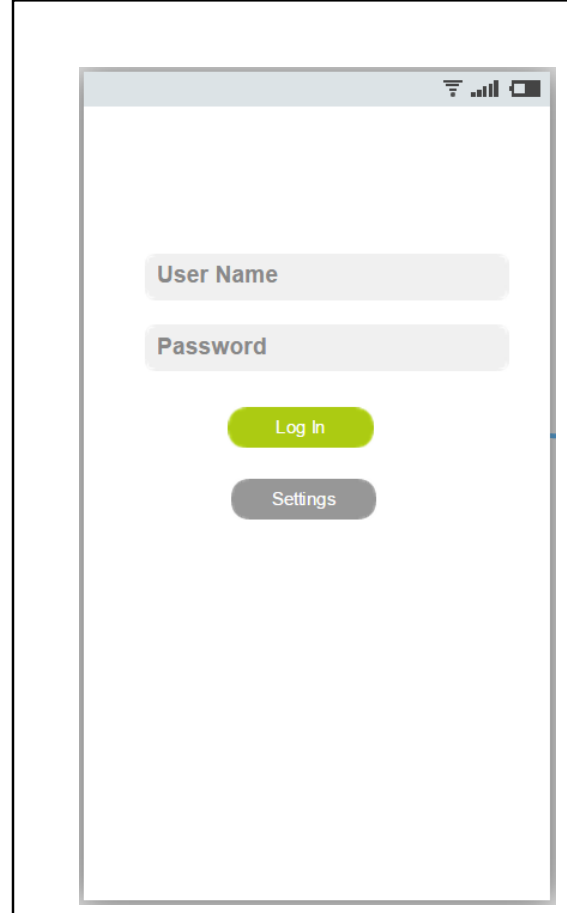

Sign In View

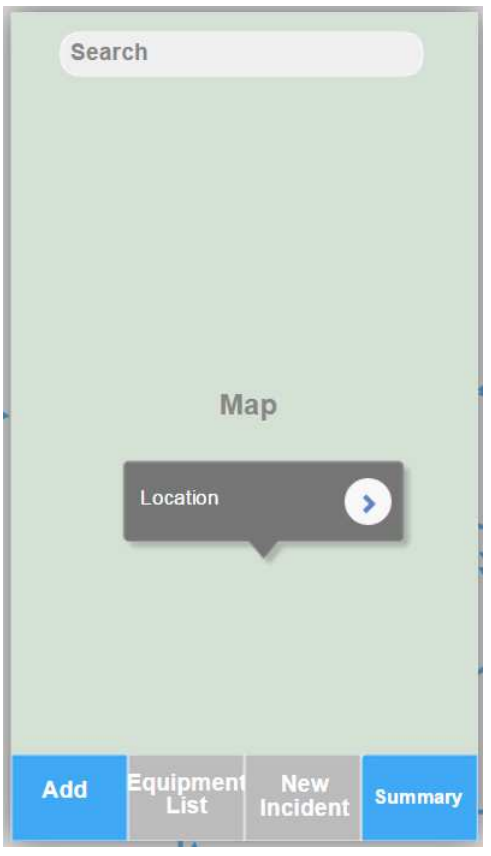

Map View

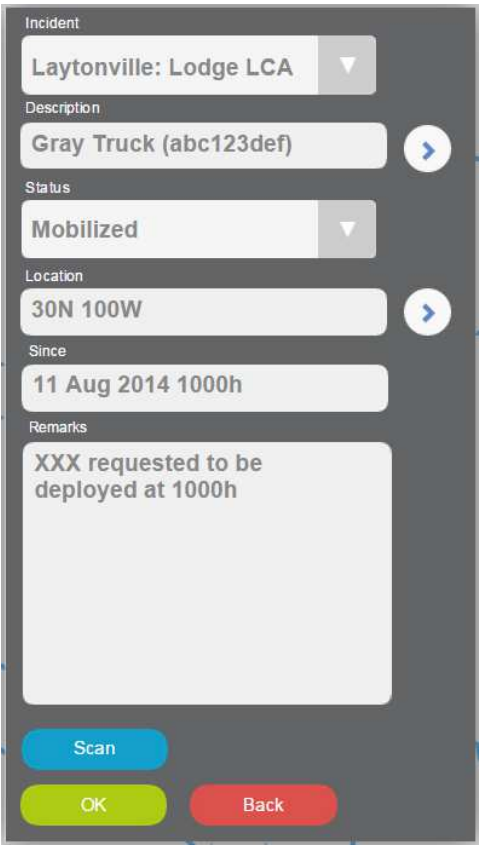

Equipment Detail View 
Prototype View 2:

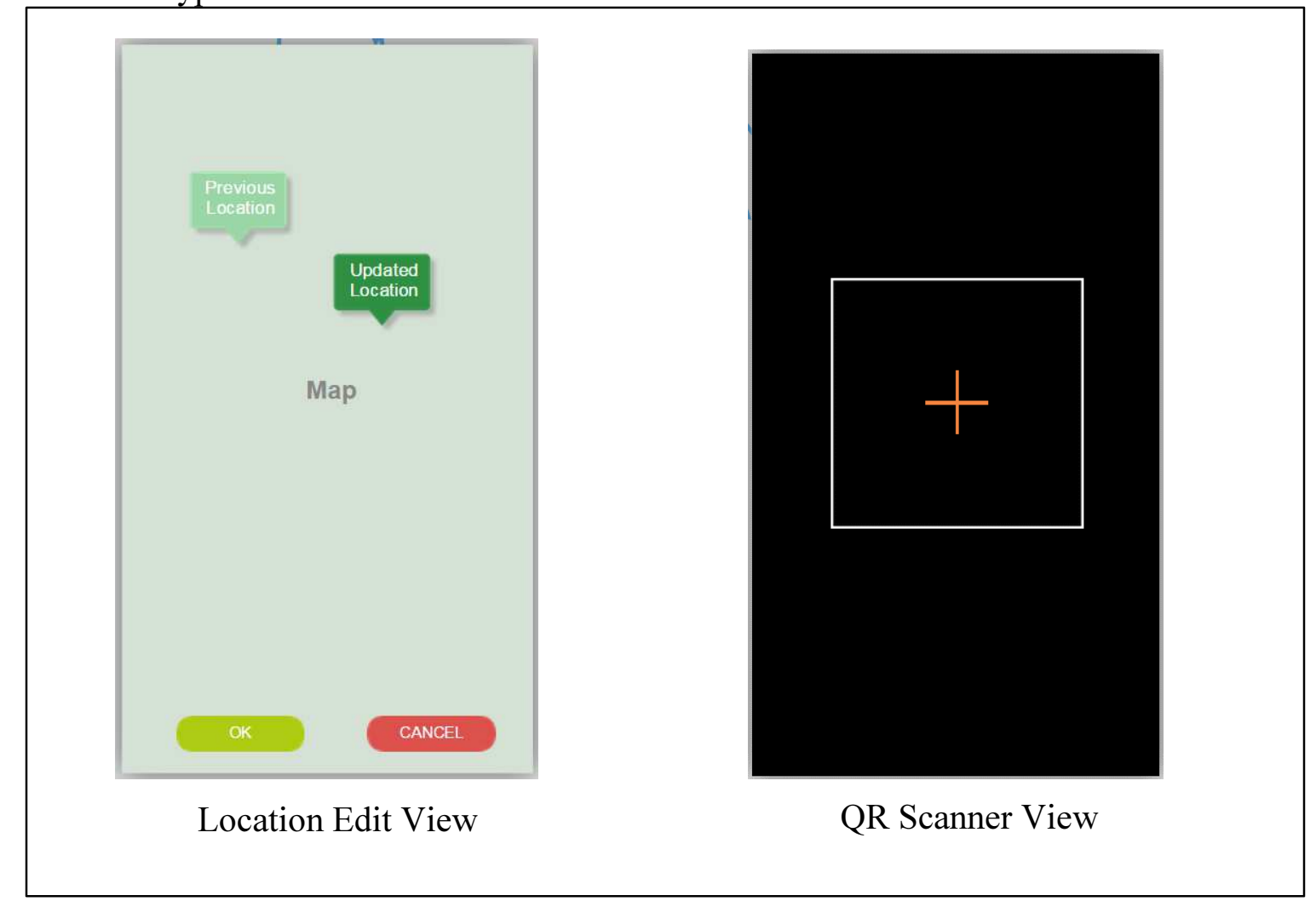




\section{Appendix E. Symbology}

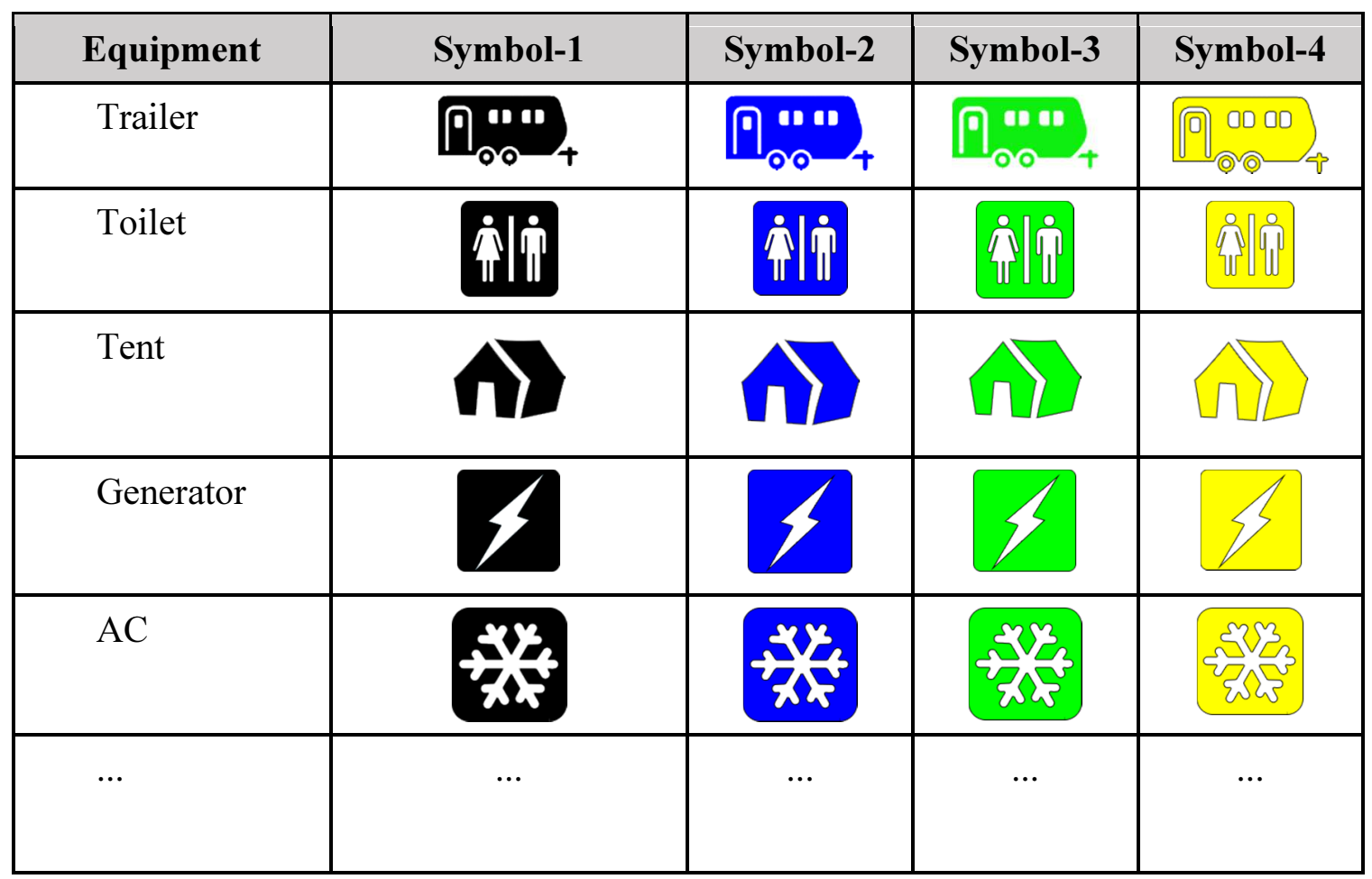




\section{Appendix F. Installation Steps for CocoaPods and ArcGIS Runtime for iOS}

(Below are procedures partially extracted and modified from cocoapods.org and developer.arcgis.com)

To install CocoaPods, open terminal in Mac and key in the following (Administration privilges required):

\$ sudo gem install cocoapods

Navigate to your Xcode project directory, create a "Podfile" with smart default by keying in:

$\$$ pod init

Then modify the dependencies in "Podfile" in your Xcode project directory:

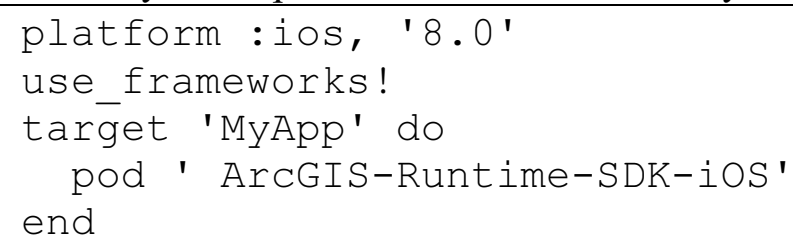

To install ArcGIS Runtime SDK for iOS, key in:

$\$$ pod install

This will download the ArcGIS framework to your machine and place it inside your project's Pod directory. It will also make the necessary changes to your project's build settings to correctly reference the ArcGIS framework.

Open the project workspace $\left({ }^{*}\right.$.xcworkspace file) and add the import statement \#import $<$ ArcGIS/ArcGIS.h $>$ to any Objective-C header (.h) or implementation (.m) file in which you wish to use the API. 


\section{Appendix G. Procedures to Install Python Libraries for Windows (pip, pillow, and qrcode)}

1. Install pip (Dependency manager for Python):

To install pip, securely download get-pip.py (https://bootstrap.pypa.io/get-pip.py)

Then run the following (which may require administrator access) in command:

python get-pip.py

pip.exe should be found in " $\{$ Python Installation Path $\} /$ Scripts" folder.

2. Install Pillow (a fork of python imaging library).

Navigate to where pip.exe is, run the following:

$\$$ pip install Pillow

3. Install qrcode (qr code library).

$\$$ pip install qrcode 


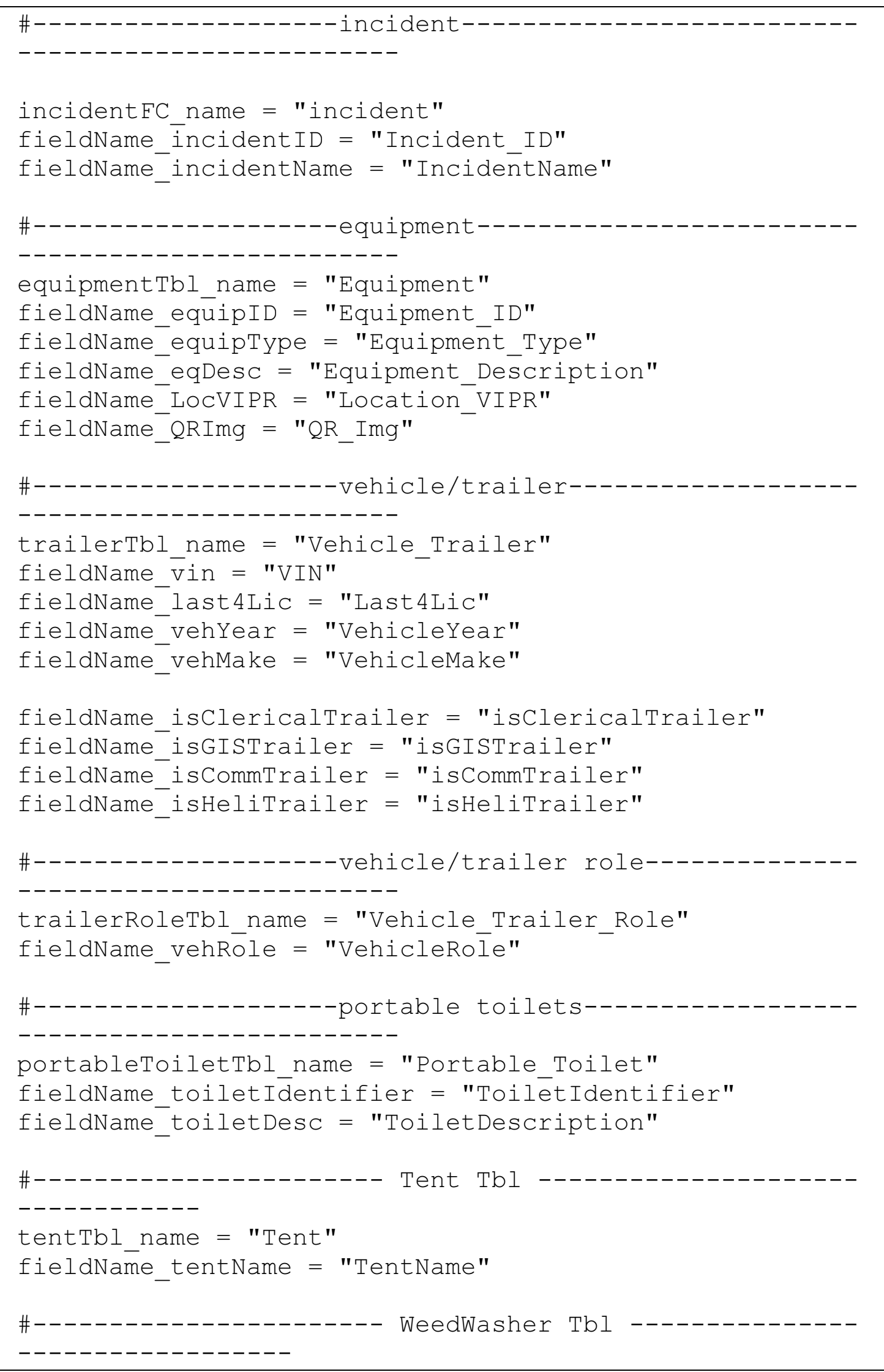




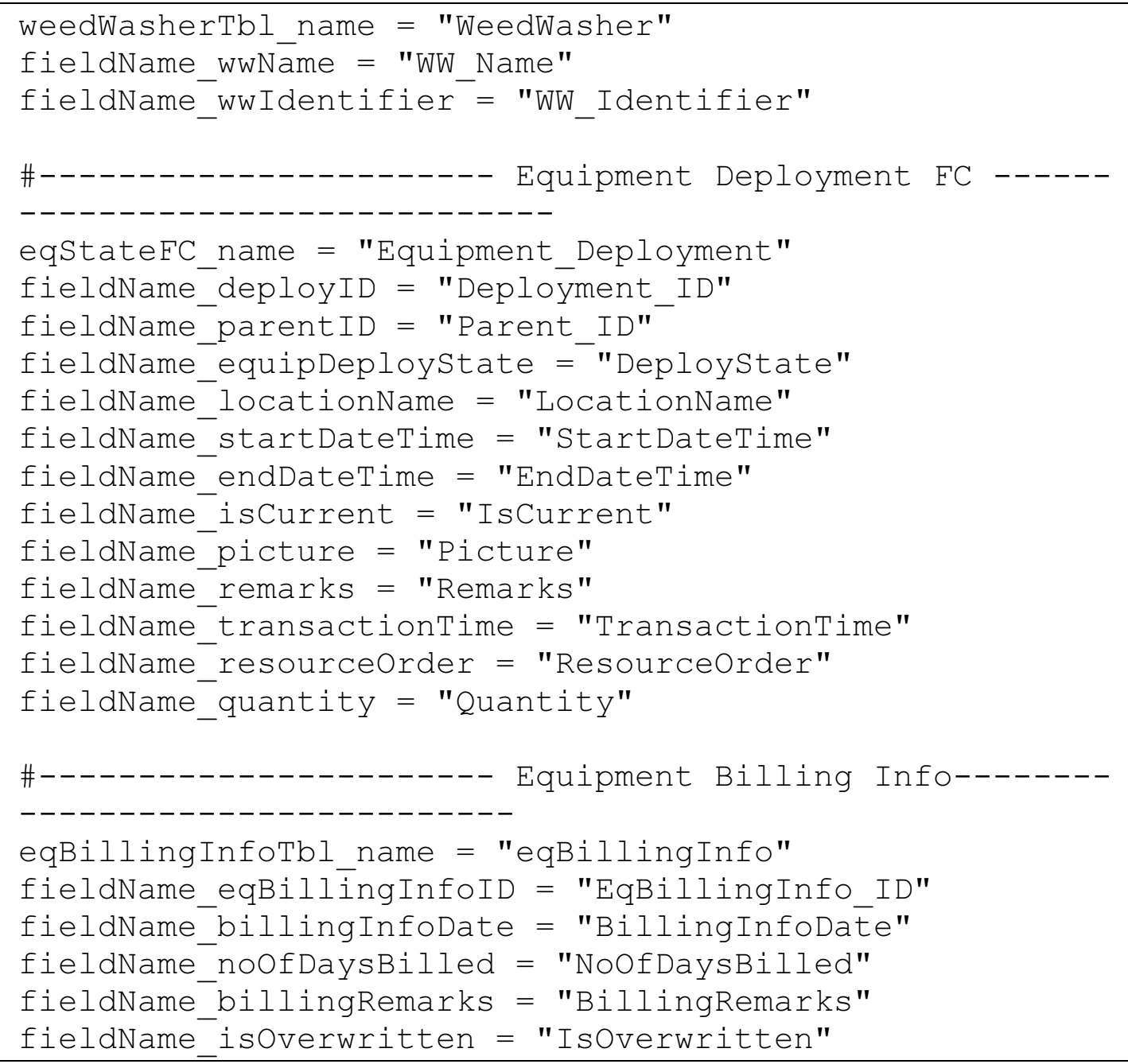




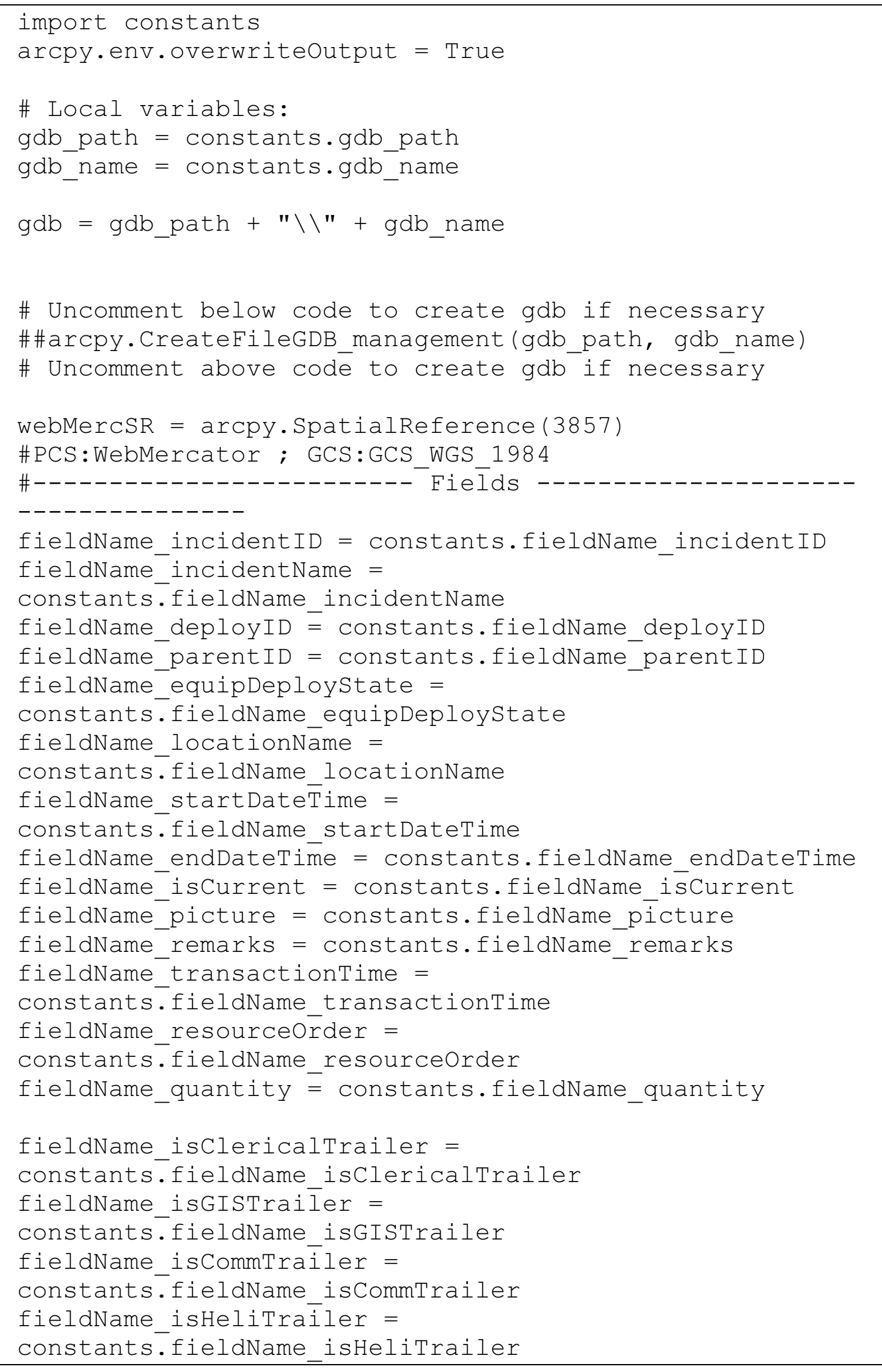




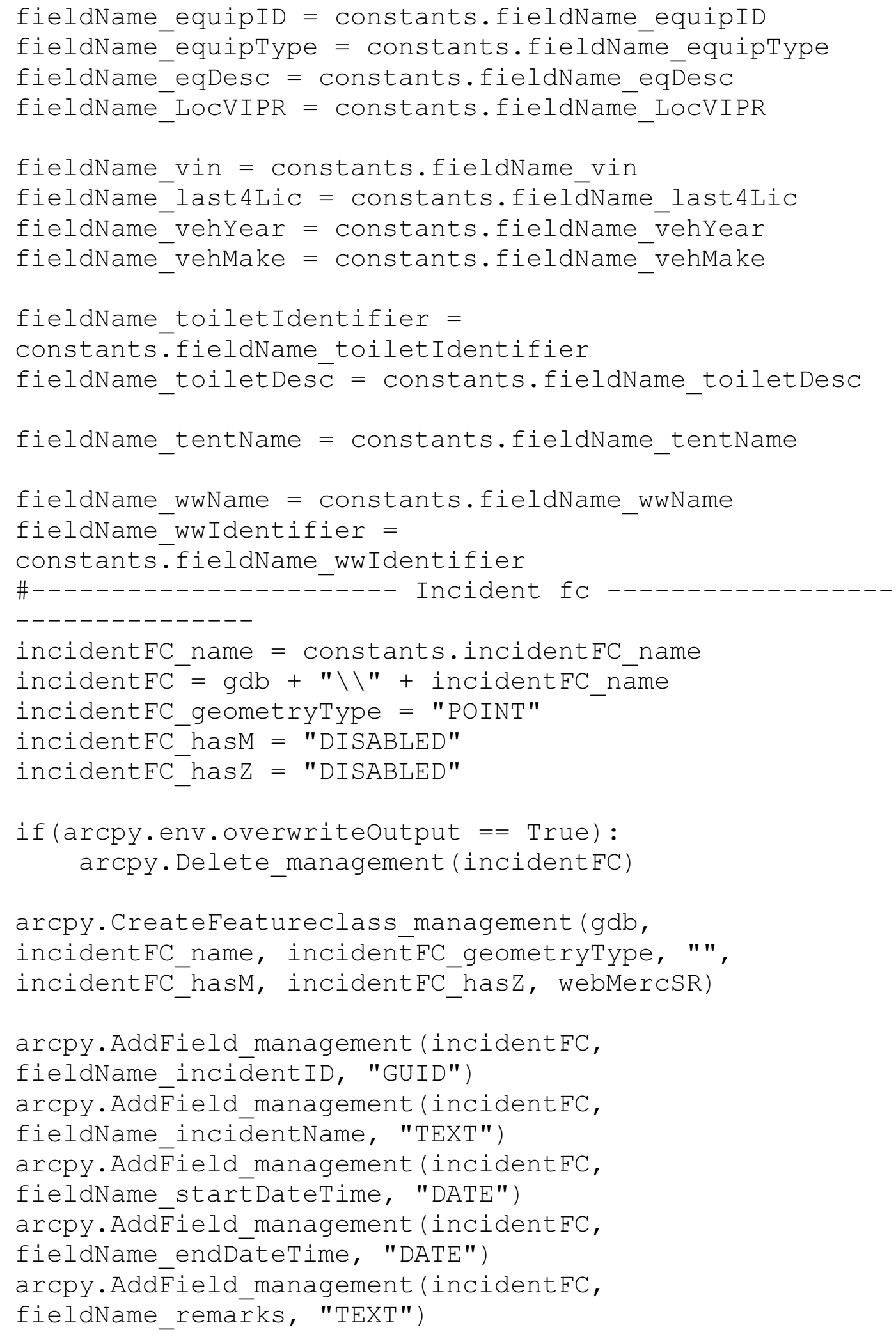




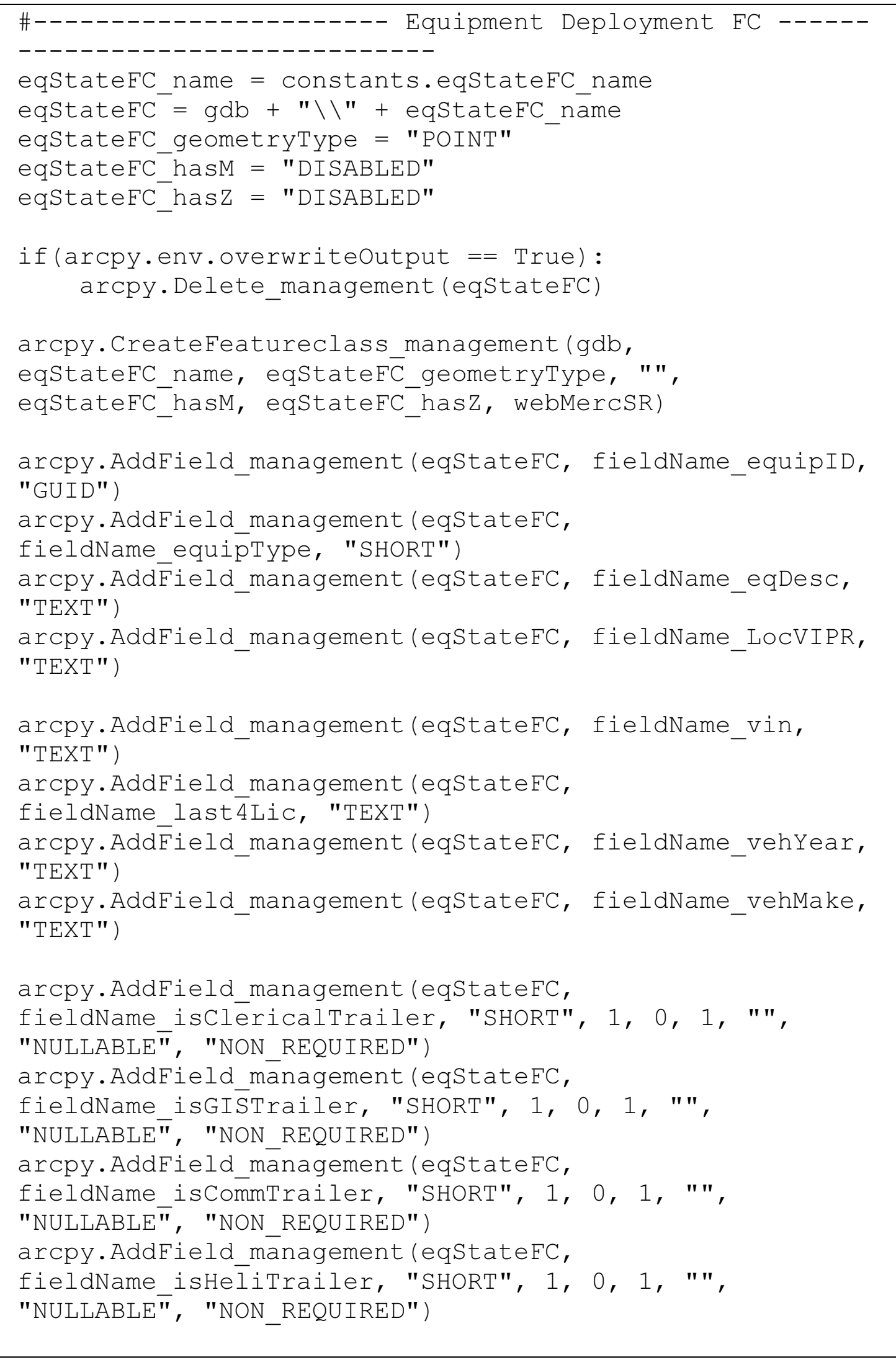




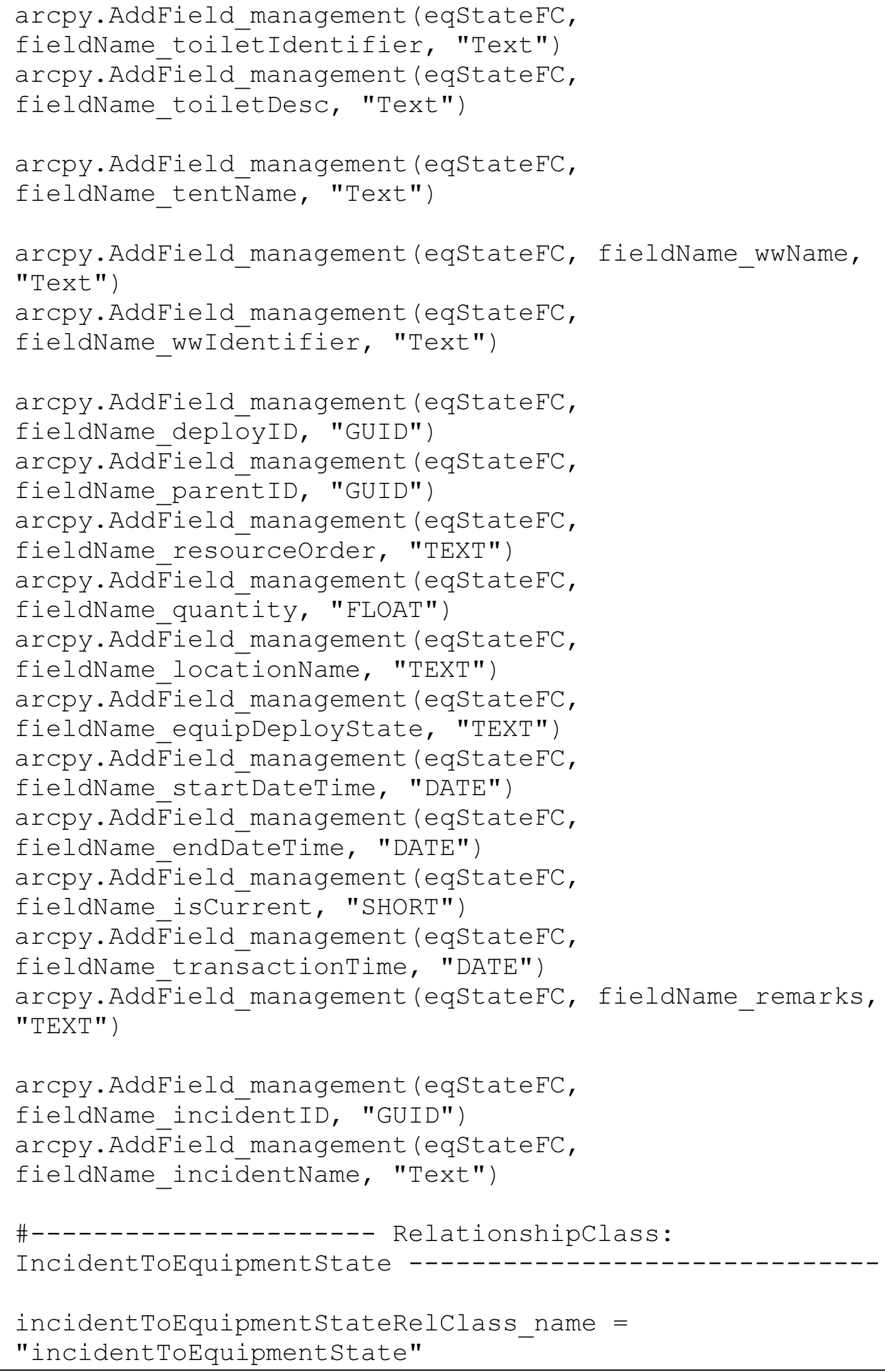




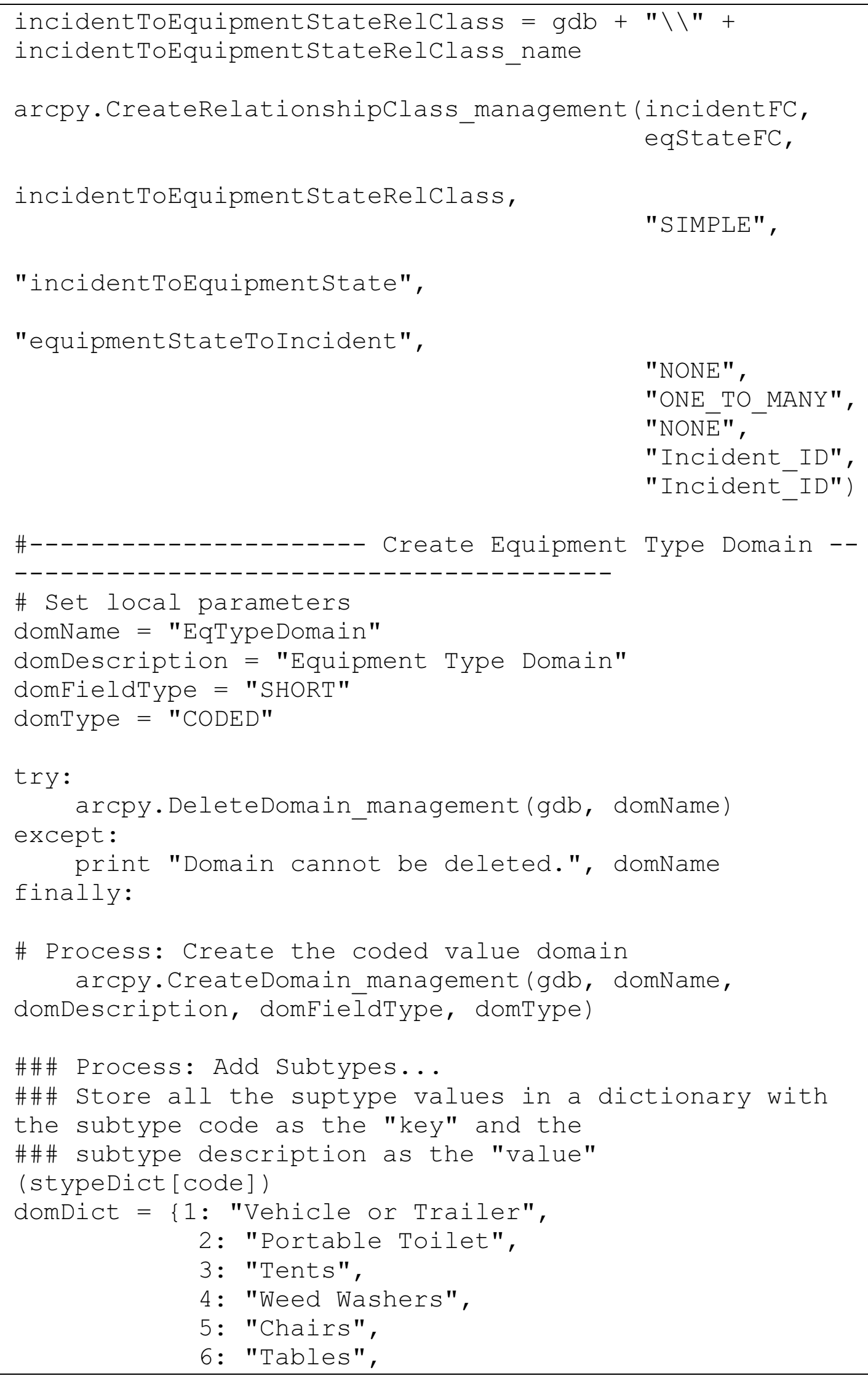




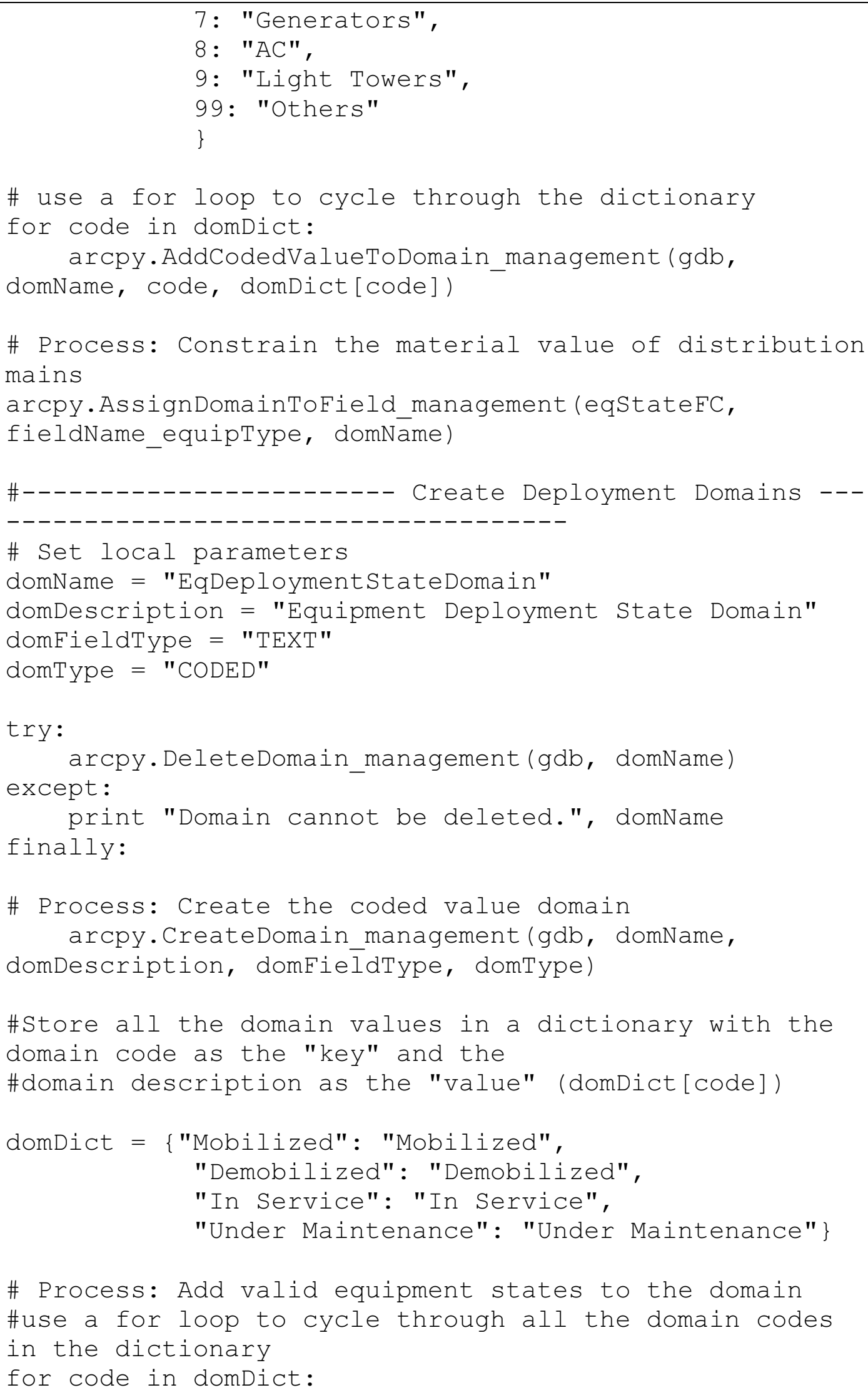




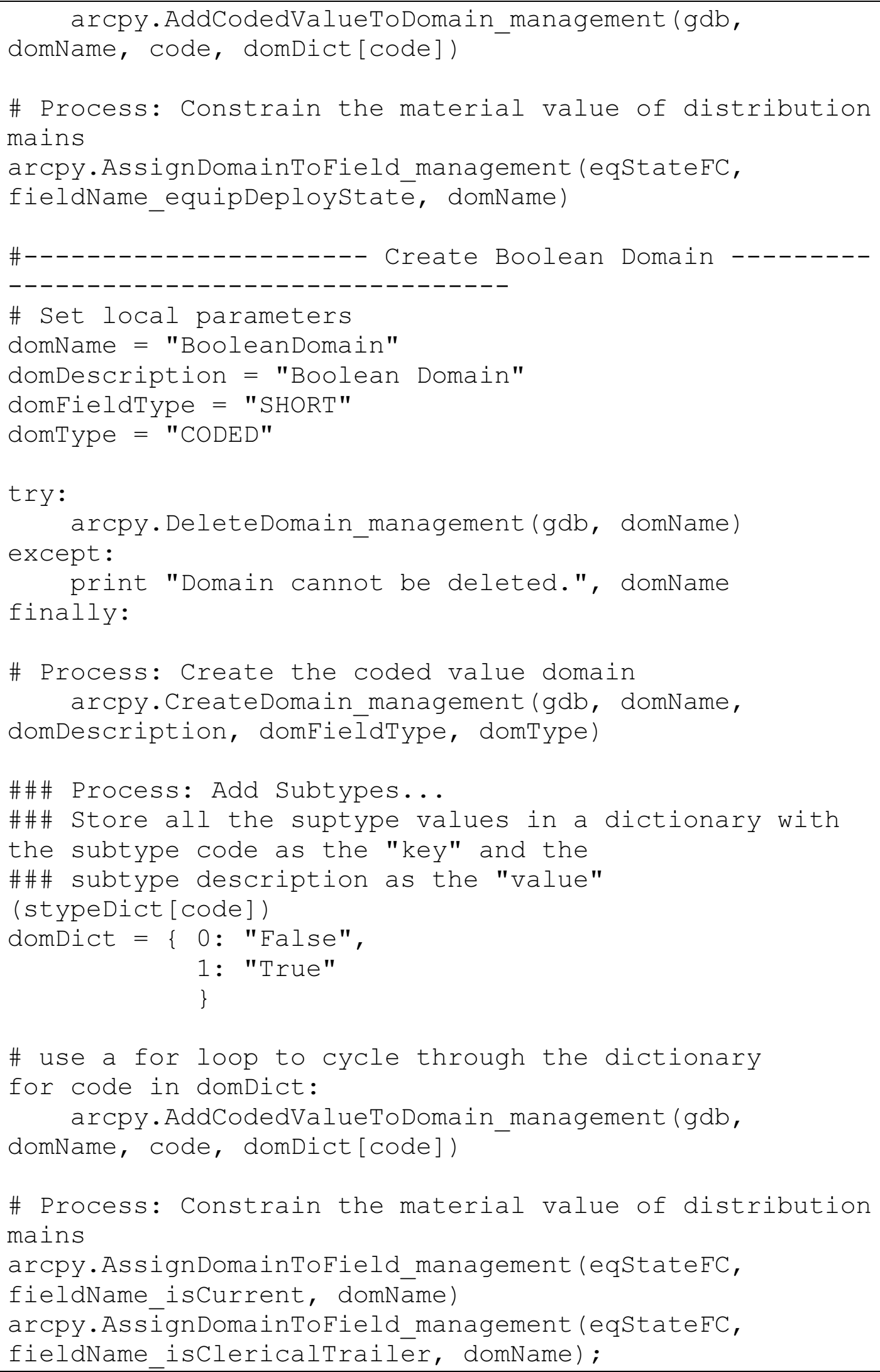




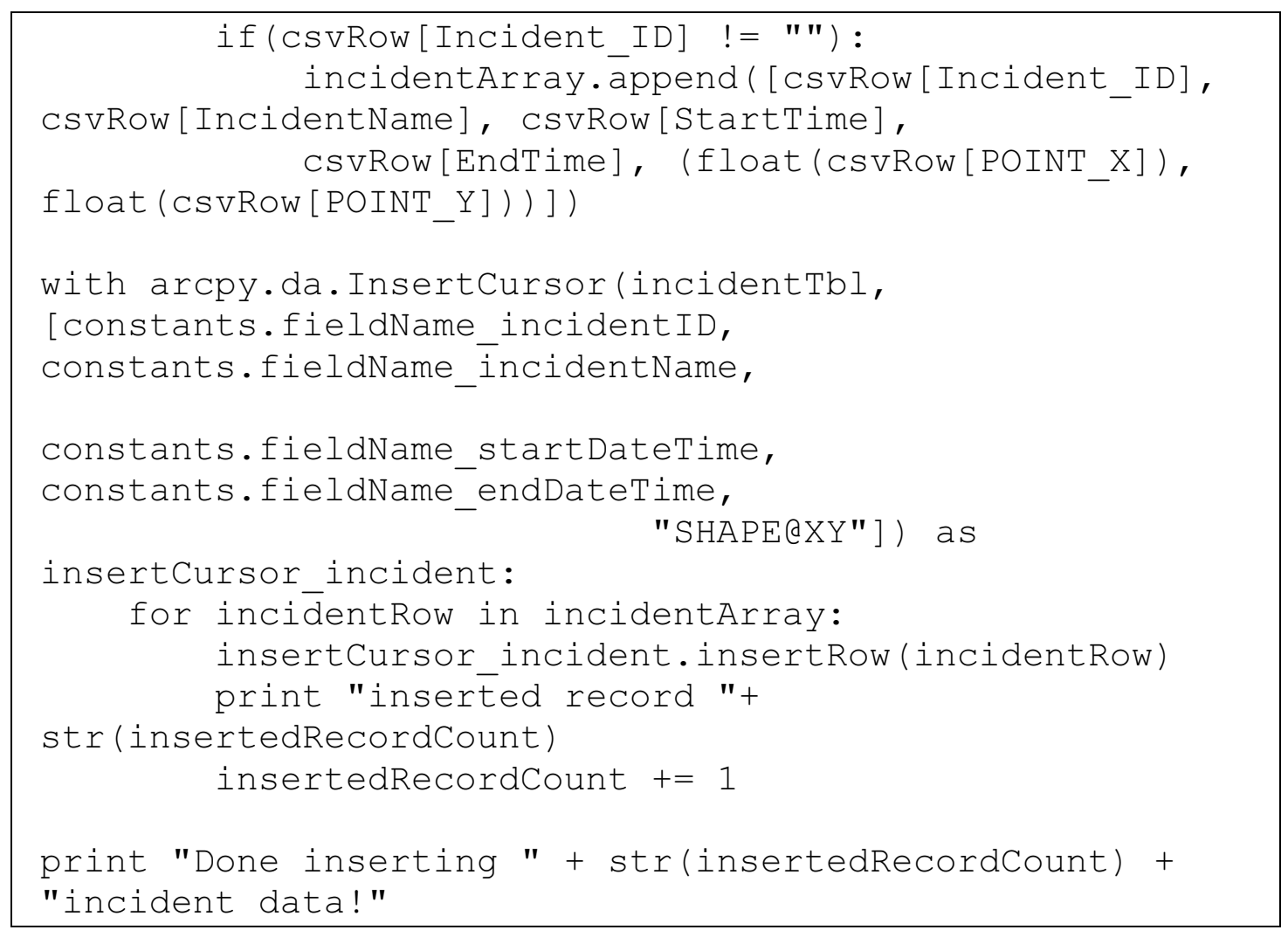

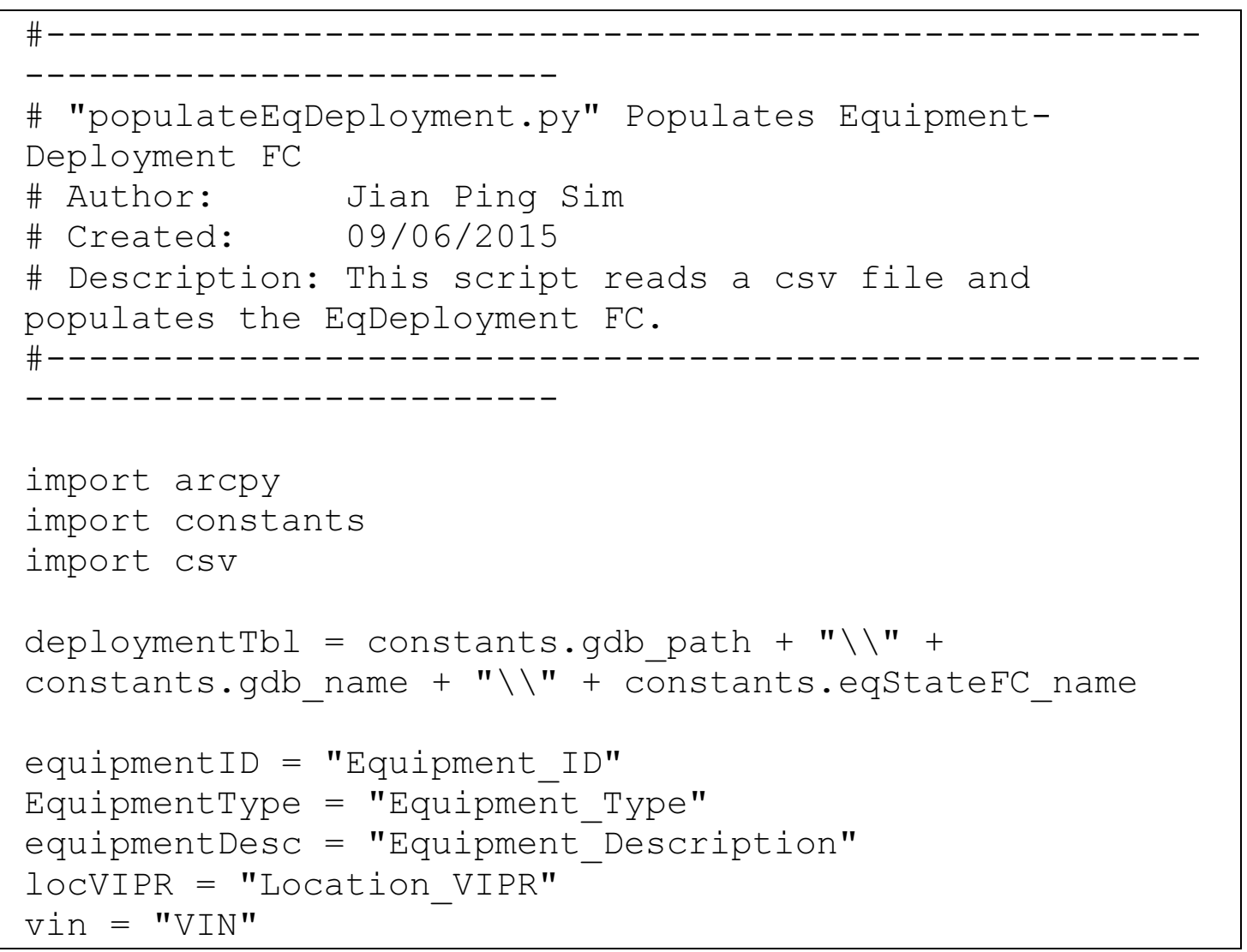




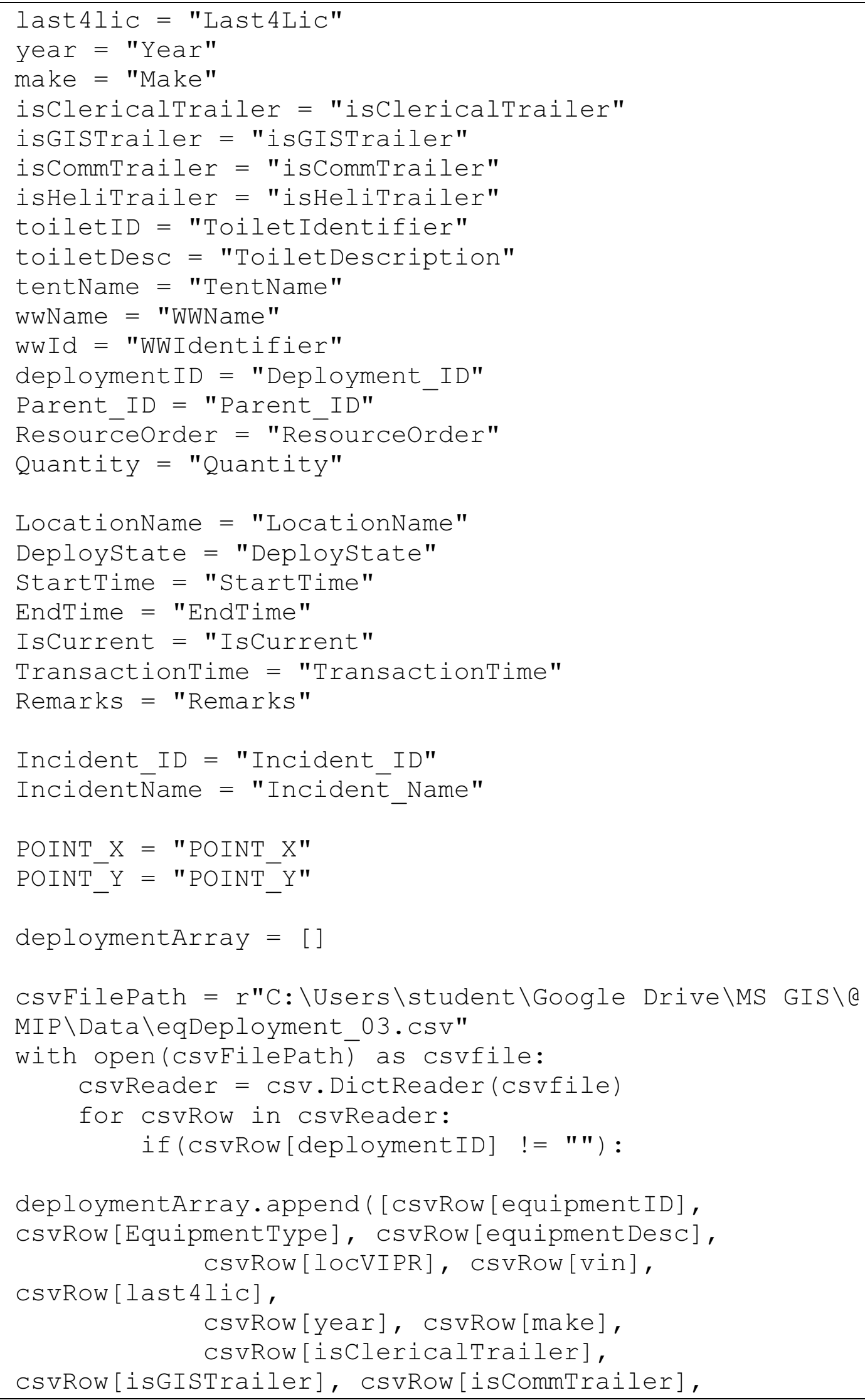




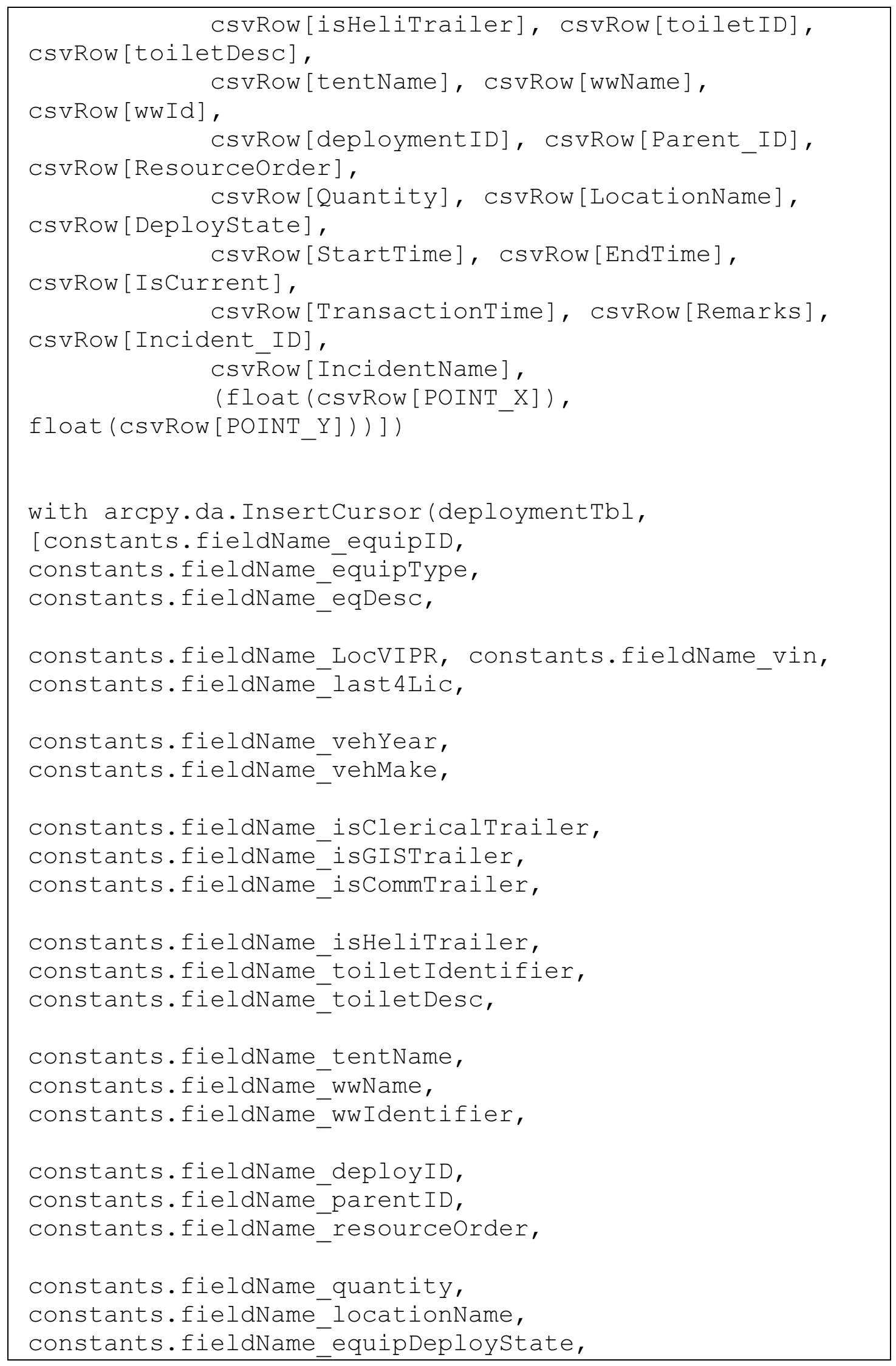




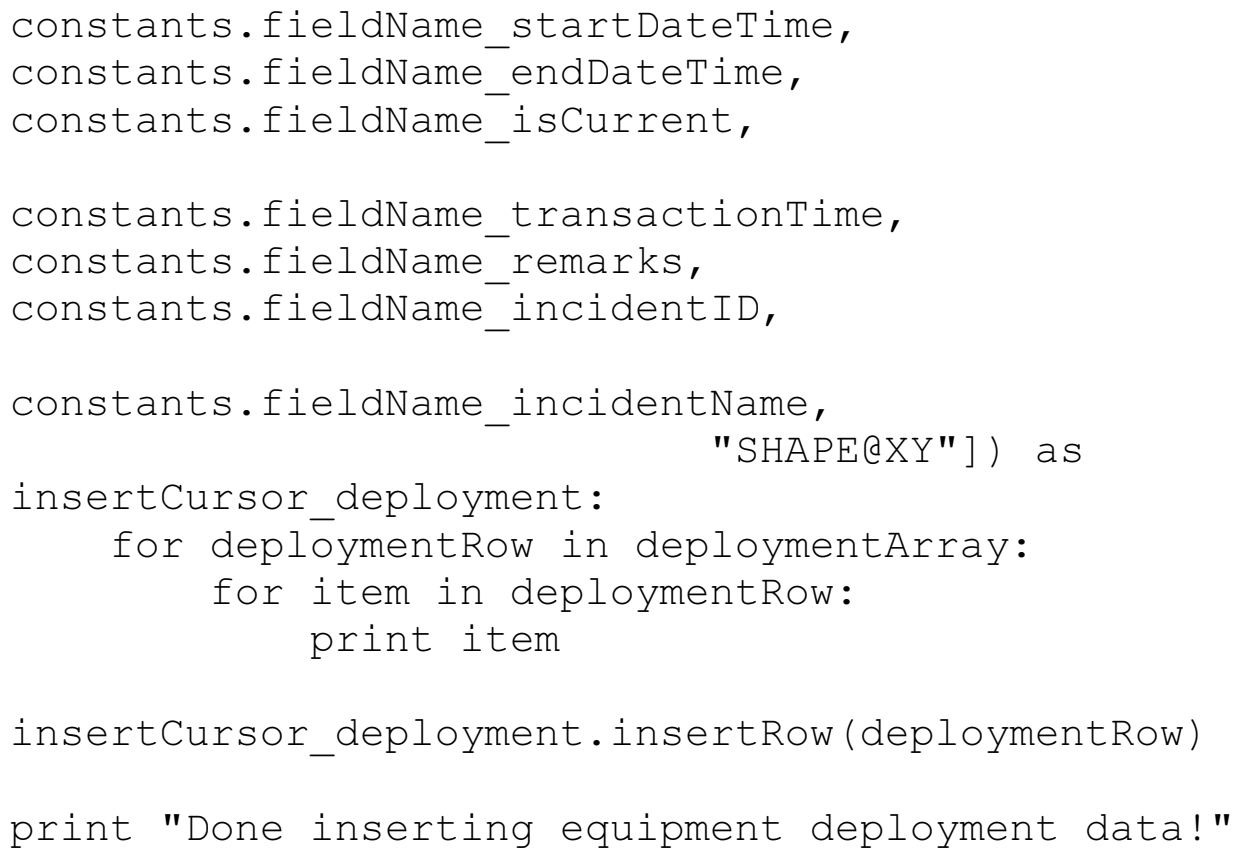




\section{Appendix I. Python Script to Generate QR Code Images}

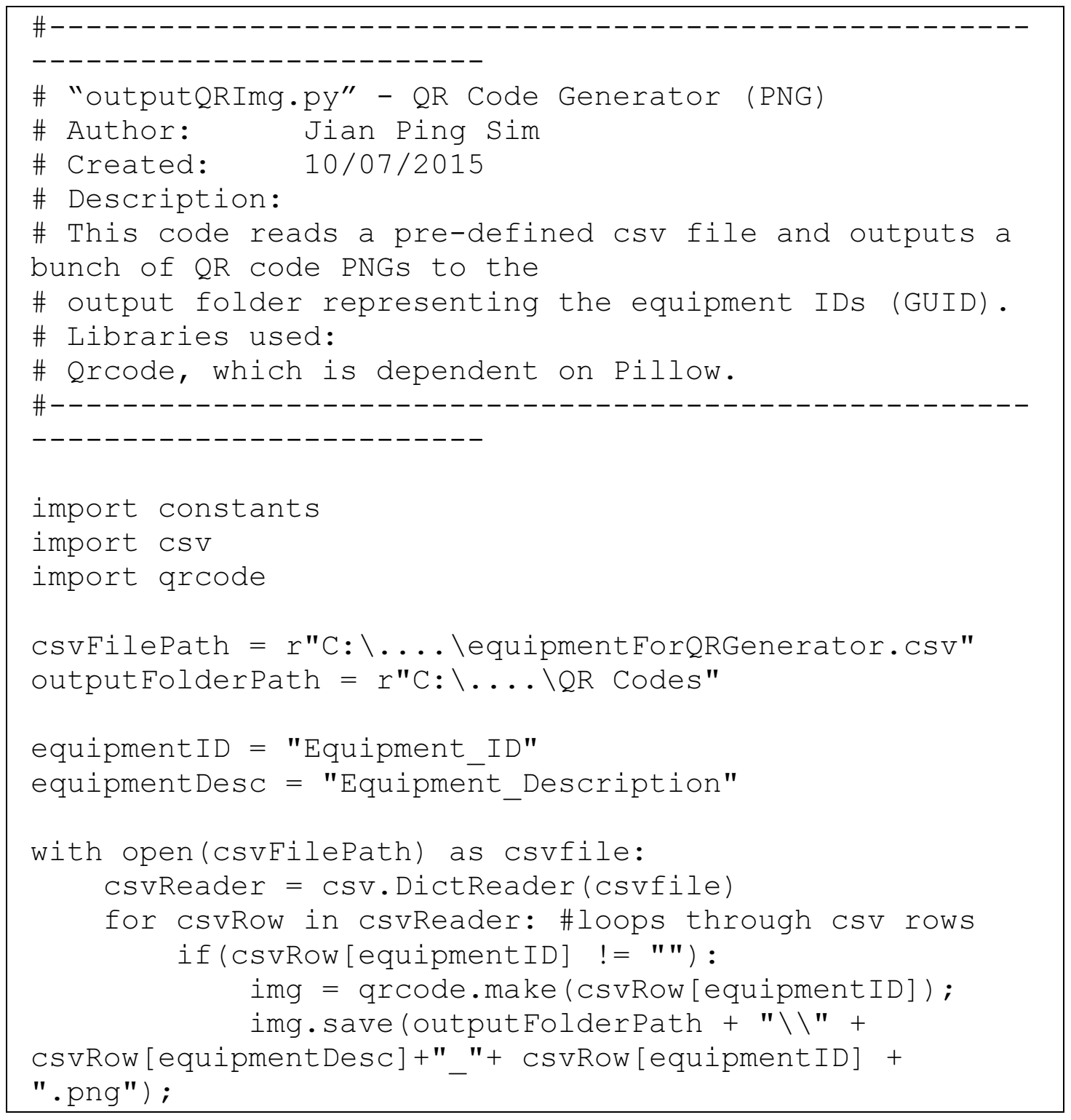

